University of San Diego

Digital USD

2014-08-14

\title{
A Comparative Study of Select Autism Advocacy and Research Organizations: Their Mission, Purpose and Focus Related to the Efficacy of Service(s) Provided to Young Adults with Autism Spectrum Disorders
}

Peter Joseph Sciabarra PhD

University of San Diego

Follow this and additional works at: https://digital.sandiego.edu/dissertations

Part of the Leadership Studies Commons

\section{Digital USD Citation}

Sciabarra, Peter Joseph PhD, "A Comparative Study of Select Autism Advocacy and Research Organizations: Their Mission, Purpose and Focus Related to the Efficacy of Service(s) Provided to Young Adults with Autism Spectrum Disorders" (2014). Dissertations. 864.

https://digital.sandiego.edu/dissertations/864

This Dissertation: Open Access is brought to you for free and open access by the Theses and Dissertations at Digital USD. It has been accepted for inclusion in Dissertations by an authorized administrator of Digital USD. For more information, please contact digital@sandiego.edu. 


\title{
A COMPARATIVE STUDY OF SELECT AUTISM ADVOCACY AND RESEARCH ORGANIZATIONS: THEIR MISSION, PURPOSE AND FOCUS RELATED TO THE EFFICACY OF SERVICE(S) PROVIDED TO YOUNG ADULTS WITH AUTISM SPECTRUM DISORDERS
}

by

PETER J. SCIABARRA

A dissertation submitted in partial fulfillment of the requirements for the degree of

Doctor of Philosophy

August 14, 2014

\author{
Dissertation Committee \\ Lea Hubbard, Ph.D. \\ Anne M. Donnellan, Ph.D. \\ Steven A. Gelb, Ph.D. \\ University of San Diego
}


C Peter Joseph Sciabarra, 2014 All Rights Reserved 


\begin{abstract}
Autism has been prominently featured in the news headlines of the Western world for well over 30 years. A reported rise in the incidence of autism has sparked a corresponding increase of interest in research, treatment modalities, and political considerations related to Autism Spectrum Disorders (ASDs). The first autism organization in the United States, the National Society for Autistic Children, currently the Autism Society of America, was founded in 1965, devoted to autism research, resources, and services; the dissemination of information; and support and advocacy. Organizations devoted to autism research, resources and services, the dissemination of information, support and advocacy have since multiplied. Despite a proliferation of these similar organizations, little research has examined their effectiveness. Particularly scarce are studies on the usefulness of organizations to the young adult population with ASDs. For this study, young adults are defined as those having exited from secondary education and roughly inclusive of ages 18-29. This current age group was affected by the 2006 law mandating transition services to post-school options that commence at age 14.

The present study used a mixed methods approach to evaluate service organizations and assess their efficacy to fulfill their mission statements with regard to the target population. This study consisted of an online quantitative survey, followed by qualitative case studies of six purposively selected organizations that provide autism research, advocacy, and service. The process of organizational self-evaluation and the quantity and quality of services provided, as reported by young adults with ASDs and their families, was the initial focus. Organizational self-evaluations were then compared to interviews with young adults with ASDs and their family members. Interview
\end{abstract}


questions focused on individuals' needs and how well their needs are met by the organizations.

The federally mandated Interagency Autism Coordinating Committee identified a deficiency in knowledge with respect to adult services, supports, and community inclusion. This study is significant in that it considered organizations that purportedly provide services to young adults with ASDs, but identified the gaps in service and support, as defined by young adults with ASDs and their families, and examined how and why autism organizations currently fail to respond to their needs. 


\section{DEDICATION}

For Torey-my reason to start this program, my inspiration to finish this study, and our constant source of joy and love. Torey, I love you more than you will ever know, and you give so much more to all around you than you ever receive! 


\section{ACKNOWLEDGMENTS}

There are so many people I wish to thank and acknowledge that the list could be almost as long as this dissertation. First and foremost, I wish to thank Dr. Anne Donnellan, not only for being my co-chair but for being the impetus behind this particular study, for the insight and access she provided to so many luminaries in the field of autism research, and for her continued leadership in the field of autism research. I also thank her for her dedication to my progress and for her continued efforts long after her official retirement date from the University of San Diego. I will be very proud to have the distinction of being her final doctoral student.

I was privileged to have Dr. Lea Hubbard in class and also to have her serve as my co-chair. She challenged, supported, encouraged, and eventually found the solution to provide the opportunity to extend past my deadline in order to see this through to a successful completion. Thanks also for the willingness to allow me to continue until the "eleventh hour" and the genius suggestion of me working with Patricia Rhodes. I want to thank Dr. Steven Gelb who stepped in due to the illness of my third member, Dr. Roxanne Ruzac. Roxanne, I enjoyed our time together in class and was saddened you could not remain on my committee. I look forward to your complete recovery and seeing you back at the work you love so much. Steve, thanks for stepping in and "pinch hitting"

and all your efforts on my behalf. From the very first meeting it was obvious that you had my best interests at heart, including my own personal health and well-being.

I wish to thank so many other professors and administrative staff members at SOLES. While in no particular order, all of the following played a critical role in encouraging, challenging, and seeing me through to completion: Dr. Mary Scherr, my 
first advisor and a brilliant, kind, and compassionate woman; Dr. George Reed for your continued support, your riveting classes, your humor, and your continued friendship and camaraderie; Dr. Fred Galloway-I never thought I would take Quantitative Analysis II as an elective ... and enjoy it! I thank you for the guidance of always never betting on the West Coast teams traveling cross country on a football Sunday, and the wisdom of "the best dissertation is a done dissertation." SOLES enjoys so many outstanding professors and administrators starting with the Dean, Dr. Paula Cordiero; our new department chair, Dr. Afsaneh Nahavandi; Dr. Zachary Green and the terrific experience he leads in adult development; Dr. Terri Monroe, my first professor way back in the Fall of 2005 for LEAD 600, Dr. Bob Donmoyer, Dr. Cheryl Getz, two other "angels" who helped all of this happen: Heather Gibb and Beth Garofalo.

As I alluded to earlier, a special "angel" entered my life in April and truly pushed me over the finish line. Dr. Tricia Rhodes, without your guidance, concern, and expert advice, this never would have ended in success. You were "heaven sent" at exactly the right time when I needed you most. I am forever in your debt.

I have had the absolute pleasure to study with some of the best, most talented, intelligent, and fun classmates anywhere-and also some of the nicest people I have ever met, starting with my two long-time study buddies: Doctors Whitney McIntyre-Miller and Julie Cantillon. You two are the best! I was privileged to study with and call my friends: Taylor Peyton-Roberts, Kacy Kilner-Hayes, Rachel Homel-Rice, David Facer, Robin McCoy, Jessica Luchesi, Crystal Dujowich, Mike Kelly, Heather Carpenter, Karen Kramer-Horning, Sara Henry, Julie Cramer, and so many talented and dedicated students-all now doctors and professors in their own right. 
To my parents, Mary and Sal Sciabarra, both only high school graduates who lived their childhood in the Great Depression. They sacrificed so much to send all three of their children to the best private Catholic high schools in New York City. I can remember them saying on countless occasions, "they can never take your education away from you." Their dedication to and priority of education has always been a value instilled in me by them and I can never thank them enough for that lesson.

Finally to my wife Carol and sons Torey and Nick, who made the real sacrifice in countless hours that I was not available to be there for and with them while working on this degree and study: Thank you for all the love and support and encouragement to see this through to completion. I love you all! 


\section{TABLE OF CONTENTS}

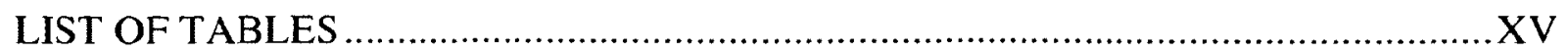

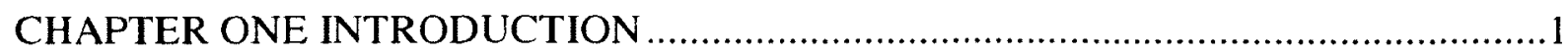

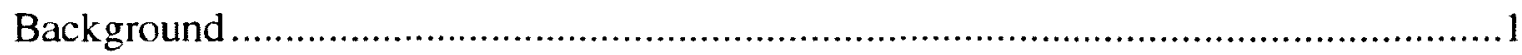

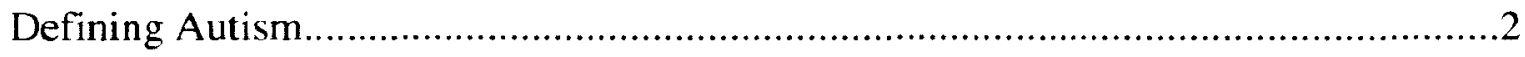

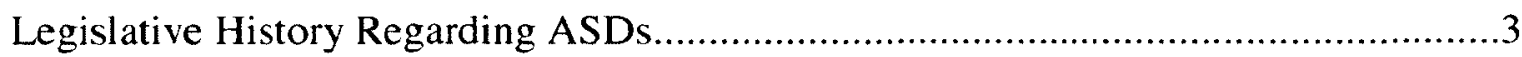

Organizations That Address Autism Spectrum Disorders Today …...........................8

Young Adults with Autism Spectrum Disorders ……...............................................

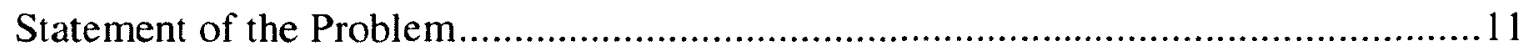

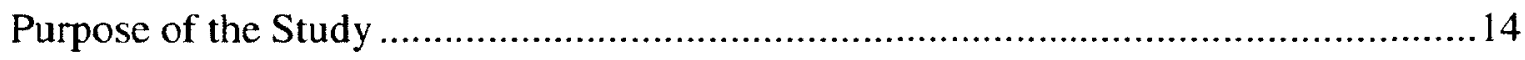

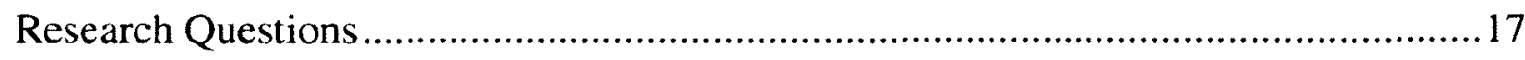

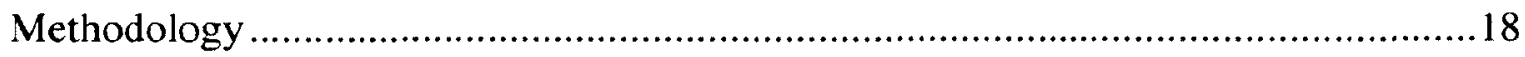

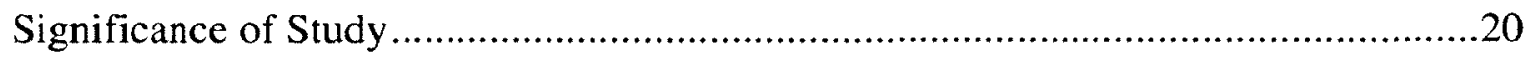

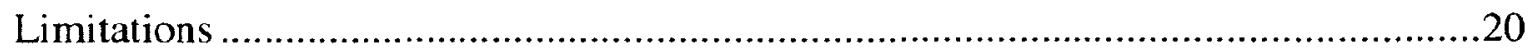

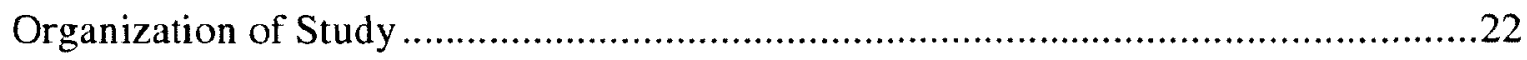

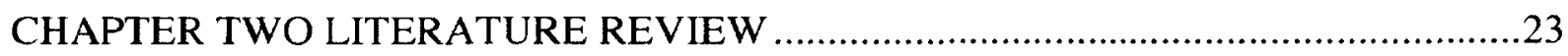

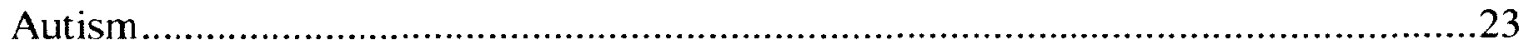

Services for Those With Developmental Disabilities............................................27

Specific Challenges for Adults with Autism ………..............................................29

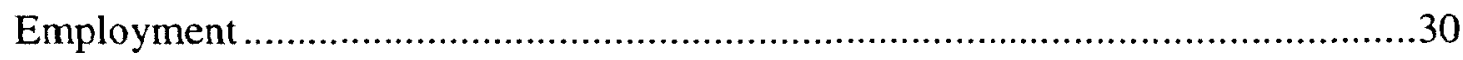

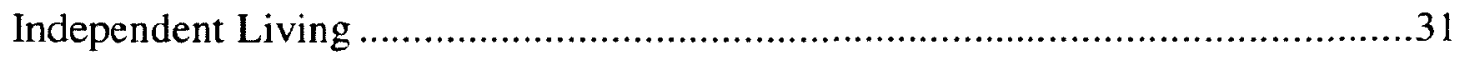

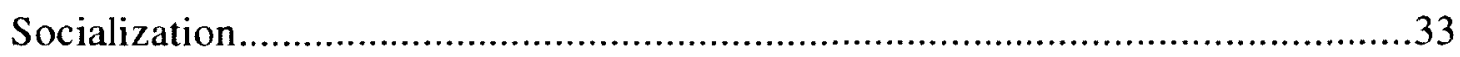

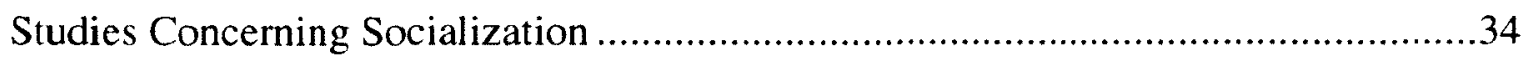




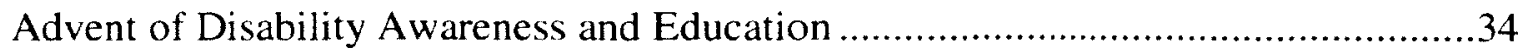

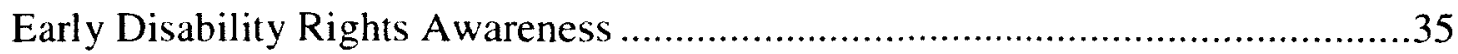

Rise of Service-Providing Government Agencies ...................................... 38

Intervention and Therapy Organizations ............................................ 40

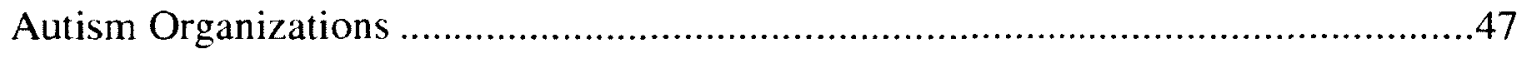

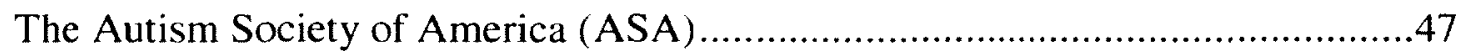

Association of Retarded Citizens (The Arc) ...........................................48

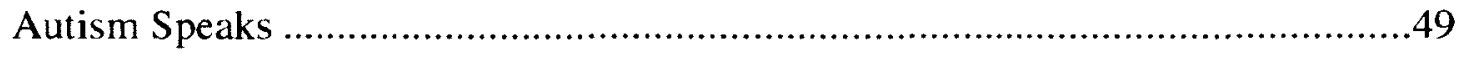

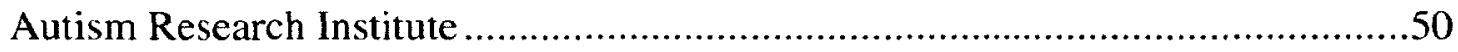

Autism National Committee (AUTCOM) ...................................................50

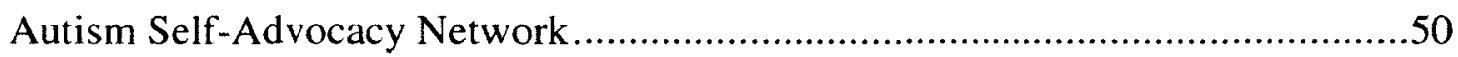

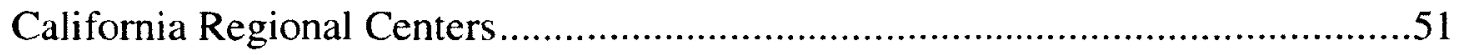

Continuing Need for Autism Services ..................................................51

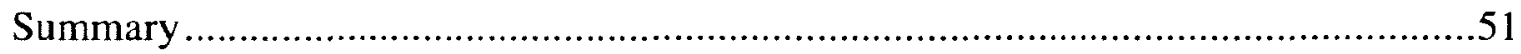

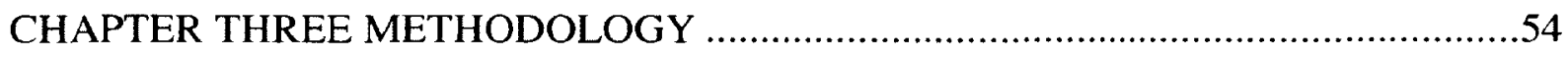

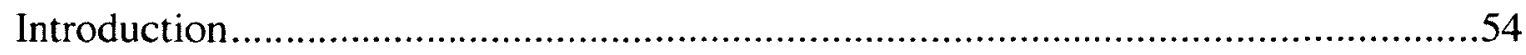

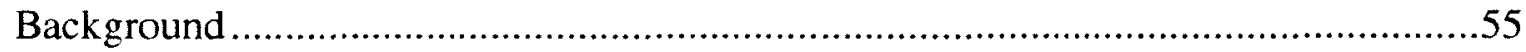

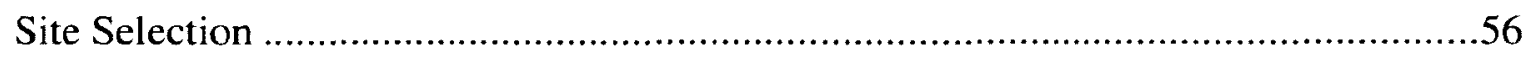

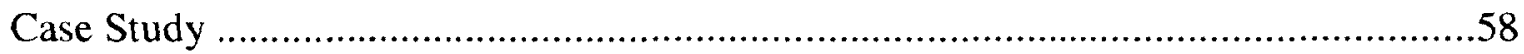

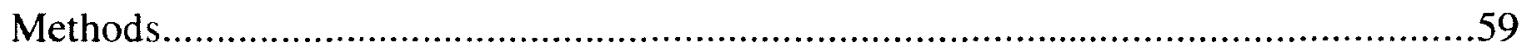

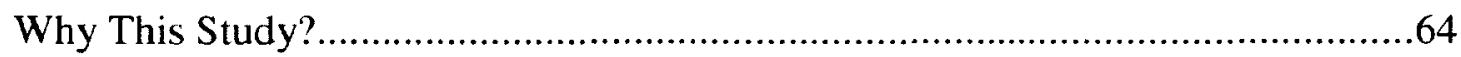

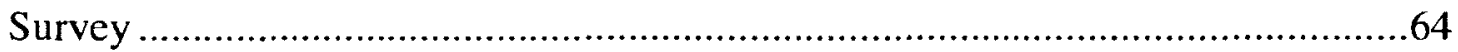

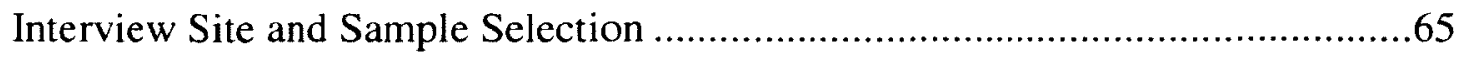




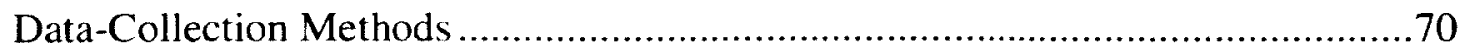

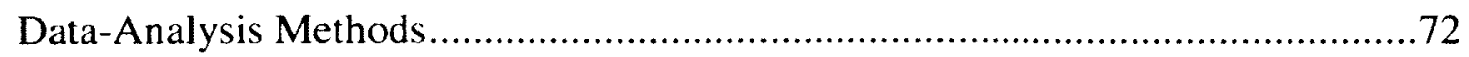

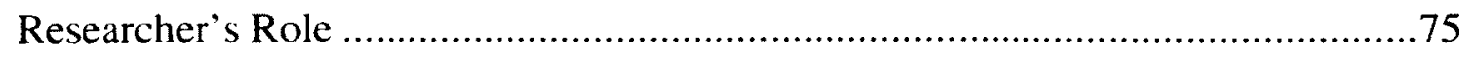

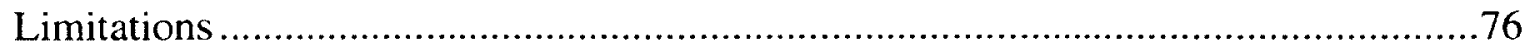

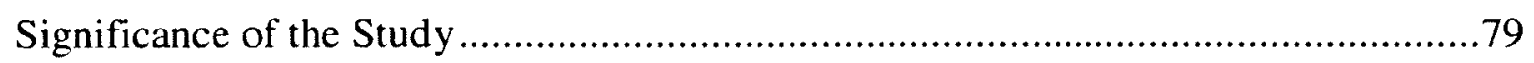

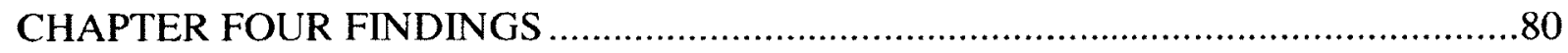

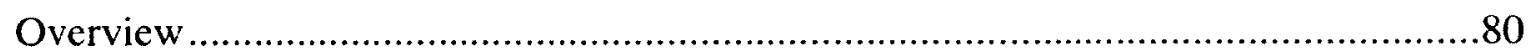

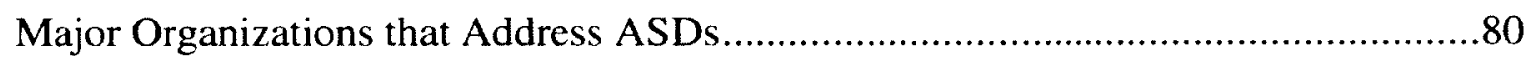

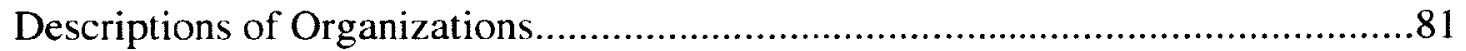

Organizational Mission Statements and Perception of Roles ...............................83

Organizational Policies, Procedures, and Actions ……………….......................89

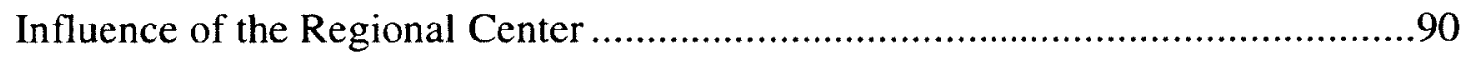

Organizational Supports and Challenges ..........................................................

Definition of Needs and Evaluation of Organizations that Address Autism

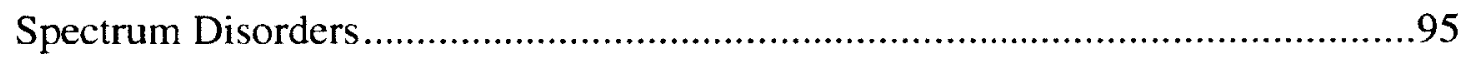

Summary of Research Questions 2 and 3 Findings .............................................105

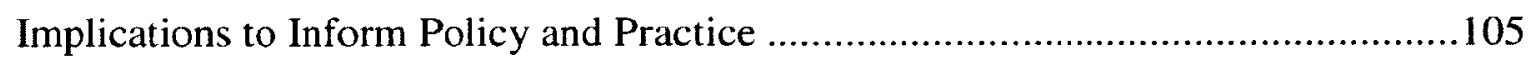

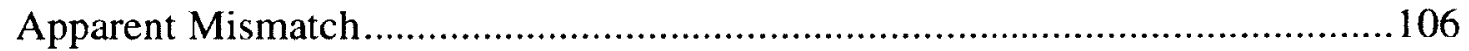

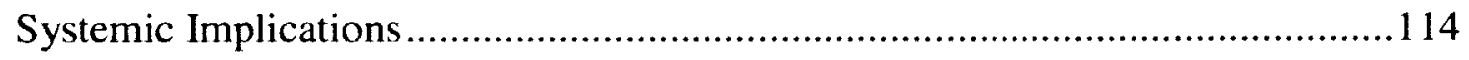

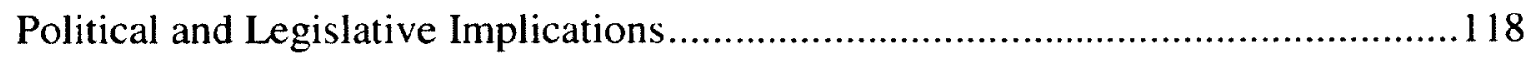

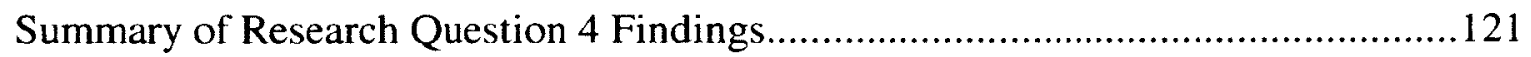

CHAPTER FIVE CONCLUSIONS, IMPLICATIONS, AND

RECOMMENDATIONS FOR FURTHER STUDY …..................................124 
Summary of Major Findings 125

Major Themes

Theme 1: Nearly Every Aspect of a Normal Adult Life is a Challenge 127

Theme 2: The Problem is Rapidly Expanding 129

Theme 3: Confusion and Lack of Information, Research and Coordination .......130

Theme 4: Adult Issues in ASDs Appear to be an Afterthought 132

Personal Reflections.

Limitations 138

Recommendations for Future Research

Research on Adult Outcomes. 141

Coordination Between Organizations, Governments, and Consumers

Civil Rights/Disability Rights and National Health Care

Financial Accountability of Organizations

Local Community Involvement at a Personal Level

Conclusion 145

REFERENCES

APPENDICES 158

APPENDIX A ONLINE SURVEY VIA SURVEY GIZMO 159

APPENDIX B RESEARCH INTERVIEW FORMAT FOR INDIVIDUALS

REPRESENTING AUTISM SUPPORT AND RESOURCE

ORGANIZATIONS 168

APPENDIX C RESEARCH INTERVIEW FORMAT FOR YOUNG AUTISTIC

ADULTS/PARENTS 
APPENDIX D SAMPLE EMAIL REQUEST TO INTER VIEW CANDIDATES ........173

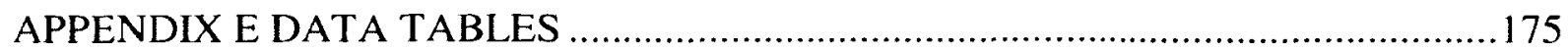

APPENDIX F RESULTS OF SAN DIEGO REGIONAL CENTER CLIENT POLL

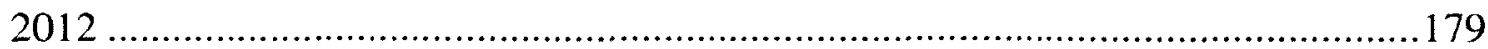




\section{LIST OF TABLES}

Table 1 Important Disability Legislation and Legal Rulings and year of enactment .........4

Table 2 Independence and Social Outcomes in Follow-Up Studies of Adolescents and Adults 35

Table 3 Sampling of National Disability Organizations and year founded in the United States

Table 4 Sampling of Autism Research and Service Organizations .46

Table 5 Summary of the Mission Focus and Summarized Mission Statements of

Selected Organizations .62

Table 6 Interview Participants From Autism Organizations .67

Table 7 Parent/Autistic Adults Interview Participants...........................................68

Table 8 Political/Government Interview Participants..........................................69

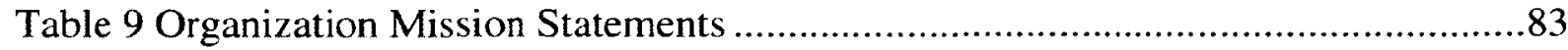

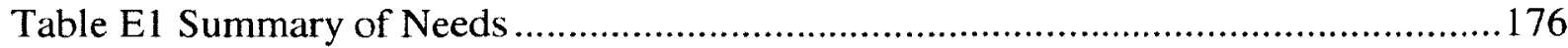

Table E2 Summarized Survey Responses.................................................. 176

Table E3 Employment Data (Listed by Raw Number and Percent of Total) ............... 177

Table E4 Description of Employment Situation ................................................ 177

Table E5 Postsecondary Education and/or Vocational Training Satisfaction (Listed by

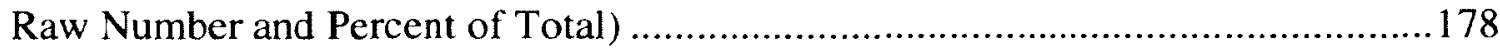

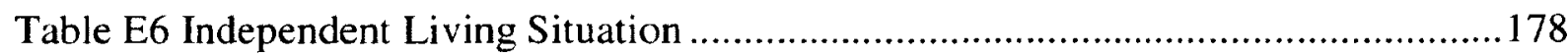

Table F1 Summary of San Diego Regional Center Client Poll 2012 by Percentage...... 180 


\section{CHAPTER ONE}

\section{INTRODUCTION}

\section{Background}

For well over three decades, autism spectrum disorders (ASDs) have been prominent in the headlines of the national and health news in most of the Western world. Since the mid-1990s, an intense concern has arisen regarding the increasing number of children diagnosed with ASDs. Catherine Rice reported on the Autism and Developmental Disabilities Monitoring Network (ADDM):

In 2006, on average, approximately $1 \%$ or one child in every 110 in the 11 ADDM sites was classified as having an ASD. The average prevalence of ASDs identified among children aged 8 years increased $57 \%$ in 10 sites from the 2002 to the 2006 ADDM surveillance year. (Centers for Disease Control and Prevention [CDC], 2009)

This number is corroborated in numerous other studies, including the 2007 National Survey of Children's Health, funded by the Health Resources and Services Administration (2009), a branch of the U.S. Department of Health and Human Services. ADDM data from 2008 increased the prevalence of ASDs to one in 88 (Centers for Disease Control and Prevention [CDC], 2012) and as recently as March, 2014 the CDC now lists the rate of incidence as one in 68, a 30\% increase in just 2 years (CDC, 2014).

The alleged dramatic increase in autism globally has become a major focus of the international media. In particular, the media extensively has covered treatment options, potential causes, children of celebrities diagnosed with ASDs, and autism-related legislation and funding. Autism is featured in national network news, documentaries, informational television and radio programs, full-length feature movies, and books. Its increase has been covered in nearly every major form of publication, including newspapers, magazines, and professional medical journals. 


\section{Defining Autism}

From the outset, attempts to define autism have been complex. The disorder incorporates a specific set of diagnostic criteria, many of which are found in nearly every child at some age and stage of their development.

ASDs are defined by the Autism Society of America (ASA) as follows:

A complex developmental disability that typically appears during the first three years of life and is the result of a neurological disorder that affects the normal functioning of the brain, impacting development in the areas of social interaction and communication skills. Both children and adults with autism typically show difficulties in verbal and non-verbal communication, social interactions, and leisure or play activities. (ASA, 2010, para 1)

Prior to 2013, the CDC listed three broad categories of ASDs: Autistic Disorder ("classic autism"), Asperger Syndrome, and Pervasive Developmental Disorder-Not Otherwise Specified (also known as "atypical autism"; CDC, 2012). In the definition of autism in the 4th edition of the Diagnostic and Statistical Manual of Mental Disorders (DSM-IV), the American Psychiatric Association also included two other disorders: Rett's Syndrome and Childhood Disintegrative Disorder (1994, pp. 70-71). In May 2013, these definitions were superseded in DSM-5. The conditions associated with autism are now known simply as ASDs, as the spectrum of impairment ranges from least severe (Asperger Syndrome) to most debilitating (severe classic autism). The full set of diagnostic criteria in the DSM-5 is several pages long but can be summarized as consisting of "persistent deficits in social communication and social interaction across multiple contexts" and "restricted, repetitive patterns of behavior, interests or activities" (American Psychiatric Association, 2013). Also three different levels of severity range from Level 1 (requires support-least severe) to Level 3 (requiring very substantial support-most severe). 
Not only has the attempt to define and describe ASDs been a storied one, the political process with which it has been addressed has played a unique role in how the disorder is approached today. In particular, I briefly explore below a history of legislation designed to address the rights and needs of those with disabilities including ASDs.

\section{Legislative History Regarding ASDs}

Commencing in 1963, a series of laws were enacted to guarantee the equal right to education for children with disabilities. Table 1 lists some of the most important laws and the year they were enacted. These laws started with the basic premise that funds would first be provided to build facilities to educate children with disabilities and eventually progressed to mandating free and appropriate public education in the least restrictive environment. Recent laws included the provision for transition planning to begin no later than the age of 14 .

Originally authorized in 1963 as Title I, Public Law 88-164, the Mental Retardation Facilities Construction Act was later reauthorized as the Developmental Disabilities Assistance and Bill of Rights Act of 2000 (PL-106-442). This act recognized the need for support of those with developmental disabilities to extend beyond the classroom and into the community. It authorized the funding of programs at the community and state level to serve individuals with developmental disabilities. 
Table 1

Important Disability Legislation and Legal Rulings and year of enactment

\begin{tabular}{|c|c|}
\hline Year & Act \\
\hline 1963 & $\begin{array}{l}\text { Mental Retardation Facilities and Community Mental Health Centers } \\
\text { Construction Act }\end{array}$ \\
\hline 1965 & Elementary and Secondary Education Act, School Districts - Federal Aid \\
\hline 1966 & Elementary and Secondary Education Act \\
\hline 1968 & Vocational Education Act Amendments \\
\hline 1970 & Education of the Handicapped Act \\
\hline 1971 & $\begin{array}{l}\text { Pennsylvania Association for Retarded Children v. Commonwealth of } \\
\text { Pennsylvania }\end{array}$ \\
\hline 1972 & Mills v. Board of Education (Washington, DC) \\
\hline $\begin{array}{c}1972- \\
1974\end{array}$ & $\begin{array}{l}\text { State Education Legislation (Faced with litigation, } 27 \text { states enacted laws } \\
\text { protecting the educational rights of students with disabilities.) }\end{array}$ \\
\hline 1973 & Rehabilitation Act of 1973 (Section 504) \\
\hline 1974 & $\begin{array}{l}\text { Education of the Handicapped Act Amendments (The amendments were to } \\
\text { reauthorize increased federal spending for the education of handicapped } \\
\text { children) }\end{array}$ \\
\hline 1975 & Education for All Handicapped Children Act \\
\hline 1975 & The Developmental Disabilities Assistance and Bill of Rights Act \\
\hline 1983 & Education of the Handicapped Act Amendments \\
\hline 1984 & $\begin{array}{l}\text { Amendments to the Developmental Disabilities Assistance and Bill of } \\
\text { Rights Act }\end{array}$ \\
\hline 1986 & Education of the Handicapped Act Amendments \\
\hline 1990 & Individuals with Disabilities Education Act (IDEA) \\
\hline 1990 & $\begin{array}{l}\text { Amendments to the Developmental Disabilities Assistance and Bill of } \\
\text { Rights Act }\end{array}$ \\
\hline 1997 & Amendments to the Individuals with Disabilities Education Act (IDEA) \\
\hline 2001 & No Child Left Behind Act of 2001 \\
\hline 2004 & Individuals with Disabilities Education Act of 2004 (IDEA 2004) \\
\hline
\end{tabular}

Note. From The Minnesota Governor's Council on Developmental Disabilities, 2011. 
In California, in the late 1960s, the Department of Developmental Services (DDS) set up a system of regional centers to administer the mandates of the Developmental Disabilities Act. The California DDS described the 21 regional centers as nonprofit private corporations that contract with the Department of Developmental Services to provide or coordinate services and supports for individuals with developmental disabilities. The Regional Centers have offices throughout California to provide a local resource to help find and access the many services available to individuals and their families. (2010, para 1)

Regional centers do not directly provide services, with the exception of assessment and case management. The centers assess the needs and purchase services for individuals identified as qualified recipients under federal and state mandates. The decade of the 1970s was the start of some landmark legislation affecting persons with developmental disabilities and specifically started to address the needs of persons with ASDs.

The Vocational Rehabilitation Act of 1973 can be considered the "Civil Rights Act" for persons with disabilities. Section 504 of the law states,

No otherwise qualified individual with a disability in the United States, as defined in section 705(20) of this title, shall solely by reason of her or his disability, be excluded from participation in, be denied the benefits of, or be subjected to discrimination under any program or activity receiving Federal financial assistance. (U.S. Department of Justice, Civil Rights Division, 1973 para a)

In Section 794, education is specifically delineated under programs that receive federal financial assistance. It states that this law applies to "2)(A) a college, university, or other postsecondary institution, or a public system of higher education; or (B) a local educational agency (as defined in section 8801 of Title 20), system of vocational education, or other school system" (U.S. Department of Labor, 1973).

In 1975 Public Law 94-142, also known as The Education for All Handicapped Children Act (EAHC; Individuals with Disabilities Education Act [IDEA], 1975), mandated that those children with disabilities aged 3-21 receive a free and appropriate 
public education in the least restrictive environment possible and an individualized education program with due-process guarantees, for as long as that education is made available to nondisabled children (Library of Congress, 1975). Of note, no constitutional right exists to a funded education; however, a right does exist to equal protection and access. Therefore, if a state decides to fund the education of any child, it must also fund the education of children with disabilities. In 1990, this act was renamed the Individuals with Disabilities Education Act (IDEA).

Legislators have made numerous amendments and changes to this law since it was first passed in 1975.

Changes implicit in the law included efforts to improve how children with disabilities were identified and educated, to evaluate the success of these efforts, and to provide due process protections for children and families. In addition, the law authorized financial incentives to enable states and localities to comply with Public Law 94-142. (U.S. Department of Education, Office of Special Education and Rehabilitative Services, Public Law 94-142, 2007, para 2)

Other amendments included mandating that programs and services be made available starting at birth (1986), as well as including families through the use of Individualized Family Service Plans. In addition, the Department of Education stated that transition planning should start no later than the age of 14 (1997). At roughly the same time a legislative action was taking place in California that would have significant long-term implications for adults with ASDs in that state.

In California, the Federal Developmental Disability Law was implemented in the Lanterman Act. Lanterman was a state assemblyman who proposed the act in 1973, which eventually became law in 1977 . Section 4620 of the law is the key provision stating, "Persons may have access to the facilities and services best suited to them throughout their lifetime" (California Department of Developmental Services, 2010a). 
Unique to the State of California, this crucial sentence includes the commitment to support individuals throughout their entire life. Those three critical words, "throughout their lifetime" changed the landscape for adults with ASDs in California forever. The distinction is that instead of being merely eligible for services and supports that may or may not be available, young adults with ASDs are entitled to those services and supports. This distinction and all the ramifications of entitlement will be discussed at length in Chapter 4.

Theoretically children with ASDs should experience a smooth transition of support and resources from school to postsecondary education. The IDEA details transition assistance and planning that should be in place starting in high school: 'IDEA requires that transition planning begin at the earliest age appropriate. For each student with a disability, beginning at age 14 (or younger, if determined appropriate by the IEP team)" (NCSET, 2002, para 3).

Despite these laws, students, parents, families, schools, and public resources have recognized a gap between the desired plan for a smooth transition and the actual reality.

Federal measures have been put in place to ensure schools plan for transition (IDEA, 2004); however, transition planning and implementation is falling short of what the federal government intended for many with ASD. Students often do not receive the services and supports needed to address the complex set of issues they possess. (Hendricks \& Wehman, 2009, p. 84)

The identification of the lack of attention to and resources for young adults with ASDs is the basis for this research study.

The population I studied is young adults with ASDs between 18 and 29 years of age. These young adults were in school when the mandates for individualized instruction, programming, and specific transition to adulthood programs were enacted. Despite the federal, state, and local agencies funded to serve them, a real gap in services and supports 
remains for this population. Attempts to fill this gap for transition services, as well as for primary care, was the origin of the establishment of nonprofit autism organizations. Of the plethora of legislative attempts to address the needs and rights of those with ASDs, a variety of organizations have sprung up to meet them. These nonprofit organizations identified a need for many autism-support services that were no longer being provided through the school systems and other federal, state, and locally funded agencies and organizations.

\section{Organizations That Address Autism Spectrum Disorders Today}

Today, literally hundreds of organizations address the needs of persons with ASDs. In this study I focus on seven of them. Autism service and resource organizations range from large national and even international organizations such as Autism Speaks to larger national organizations like the ASA, and all its local affiliate organizations. Also prevalent are many specialized organizations such as the Autism Self-Advocacy Network (ASAN) and the Autism National Committee (AUTCOM) that focus on issues of selfadvocacy and civil rights for persons with ASDs. In California, where this study is focused, an additional entity is the network of the 21 regional centers.

The majority of organizations are in the nonprofit sector and all vie for limited federal and state funding. With the exception of the regional centers, which are funded by the California DDS, these organizations all rely, to varying degrees, on donations and fundraising activities to finance their research and service offerings. In addition to competing for limited funding, grants, and donations, the organizations also coexist with a natural tension between them. 
An example of this tension and competition is demonstrated by the following: Autism Speaks claims to be the nation's largest autism science research and advocacy organization. Their mission statement declares that the organization is "dedicated to funding research into the causes, prevention, treatments and a cure for autism; increasing awareness of autism spectrum disorders; and advocating for the needs of individuals with autism and their families" (Autism Speaks, 2011). The ASAN asserts that "65 percent of the funds raised by Autism Speaks go toward scientific research and identifying autismcausing genes. Autism Speaks only allocates 4 percent to services for individuals and families" (ASAN, $201 \mathrm{lb}$ ). This is representative of some of the infighting and differences of opinion between organizations.

Although it seems logical that many organizations have been established to help mitigate the gap in autism services after the age of 21 and to provide resources and information, their very existence has given rise to a series of new problems. Parents are now inundated with information from a slew of organizations all purporting to be critical to the success of their child or young adult. Parents may feel bewildered and unsure of which organization would best meet their specific needs. To date, researchers have failed to categorize the services these organizations provide, how they implement their services, and how they are viewed and evaluated by those who use their services. Even with all of the emphasis and focus on ASDs, one group-young adults-are not getting the help they desperately need for a variety of reasons.

\section{Young Adults with Autism Spectrum Disorders}

Despite the considerable money spent on persons with ASDs in the United States, in general, the young adults who have already graduated from or advanced past high 
school or are over 21 years of age appear to be underserved. The average high school graduate is about 18 years old, and while IDEA ensures a free and appropriate education through 22 years of age, the average life expectancy in the United States is approximately 77 years. The young adult with autism who has just graduated from high school or exited public school support faces approximately 55 to 60 years of life; perhaps an independent life for which the young adult is minimally prepared.

The adult autistic community has specific needs that include support for education, employment accommodations, and independent, semi-independent or supported living arrangements. To live a healthy adult lifestyle, young adults with autism need significant supports like proper accommodation, vocational assistance, socialization opportunities, and access to transportation.

A contributing factor to the struggles of this population is that most have no outward identifying indicators of their condition. They are not confined to wheelchairs, they do not look significantly different from their neurotypical peers, many are verbal, and at first glance, appear to be just like any other young adult.

Despite the creation of research, advocacy, and assistance organizations, such as the ASA, Autism Speaks, and many others, a lack of widespread knowledge and understanding exists regarding the availability of supports for young adults with ASDs. This deficiency or gap in support was recognized nationally, resulting in the enactment of Public Law 109-416, also known as the Combating Autism Act of 2006, and the subsequent formation of the Interagency Autism Coordinating Committee (IACC) in 2006 (U. S. Department of Health and Human Services, 2007). One of the three main tenets of the IACC mission is to, "Increase public understanding of the member agencies' 
activities, programs, policies, and research by providing a public forum for discussions related to ASD research and services" (IACC, 2010, para 5). Even with the Combating Autism Act and the formation of this coordinating committee, a gap continues to exist in the provision of information regarding ASDs. A corresponding gap occurs in appropriate services available for young adults with ASDs. A well-documented need continues for the existence of independent autism advocacy, research, and services organizations.

\section{Statement of the Problem}

Numerous organizations in the United States support and advocate for persons with autism. Although service organizations generally have a similar mission to support young adults with ASDs, their approach and philosophical foundations differ greatly, giving rise to several concerning questions: What is their specific mission statement? How do they implement their stated mission of service? How do they evaluate success and areas of (needed) improvement? How do young adults and their families evaluate the service and support they receive? Finally, despite the increasing number of service organizations, What are the needs of the adult autistic community that continue to be unmet?

Sparse empirical evidence describes the goals and effectiveness of the various autism service organizations. Little is known not only about the model(s) they use in attempting to meet their objectives; equally unknown is how young adults with ASDs rate their satisfaction with supports and services, particularly during the critical transition period from postsecondary education to vocational career training, employment, and independent living. 
A review of current literature reveals little published research based on the needs of the expanding adult population with ASDs, with sparse feedback from this population regarding whether their unique needs are being met. The incidence of diagnosed autism is continuing to rise, and the lack of appropriate support and resources is becoming a very large problem. The initial review of the literature suggests three main areas of concern:

1- Autism service organizations lag behind other disability organizations in the ability to support adults with ASDs to lead autonomous lives, including further education, meaningful employment, independent living, and opportunities for leisure and recreation in the community (National Organization on Disability, 2000).

2- Adult outcomes in the areas of employment and independent living are worse for those with autism than for those with other disabilities (Cameto, Marder, Wagner, \& Cardoso, 2003; Chappela \& Somers, 2010; Cimera \& Cowan, 2009).

3- Very few studies have documented or evaluated how well the needs of the adult autistic population are met through service organizations (IACC, 2010; Robertson, 2010). The void of research focused on service organizations meeting the needs of young adults with ASDs was a major impetus for the focus of this study.

The literature confirms that the majority of resources in the field of autism to date focus on "causes, treatments and cures," rather than actually assisting individuals with autism. The literature also clearly suggests that adults with autism are particularly underserved. According to the 2010 IACC Strategic Plan, the total budget for autism 
research over the 4 years since its inception in 2006 has totaled over $\$ 1$ billion, with the 2010 annual total over $\$ 220$ million. Of the $\$ 1$ billion total budget, only a little over $\$ 100$ million or about $10 \%$ is or has been dedicated to adult quality of life and communityservices initiatives and studies. Comparably, over $\$ 140$ million alone has been allocated for research of a diagnostic instrument and early diagnosis-impact studies (IACC, 2010). Given that most research has ignored supports for those who actually have autism, stakeholders do not know the effects of policies and current legislation on the ability of adults with ASDs to lead self-determined lives and obtain meaningful employment and further education. Nor do stakeholders know what possibilities could exist for those with ASDs if better supports and assistance were available.

Finally, review of the literature on autism suggests that, although a myriad of organizations have arisen in the last decade in part to address the needs of young adults with ASDs, these organizations have conducted little empirical research to understand their ability to meet the needs of those they are meant to serve. Without this information, the parent seeking assistance to improve the lives of their young adults with autism are left confused and may not be receiving the kind of support that is needed or appropriate (Gerhardt \& Lanier, 2011; Howlin, Goode, Hutton, \& Rutter, 2004).

One factor limiting the dissemination of information on how best to help this population is the tension and competition between two factions in the research community. From my perspective, the two camps could be loosely labeled the "causes and cures" versus the "supports and advocacy" groups.

Although these groups already expend significant energy and resources almost equally to "causes and cures" and early intervention/therapy for kindergarten to 12 th- 
grade school-aged children, they focus less on the question of what happens when the young adult on the autism spectrum completes or does not complete high school and is expected to live, work, and function in adult society (Cimera \& Cowan, 2009; Eaves \& Ho, 2007; Robertson, 2010). Robertson recently wrote,

Quality of life oriented autism research has received relatively little attention when compared to the preponderance of causation oriented autism research. Searches of Google Scholar and several major academic databases (ex. Psychinfo, Proquest, JSTOR, etc.) yield more than 150,000 papers written about autism over the last several decades. The vast majority of these papers focus on the genetics of autism, physiology, and non-genetic (environmental) factors that may influence the trajectory of the neurological-developmental disability. Only a tiny fraction of scholarly articles about autism in the academic literature have examined real-life concerns presently impacting autistic adults, such as access to essential augmentative and alternative communication (AAC), social acceptance, and compatible employment options. (2010, para 9)

This research study will examine existing supports and resources offered by a representative sample of some of the largest and most popular autism organizations and their smaller local affiliates, which ostensibly serve the young-adult population with ASDs. I provide a comparative analysis of ASD-focused organizations to determine what services the organizations report they provide and how young adults and their families perceive the scope and helpfulness of the services provided by the organizations. This study also attempts to identify what community and organizational gaps exist in supports and services for this population.

\section{Purpose of the Study}

The purpose of this study was to investigate a sampling of autism service and research organizations and evaluate how well they achieve their stated mission. This case study focused on young adults with ASDs, designed to provide a "snapshot" of the current situation, rather than a time series or progression of how well the situation for young adults with ASDs either has or has not progressed in employment, independent 
living, and further education. In this study, I compared how organizations self-evaluate their performance and how actual users of their services rate them. All the organizations studied have a primary mission statement that purports to support the autistic community. I did not consider organizations whose purpose is primarily focused on children. Each organization studied has at least a portion of their mission devoted to serving young adults with ASDs.

What is known is adult outcomes of those with ASDs have been less than encouraging. Howlin, in England, studies and writes extensively on the subject of adult outcomes in autism. ${ }^{1}$ Howlin (1997) published a compilation of results from 16 discrete studies from 1956 through 2004, all of which focused on the adult outcomes of children diagnosed with ASDs. This research looked at many factors and broadly summarized the adult outcome as either "good," "fair," or "poor." The 16 studies, comprised of 872 individuals, reported nearly $45 \%$ with "poor" adult outcomes and $23 \%$ were listed as having a "fair" outcome (Howlin, 1997, p. 35).

Howlin (1997) does state, however, that outcomes do seem to be improving for adults with ASDs, finding far more success stories of individuals able to lead more fulfilling lives, but went on to state,

These achievements do not come easily, however. Jobs are often found only with the support of families; opportunities to live independently seem to depend heavily on local provision; and friendships are often forged through special interests and skills rather than via spontaneous contacts. (Howlin, 1997, p. 44)

Eaves and Ho (2007) reported, in a Canadian study, "Little is known about transitions to the adult world, but it is thought to be a confusing maze of misinformation,

\footnotetext{
${ }^{1}$ Due to sparse research in the United States, many examples of adult outcomes are generated by studies of populations who reside outside the United States.
} 
limited opportunities, insufficient resources and inappropriate or time limited services" (p. 739). Although very few studies have been conducted in the United States specifically related to employment outcomes for those with ASDs, the results reported primarily in Canada and the United Kingdom seem to be discouraging. With the establishment of new organizations whose purpose is to support and assist young adults with ASDs, the question arises as to why the results are not better.

In 2009, Cimera and Cowan authored one of the few studies on adult outcomes that focused on employment statistics following vocational training for persons with disabilities. They proposed two significant interpretations of their findings. First, "Individuals with autism on average simply require more services to become employed than nearly all other populations" (p.287). Second is a hypothesis: "Because of the nature of their condition, they are unable to work many hours per week or obtain jobs that pay higher wages" (Cimera \& Cowan, 2009, p. 288). Several studies conducted in the United Kingdom, Canada, and Australia draw similar conclusions (Howlin, 1997; Howlin, Alcock, \& Burkin, 2005; Howlin, Goode, Hutton, \& Rutter, 2004).

Currently the adult ASD community is at a disadvantage in their ability to obtain meaningful employment and to find an appropriate living situation, whether it be independent, semi-independent, or in a supported living environment. In addition, certain critical quality-of-life issues like self-determination and the ability to advocate for their employment and housing are more difficult for them. Although employment rates for all persons with disabilities are declining, the autism community appears to be particularly negatively affected. Only $30 \%$ of persons with disabilities are working either full or part time and two thirds of those who are not working would like to be employed (National 
Organization on Disability, 2000). With only $15 \%$ employed in 2003 , individuals with ASDs are least likely of any disability community to be employed (Cameto et al., 2003). The numbers are consistently poor with only $6 \%$ of persons with ASDs reportedly employed full-time in 2010 (Chappela \& Somers, 2010). These statistics suggest that barriers exist for young adults on the autism spectrum to find meaningful employment. Due to the nature of the deficits associated with autism, it is unclear, from the relatively few studies, if barriers to employment are attitudinal, systemic, or inherent.

The prospect of independent, semi-independent, or supported living for those with ASDs is similarly discouraging. Adding to this discouragement is the paucity of similar studies conducted in the United States. An Internet search on the topic "autism service and research" yielded over 50 U.S. organizations that list autism service or research as their primary focus, yet very few studies address the issues raised. The magnitude of the problem described above and a poor outlook for adults with ASDs to obtain meaningful employment and live independently, in relationship to the existence of a plethora of autism-specific service organizations, led to the formation of four research questions that were used to guide the study.

\section{Research Questions}

This research study focuses on organizations that serve the needs of young adults with ASDs. The four research questions that guided this study follow:

Research Question 1: How do organizational models designed to support young adults with autism understand ASDs and how do they define their specific role in providing support to this population? 
- What are the policies, organizational procedures, and practices to address their target population?

- What factors support or challenge their efforts?

Research Question 2: How do young adults with ASDs who have used one or more of these organizations' services define their needs?

- How do young adults with ASDs evaluate whether the various organizations meet their needs?

Research Question 3: How do the parents and family members of young adults with ASDs define the needs of their autistic family member?

- In what ways do parents and family members evaluate the services of the organizations studied in meeting their family member's needs?

Research Question 4: What implications can be drawn from these findings that could help inform policy and practice for organizations that attempt to provide service to young adults with ASDs?

\section{Methodology}

This research study used a mixed-methods approach that focused on how each of the organizations self-evaluate their performance in relationship to ASDs and the needs of their young-adult clients. By examining the ideologies, language, beliefs, and assumptions that inform and influence their work, I considered how organizations articulated their mission and goals, the organization and arrangement of their policies and practices to meet their goals, what supports and challenges their work, and how do organizations perceive their effectiveness. Most importantly, this study highlights and focuses on young adults with ASDs and their families who use organizational services 
and their perception of the services they receive in relation to their ability to transition to adult living, as well as ongoing supports for young adults.

The results of an initial survey identified several organizations that I then selected for more comprehensive study. I then compared these organizations to determine the effectiveness of their service model(s), ascertain which organizations accomplish their mission, and where and why they may fall short. The net result was to have a "snapshot" in time that displays what needs are and are not being met for young adults with ASDs, and whether these independent autism-resource organizations are fulfilling their mission statements.

In constructing this study I first wanted to use a survey to generate some baseline data and validate or refute some assumptions. I collected data through an online survey and analyzed them using basic statistical methods. Next I used the survey to identify potential volunteers to be interviewed from the participants who were either young adults with ASDs or their immediate family members, most likely parents. I already knew which organizations would be my focus; however, I used the survey to identify any others that should be included.

I then conducted three sets of interviews. The first were with young adults with ASDs and/or their parents. The next set was with senior representatives of all the organizations included in the study. Finally I interviewed a panel of professional experts with extensive experience in the field of developmental disabilities, and specifically autism. I provide an in-depth description of the methodology and data analysis conducted in Chapter 3. 


\section{Significance of Study}

The gap in services, information, and supports is an important problem, because the incidence of autism-related disorders is still reported to be increasing at an alarming rate. This increasing rate also suggests a growing population of young adults on the autism spectrum will enter the ranks of the adult autistic population each year and will still be in need of transition assistance and organic support to lead productive and fulfilling lives.

This population of individuals was chosen for this study because they were in school when transition programs were mandated to meet their upcoming adult needs. This population is also reflective of the increasing number of individuals with ASDs presently challenging public and private systems. The focus of this study is on California residents as it is the only state, by virtue of the provisions of the Lanterman Act, to have established an entitlement program for adults with developmental disabilities.

With continued shrinking healthcare funding and a continually expanding population of young adults with ASDs, this is a significant problem and one which needs to be illuminated and explored now.

\section{Limitations}

My status as the parent of a young adult with ASD is a source of potential bias for this study. It is not reasonable to think that my life experiences over 20 years of living with a son with autism will not affect this study. To counter this prospect I did use second readers and individuals outside the autism community to offer critiques and ask challenging questions to some of my assumptions and interpretations. To assume that I was able to completely remove my own feelings and opinions would be unrealistic. 
The small scope of survey and interview participants is also a limitation and means that the findings cannot be generalized to a larger population. The geographic limitation of this study, centered mainly in southern California and specifically in San Diego, is another limitation. San Diego, and California in general, appear to be at the leading edge of autism awareness and research, so findings of inadequacy here may suggest that the situation may be much more dire in less autismcentric areas of the country. Additionally the unique aspects of the Lanterman Act and the significance of lifelong entitlement to services make this study very specific to the situation in California.

Another bias I recognize is that I have had personal experiences with most of the organizations studied. Again the use of second readers and the critique of my committee members helped alleviate some of that bias.

Another potential limitation is that the data were based solely on those participants I was able to reach through the survey and those who are intimately familiar with the issues involved. I sense a much larger majority is uninformed and unaware of the enormity of the issue, who struggle on a daily basis to obtain even a minimal level of assistance for their family member with ASDs.

Finally, I recognize that due to my family situation I am immersed in the topic of adults with ASDs on a close, daily, and personal basis. Still, in spite of these limitations, I believe I was able to offer a critical perspective and draw logical conclusions from the data as it was presented. 


\section{Organization of Study}

In the following chapters I describe and report on the research I conducted.

Chapter 2 is a detailed review of the literature. Chapter 3 outlines the methodology I used as well as my data-analysis techniques. In Chapter 4 I present the significant findings to the four research questions. Finally, in Chapter 5, I present conclusions, themes, and recommendations for further study. I also share my personal reflections on the 4 years that were dedicated to this study.

The literature review that follows in the next chapter represents a portion of the extensive professional writing and research on the subject of autism. It also points out a glaring deficiency in the number of studies and amount of research conducted on the topic of adults with ASDs. Particularly discouraging is the paucity of studies conducted in the United States with respect to adult outcomes in the areas of employment, education, vocational rehabilitation, independent and semi-independent living arrangements, social interaction, and recreational opportunities. 


\title{
CHAPTER TWO
}

\section{LITERATURE REVIEW}

\begin{abstract}
Autism
As stated in Chapter 1, ASD is defined by the ASA as

a complex developmental disability that typically appears during the first three years of life and is the result of a neurological disorder that affects the normal functioning of the brain, impacting development in the areas of social interaction and communication skills. Both children and adults with autism typically show difficulties in verbal and non-verbal communication, social interactions, and leisure or play activities. (ASA, 2010, para1)
\end{abstract}

I restated the definition of autism because autism is a complex disorder that has been defined differently over the years. In no small measure, the complexity of the disorder and the changes to the definition of what ASDs are contributes to the current state of affairs for young adults with ASDs and is critical to understanding their situation.

The modern history of autism began in 1943/1973, when child psychologist Kanner first used the term to describe a pattern of behaviors observed in children in a clinic at Johns Hopkins University in Maryland. The early understanding of the condition was muddled by Kanner's inaccurate statement regarding observation of a lack of warmth and attachment displayed by mothers and fathers toward their children with autism (1943/1973). In a 1949 paper, Kanner elaborated on this observation, citing that the autistic condition may be linked to a "genuine lack of maternal warmth" (1949). This suggestion of causation was later adapted by other researchers. It is not quite clear who first used the term "refrigerator mother," but that term became a popular, although shortlived theory ${ }^{2}$ regarding the cause of the condition. This theory, in part, blamed the autistic

\footnotetext{
${ }^{2}$ Some disagreement exists over who first used the term "refrigerator mother." Kanner (1949), while not a user of the term, certainly felt some responsibility for even the introduction of the concept of mothers not
} 
condition on a lack of warmth and bonding received from the child's mother. Other researchers, including most notably Bettelheim, contributed to this theory in writing The Empty Fortress: Infantile Autism and the Birth of the Self (Bettelheim, 1967; Piven \& Palmer, 1997; Piven, Palmer, Jacobi, Childress, \& Arndt, 1997). Bettelheim was among the first to use the phrase "refrigerator mother," whereas Piven, Palmer and colleagues conducted studies on the parents and family members of children with autism. They also cited a potential link between social and communication deficits in the family and autism.

Others conducting early research on autism included Rimland (1964), Eisenberg and Kanner (1956), Wing (1969), and Rutter (1966). The "refrigerator mother" theory was quickly challenged by several of these autism researchers, especially Rimland (1974), the parent of a son with autism born in 1956.

Approximately the same time Kanner was writing about autism, Asperger (1944) of Germany was doing similar research and identified autistic characteristics that later became known as Asperger syndrome. Asperger's studies revealed similar behaviors among verbal children to Kanner's studies on autism. Asperger's research became popularized in the United States after publication of Wing's paper, Asperger's Syndrome: a Clinical Account (1981/2009).

One aspect of the autism topic that has garnered much recent attention is the questionable notion of a possible "autism epidemic":

In 2006, on average, approximately $1 \%$ or one child in every 110 in the 11 ADDM sites was classified as having an ASD. The average prevalence of ASDs identified among children aged 8 years increased $57 \%$ in 10 sites from the 2002 to the 2006 ADDM surveillance year. (CDC, 2009)

bonding with their child as a possible explanation for the cause of autism. Feeling responsible for the introduction of the concept, Kanner apologized at the 1969 meeting of the National Association of Autistic Children, which would later become the ASA. 
These numbers are corroborated in numerous other studies including the 2007 National Survey of Children's Health, funded and published by the Health Resources and Services Administration (2007), a branch of the U.S. Department of Health and Human Services.

As discussed in the introduction, the rising incidence of autism has been described by some as epidemic. The numbers are continually updated and debated, but multiple sources continue to assess the incidence at roughly one in a hundred or $1 \%$ of all children in the United States (CDC, 2010). Most recently the ADDM data from 2008 increased the prevalence to as high as one in 88 (CDC, 2012).

Many question whether this increase in reported incidence is truly representative and deserving of the term "epidemic." The "autism epidemic" label is disputed by Gernsbacher, Dawson, and Goldsmith (2005), who argued there are three primary reasons the increase in autism diagnoses have been misunderstood: "lack of awareness about the changing diagnostic criteria, uncritical acceptance of a conclusion illogically drawn in a California-based study, and inattention to a crucial feature of the 'child count' data reported annually by the United States Department of Education" (Gernsbacher et al., 2005, p. 57).

Others who have questioned the term "epidemic" are Wallis (2007), Salahi and Chitale (2008) and Grinker (2007) in the book Unstrange Minds: Remapping the World of Autism. These researchers, in similar fashion, supported the opinion that a combination of expanding diagnoses, diagnostic definitional changes, accounting of the population, and numerous other anomalies, including the desire for access to services for school-age children, have created the appearance of an epidemic. Additional academic studies 
pertaining to an "autism epidemic" include Fombonne (2001), Yeargin-Allsop et al. (2003), and Shattuck (2006).

Another explanation for the increased incidence of autism is diagnoses being made at an earlier age.

ASDs begin before the age of three and last throughout a person's life, although symptoms may improve over time. Some children with an ASD show hints of future problems within the first few months of life. In others, symptoms might not show up until 24 months or later. Some children with an ASD seem to develop normally until around 18 to 24 months of age and then they stop gaining new skills, or they lose the skills they once had. (CDC, 2010)

"Although evidence supports better detection of such differences during the second year of life (12-24 months), some reports reveal developmental anomalies present during the first year" (Goin \& Myers, 2004, p. 10).

Until very recently, the diagnosis of autism was essentially a clinical observation rather than objectively measured criteria. In the past 5 years, research by Torres et al. (2013) of Rutgers University allows mapping of body movements as a possible early indicator of autistic tendencies as well as an object measure of changes in behavior and learning. Torres stated,

We have maps of our body in various parts of the brain that tell you, for example, where your foot is in relation to your hand, or when and where someone touched you. But for them, this information is corrupted. From moment to moment the timing of their motions is different. It's like a radio tuned to the wrong frequency. (Stetler, 2013, para 6).

Torres' methodology allows for the first measure of autism and, in the future, is likely to be used to diagnose young children and others to allow for a more scientific look at the "epidemic." Irrespective of whether the increase in autism diagnoses can be clarified, for now, the increasing number of children diagnosed with autism is ultimately going to result in a larger and ever-increasing population of adults with ASDs. 


\section{Services for Those With Developmental Disabilities}

Roughly at the same time as the increase in autism diagnoses, a corresponding focus on the number of services available to those who have developmental disabilities arose, including to children with ASDs. The EAHC, a federal mandate of 1975 (later to be known after 1990 as the IDEA), provided all children with a free and appropriate public education in the least restrictive environment. This education was mandated until the end of a state's legal right to education, which varies from state to state. Therapy and school accommodations designed to help children with autism have continued to increase. Even though these services are mandated by a student's individualized education program, the current adverse economic conditions have forced many public schools to reduce and restrict services. Most support ceases once the young adult leaves secondary education. The ASA's position paper on the crisis in adult services stated,

Since 1975 when the Education for All Handicapped Act (now IDEA) mandated a free and appropriate education for children with disabilities, parents took for granted their child had a firm and congressionally mandated right to services. Many are stunned to learn that when their child leaves school, the mandate for services ceases. (Sullivan, 2007, p. 1)

In 1995, the experience of the loss of services by parents was termed the "second shock" by Hanley-Maxwell, Whitney-Thomas, and Pogoloff (1995). The first shock is the original autism diagnosis. The reality that their young adult with autism will no longer have support is a harsh experience for many parents, as well as for their adult children, as chronicled by Hanley-Maxwell et al., Morgan (1996), Wehman (2006), and Hendricks and Wehman (2009).

\footnotetext{
${ }^{3}$ The exception is the State of California, due to the provisions of the Lanterman Act, which mandates entitlement to lifelong services as discussed later in this chapter.
} 
Although no state has entitlements specifically for adults with autism, California provides services throughout the autistic person's life through the DDS and 21 associated regional centers (California Department of Developmental Services, 2010a). The Lanterman Developmental Disabilities Act (AB 846) was first introduced in 1969 as AB 225 (the Lanterman Mental Retardation Services Act), and became law in 1977. It is responsible for California's unique role as the nation's foremost provider of adult autistic services. One of the stated purposes of this law is to, "enable people with developmental disabilities to have the same kind of lives as people of the same age without disabilities, and to lead more independent and productive lives in the community" (Disability Rights California, 2011, p. 1-3). A key sentence in this act mentions availability across the lifespan, and it is this sentence that provides the basis for continued adult services in California.

Although California is the only state with this guarantee of lifelong entitlement to services, the state is also financially challenged due to the large number of individuals they must serve: "Autism now accounts for an unbelievable 37\% of all new cases coming into the California Developmental Services System" (Sullivan, 2007, p. 3). Although it is not definite that this increase is due to the provisions of the Lanterman Act, it seems probable that the provision of lifetime services, as well as the need for a medically diagnosed qualifying condition to obtain services, could incentivize parents to ensure their child(ren) are formally diagnosed. An additional consideration could be families living in other states who decide to move to California, due to the provisions of the Lanterman Act. The potential of qualifying for lifelong entitlement and access to services 
for their soon-to-be young adult with autism could be a strong motivator to move to California where the Lanterman Act could have long-term care and services implications.

\section{Specific Challenges for Adults with Autism}

Young adults with autism have some very specific challenges. One challenge is the adjustment to no longer having the supports mandated by IDEA and the support structure of the secondary-education system. Students with autism attend public schools with the support of an aide or have placement in specialized classrooms; pullout services or trained resource specialists are provided. These supports often cease following high school, even in California. Giddan and Obee (1996) reported this reality in the late 1990s: "Historically, the needs of those with autism have been ignored as they grew beyond childhood into adolescence and adulthood. Institutionalization was the rule in the early decades of this century with little hope offered to individuals with autism" (p. 72).

It is also possible that some young adults with ASDs developed an overreliance on one-to-one services, verbal direction, and assistance due to participation in intensive Applied Behavior Analysis therapy programs as children. Many of these programs advocate for 40 hours per week or more of one-to-one training.

Most stereotypical behaviors and needs associated with autism, even highfunctioning autism, are likely going to be impediments to employment, independent living, and the ability to socialize and exist in the community. Gerhardt and Holmes stated in their 1997 paper on employment options and issues concerning adult outcomes in autism: "Little is known about transitions to the adult world, but it is thought to be a confusing maze of misinformation, limited opportunities, insufficient resources and inappropriate or time limited services" (p. 739). 
A report by the New York Center for Autism was developed to

provide an overview of the types of the service systems and models that currently exist which are designed to provide adults with ASD the continued and necessary support to be engaged, active citizens and lead lives of competence, quality and dignity. (Gerhardt, 2009, p. 2)

This report painted a bleak picture of the current situation for adults with autism. The authors reported poor outcomes for adults in nearly all areas of adult experience from employment to independent living, leisure, and recreational activities. Also contributing to this bleak condition are the relatively few studies performed on adult outcomes. The following excerpts from some of these few studies highlight some of the most pressing of the specific challenges faced by adults with ASDs. The areas considered are employment, independent living, and socialization.

\section{Employment}

The labor participation rate in 2010 for all people with disabilities in the United Sates was $22 \%$ compared to $70 \%$ for persons without disabilities (U.S. Bureau of Labor Statistics, 2010). A 2004 research study on employment for persons with disabilities stated: "Respondents with disabilities were nearly five times more likely to be involuntarily unemployed than their physically nondisabled community counterparts" (Turner \& Turner, 2004, p. 243). Very few in-depth research studies exist on employment outcomes for adults with autism. In the United States, the few studies conducted specifically on employment of those with ASDs reported less than encouraging outcomes.

Cimera and Cowan (2009) authored one of the rare studies on adult outcomes that focuses on employment statistics following vocational training for persons with disabilities. They proposed two basic significant interpretations of their findings. First, 
“individuals with autism on average simply require more services to become employed than nearly all other populations" (p. 288). The second states that, "because of the nature of their condition, they are unable to work many hours per week or obtain jobs that pay higher wages" (Cimera \& Cowan, 2009, p. 290). Several studies conducted in the United Kingdom, Canada, and Australia had similar conclusions (Howlin, 2000; Howlin et al., 2005, 2004).

Currently the adult ASD community appears to be at a disadvantage in the ability to obtain meaningful employment, live independently, and self-determine and advocate for these two critical quality of life issues. Whereas overall employment rates for all persons with disabilities are declining, the autism community appears to be particularly underperforming and lagging behind all other disability communities. Only $30 \%$ of persons with disabilities are working either full or part time, and two thirds of those who are not working would like to be employed (National Organization on Disability, 2000). Individuals with autism are least likely of any disability community to be employed, with only 15\% employed in 2003 (Cameto et al., 2003). The numbers appear to be consistent with only $6 \%$ of persons with an ASD employed full time in 2010 (Chappela \& Somers, 2010). These statistics and numerous other studies seem to suggest few supports and many barriers hinder the ability of young adults on the autism spectrum to find employment (SEDL, 2014).

\section{Independent Living}

The area of independent, semi-independent, or supported living for those with ASDs is similarly discouraging. Moreover a paucity of studies on this topic exists in the United States. A study conducted in Ireland found the best outcomes in the area of social 
interaction for adults with ASDs existed when individuals were provided supported living arrangements. The worst results for social interaction were in institutional or "campus" models of supported living. Further research is needed in this area to continue to determine the best supported-living arrangements for young adults with ASDs (McConkey, 2007).

The University of New South Wales Social Policy Research Centre (2008) recently reported, "The most pervasive trend in current approaches to supported accommodation in Australia and the other countries studied (the U.S. and Europe with a focus on the UK) is deinstitutionalization. The process is advancing in most countries, including Australia" (para 3). The University of New South Wales research also claimed the following: "In terms of supported living arrangements, when compared to institutions, community-based living offers better possibilities for good quality of life of people with disability" (Young, 2006, p. 422). In addition, "community-based living has been found to offer improved community access, self-determination and wellbeing, and offer more opportunities for interaction and increased input into house decision, which contributes to increased improvements in self-care and domestic skills" (University of New South Wales, 2008, para 5). Similar findings have been reported by Wehmeyer and Bolding (2001), Perry (2009), Stancliffe and Keane (2000) and Turnbull and Turnbull (2002).

The California DDS reported a changing trend in where persons with ASDs were residing between 1987 and 2007.

In 2007,89 percent of people with autism lived at home (with parents and family) compared to just 53 percent in 1987. In 1987, 31 percent of people identified with autism lived in licensed community residential facilities and this rate has gradually dropped to seven percent in 2007 . The implication is that while it is seen as a positive that the institutional population is decreasing the likelihood is that these young adults are back home again living with their parents. Similarly, 
the number of people with autism who are living at developmental centers dropped from 11 percent in 1987 to 1 percent in 2007. (Cavagnaro, 2007, p. 21)

The majority of these individuals may have returned to living with their families. The prospect of living with family members is a far better outcome than potentially being homeless, living nomadically, or in a variety of transient situations.

The amount of research data available is limited; what does exist, however, suggests the benefits of noninstitutional living arrangements for those with ASDs. Specialized and individualized arrangements tailored to each adult's needs, strengths, challenges, and desires have the best potential for successful outcomes. More research is needed in this area, as the limited findings and unique individual circumstances make it impossible to generalize from the current insufficient studies (Kozma, Mansell, BeadleBrown, \& Emerson, 2009).

\section{Socialization}

Although the prospect of employment and independent living is challenging, an additional challenge is leisure and social interaction for the young adult with autism. Gerhardt and Holmes argued that "the provision of age appropriate and enjoyable leisure and recreation activities to adults with ASD can be a particular challenge to both families and community service providers" (1997, p. 36).

A study published in 2008 of individuals with Asperger Syndrome made these observations:

Qualitative analyses of the interview transcripts revealed a number of common experiences including a profound sense of isolation, difficulty initiating social interactions, challenges relating to communication, longing for greater intimacy, desire to contribute to one's community, and effort to develop greater social/selfawareness. (Muller, Schuler, \& Yates, 2008, p. 173) 
It is likely that these same observations could be made of any sample of young adults with ASDs, not only those diagnosed with Asperger Syndrome.

The discouraging prospect for adults with disabilities led to the addition of transition services to IDEA in 2004. As Cortiella (2010) explained, "When Congress updated the nation's special education law, the Individuals with Disabilities Education Act (IDEA 2004), it sought to improve postsecondary results for students with disabilities by requiring public high schools to provide better transition planning" (para 1).

\section{Studies Concerning Socialization}

Howlin et al. (2004) compiled a list of 16 independent studies that reported social and independence outcomes for adults with autism. The studies are listed in Table 2. Although these studies use slightly different definitions of the categories good, fair, and poor, the adult outcomes labeled poor far outnumber the other two categories. In only two of 16 studies did the category of fair exceed the outcome of poor.

\section{Advent of Disability Awareness and Education}

Because the situation of autism service and supports today is grounded in the framework of previous disability community's challenges, it is fitting to consider a brief overview of the modern history of disability recognition and advancements, followed by a brief outline of disability legislation in the United States and specifically how and when the autism community entered the conversation. The history will be followed by an introduction of a representative sampling of autism-resource service organizations that are the focus of this study. 
Table 2

Independence and Social Outcomes in Follow-Up Studies of Adolescents and Adults

Characterization of outcome (if applicable) $\%$ of total $n$

\begin{tabular}{|c|c|c|c|c|}
\hline Study (year) & Total $n$ & Good & Fair & Poor \\
\hline Eisenberg (1956) & 50 & 6 & 28 & 67 \\
\hline Lockyer et al. (1970) & 38 & 14 & 25 & 61 \\
\hline Kanner (1973) & 96 & 11 & & \\
\hline Lotter (1973) & 29 & 14 & 24 & 62 \\
\hline Newson et al.(1982) & 93 & 7 & 77 & 16 \\
\hline Rumsey et al. (1985) & 14 & 35 & 35 & 28 \\
\hline Szatmari et al. (1989b) & 16 & 38 & 31 & 31 \\
\hline Tantam (1991) & 46 & & & \\
\hline Kobayashi et al. (1992) & 201 & 27 & 27 & 46 \\
\hline Venter et al. (1992) & 22 & & & \\
\hline vonKnorring \& Hagglof (1993) & 34 & 3 & 9 & 88 \\
\hline Ballaban-Gil et al. (1996) & 45 & 6 & $?$ & $?$ \\
\hline Larsen \& Mouridsen (1997) & 18 & 28 & 28 & 44 \\
\hline Mawhood et al. (2000) & 19 & 26 & & 74 \\
\hline Billstedt et al. (2003) & 83 & 0 & 24 & 76 \\
\hline Howlin et al. (2004) & 68 & 22 & 19 & 57 \\
\hline
\end{tabular}

Note. Howlin, P. et al, 2004, p. 215.

\section{Early Disability Rights Awareness}

In the mid to late $1700 \mathrm{~s}$, the first concentrated modern account of disability rights awareness was recorded in Europe. People who were deaf were recognized as a disability community, and advocates established schools for people who were deaf in Germany and in France in 1755, followed by one in England in 1760 (Lane, 1984). Other early disability studies include Pinel $(1794,1798)$ and Itard (1802). One of the earliest to study people with disabilities in the United States was Rush (1835). 
Deafness was also the first disability in the United States to warrant special attention. Opened in Hartford on April 15, 1817, the Connecticut Asylum for the Education and Instruction of Deaf and Dumb Persons (now the American School for the Deaf) became the first permanent school for the hearing impaired in America. In 1854, Gallaudet established the Columbia Institution for the Instruction of the Deaf and Dumb and the Blind in Washington, DC. This institute was authorized by Congress to confer college degrees a decade later in 1864 . Nearly 100 years later this institute would be renamed Gallaudet College and in 1986 was again renamed Gallaudet University (2014). One of the first nonprofit organizations for persons with disabilities in the United States was also established for the deaf community. The National Association for the Deaf was established in 1880 in Cincinnati, Ohio.

Other disability communities slowly followed in recognizing and accommodating disabling conditions. The acknowledgement of these conditions soon gave rise to legislation to provide for accommodations and treatment. Some of the early government disability organizations and the year they were founded are listed in Table 3.

The Smith-Sears Veterans Rehabilitation Act of 1918 was one of the first recorded laws in the United States that provided for the establishment of vocational rehabilitation for military personnel with disabilities upon their discharge from service (U.S. Commission on Civil Rights, 2000): 
Table 3

Sampling of National Disability Organizations and year founded in the United States

\begin{tabular}{cl}
\hline Year founded & Organization \\
\hline 1876 & $\begin{array}{l}\text { American Association on Mental Retardation (now known as American } \\
\text { Association on Intellectual and Developmental Disabilities) }\end{array}$ \\
1916 & Easter Seals \\
1940 & American Diabetes Association \\
1949 & United Cerebral Palsy \\
1950 & Association for Retarded Children \\
1950 & National Muscular Dystrophy Associations of America \\
1973 & National Down Syndrome Congress \\
\hline
\end{tabular}

The Social Security Act of 1935 extended vocational rehabilitation services to people who were blind as well as providing benefits to children with disabilities. Founded in 1940, the American Federation for the Physically Handicapped was "the first crossdisability national (American) political organization" (Temple University, 2011). In addition to championing the end to job discrimination, its founder, Strachan, called for new legislation that protected people with disabilities, as well as the creation of the National Employ the Physically Handicapped Week (Temple University, 2011). The postwar period in the 1950 s and 1960 s saw a continual stream of disability-rights legislation, as well as the establishment of such organizations as the Paralyzed Veterans of America, the National Paraplegia Foundation, the National Association for Down Syndrome, the Autism Society of America and the Association for Persons with Severe Disabilities (Scotch, 2001).

The Vocational Rehabilitation Act of 1973 is considered the "Civil Rights Act" for persons with disabilities. Section 504 of the law stated: 
No otherwise qualified individual with a disability in the United States, as defined in section $705(20)$ of this title, shall solely by reason of her or his disability, be excluded from participation in, be denied the benefits of, or be subjected to discrimination under any program or activity receiving federal financial assistance. (U.S. Department of Justice, Civil Rights Division, 1973, p.210)

Education is specifically delineated under programs that receive federal financial assistance in Section 794. Section 794 states that this law applies to “2)(A) a college, university, or other postsecondary institution, or a public system of higher education; or (B) a local educational agency (as defined in section 8801 of Title 20), system of vocational education, or other school system" (U.S. Department of Labor, 1973, para 1).

The EAHC, Public Law 94-142, later called IDEA was passed by Congress in 1973 and implemented in 1975. It mandated that children with disabilities were entitled to a free and appropriate public education in the least restrictive environment. The law was amended in 2004 to require transition planning for postsecondary education to begin no later than the age of 14 , and to be implemented no later than 16 years of age. The enactment of these disability-rights laws resulted in the need for sufficient agencies to provide and administer the mandated services.

Passed in 1990, the Americans with Disabilities Act has been called the "capstone to a public policy promoting community access and participation by people with disabilities." In 2009, however, Gerhardt argued that, "the impact of [the Americans with Disabilities Act] on the employment of individuals with autism has NOT yet been tested" (p. 11). The employment of individuals with ASDs continues to be unknown at the time of this study.

\section{Rise of Service-Providing Government Agencies}

The mid-19th century saw a rise in the creation and proliferation of publicly funded institutions for people with disabilities. Although the plight of people with 
disabilities was receiving regional and even national attention, the reaction, particularly with respect to mental health, was to build and administer institutional facilities where people with disabilities could be attended to and isolated from the rest of society (Wolfensberger, 1969). This increase in institutional facilities was also noted by Braddock (1999), Braddock and Parish (2001), and many others.

The institutional model was addressed by Wolfensberger in the work The Origin and Nature of our Institutional Models (1969). Wolfensberger offered a concise history of the origins of the institutional model and what ensued for persons with mental retardation and developmental disabilities. The model was an attempt to provide for the specialized needs of the individual in a caring and tailored environment. It capitalized on the "best practices" of the era, manifested in a large, factory-like setting, and in achieving economies of scale by using a standard model and routine procedures. Hindsight reveals this was not the best method of caring for persons with a wide variety of behavioral and cognitive issues and needs. In By Trust Betrayed, Gallagher (1989) detailed how the institutional model distorted and potentially victimized those it was created to serve. The worst example of victimization was witnessed in Nazi Germany where institutionalized persons with disabilities were subjected to horrific extremes of medical experimentation, abuse, torture, and sanctioned extermination (Gallagher, 1989).

Although the intent of the initial institutional models may have been noble, Wolfensberger (1969) noted the reality became, at times, something quite different. Part of this problem was due to the large number of individuals the institutional models were trying to serve. The 2007 National Survey of Children's Health stated,

Before the enactment of Public Law 94-142, the fate of many individuals with disabilities was likely to be dim. Too many individuals lived in state institutions 
for persons with mental retardation or mental illness. In 1967, for example, state institutions were homes for almost 200,000 persons with significant disabilities. (U.S. Office of Special Education Programs, 2007, para 10)

Wolfensberger's (1969) initial exposure of the potential dangers of the institutional model was soon followed by numerous studies and research that showed the shortcomings, abuse, and neglect that often resulted in the institutional model. One particularly shocking story was the infamous Willowbrook State School in Staten Island, New York, where over 6,000 children with mental disabilities were housed in a facility with a designed maximum capacity of 4,000 . Willowbrook became the focus of attention following a 1965 visit by then New York Senator R. F. Kennedy. Kennedy described the appalling conditions, overcrowding, neglect, and abuse in a statement to a Joint Legislative Committee on Mental Retardation in September 1965.

Nothing was done or changed at this facility until a television documentary in 1972 exposed the continued deplorable conditions. This report by television journalist Rivera focused national attention on the topic. Even with the resulting renewed scrutiny and oversight, Willowbrook was not closed until 1987. Many examples of institutional neglect and abuse continue to this day, fueling the formation of organizations such as the Coalition against Institutional Child Abuse, as well as many informational alerts by the ASAN, the AUTCOM, and many other advocacy organizations.

\section{Intervention and Therapy Organizations}

As previously discussed, the increase in autism diagnoses is well documented. Whether an actual increase in the incidence of autism exists or it can be explained by grounded hypotheses, a by-product to the increase in reported incidence has been a corresponding increase in the number of organizations, institutes, websites, treatment facilities, and theories for treating or servicing those with autism. These organizations are 
purportedly designed to offer support for those diagnosed with ASDs, as well as their parents and family members, teachers, health professionals, and school and medical administrators, to assist with the ever-increasing autistic population. Discussed as part of this study are the ASA and a sampling of the hundreds of other organizations offering service to the autism community.

Central to the proliferation of autism organizations is the growth of "earlyintervention" strategies and programs for "treating" the symptoms (Corsello, 2005). Many of these strategies and programs go so far as to promise "recovery." One of the earliest pioneers, Lovaas, used an applied-behavior-analysis model that incorporated rewards for correct responses to verbal and physical prompts and punishment for incorrect or nonresponses. Eventually the Lovaas model eliminated punishments and solely focused on rewards for correct or encouraged behaviors. The Lovaas Institute website continues to claim:

His Lovaas Model of Applied Behavior Analysis is based on 40 years of research and is backed by published studies showing half of children with autism who receive this intensive treatment become indistinguishable from other children on tests of cognitive and social skills by the time they completed first grade. (Lovaas Institute, 2014, para 2)

"Lovaas" type programs have proliferated, and many other services make similar claims including such organizations as Play and Language for Autistic Youngsters, the Son-Rise Program, and Treatment and Education of Autistic and Related Communication Handicapped Children. In summation, a flourishing and profitable growth industry exists for those providing services to children diagnosed with ASDs.

Certainly a demand exists for many specialized services offered by providers with specific training in working with children on the autism spectrum. Few providers produce documented evidence of significant improvements. Negative findings or "failures" from 
this applied field are not published. The initial research by Lovaas in 1987 was conducted on a very small sample of children and its scientific integrity has been questioned by many (Schopler, Short, \& Mesibov, 1989; Schreibman, 2000). As Granpeesheeh and others noted, however, in 2010 ,

In the past 20 years, seven long-term, large-scale, controlled studies have demonstrated that children who receive more than 25 hours per week of [Applied Behavior Analysis] for more than one year make tremendous gains. ... Historically EIBI (Early Intensive Behavior Intervention therapy) research has been criticized for its small sample sizes, lack of randomized control trials and failure to include procedural integrity measures. However, the growing collection of well-designed research studies, particularly in the last few years, has made progress in addressing these concerns. (p. 165)

Lovaas' initial research most certainly fell in the first category of small sample size and lack of procedural integrity.

A percentage of unscrupulous practitioners prey on the fears of ill-informed or desperate parents. Grandin is a world-famous person with autism who achieved recognition as a young person and has since made incredible contributions to the field of animal welfare and humane animal treatment. Grandin earned a Ph.D. in animal science, but is equally famous for books, writings, and lectures on life with autism. In 2008 , Grandin opined on the presence of unscrupulous practitioners:

Some go so far as to tell the parents their child is doomed unless they use their program or product. One parent called me about a situation just like this. The family was ready to sell their house to have the funds needed to send their fouryear-old child with autism to a special school in another state. (p. 29)

Regrettably, many examples of this fear tactic are used on parents who are desperate to help their child who has an autism diagnosis.

An example of one particularly interesting program is called Byonetics, which claims to have a $70 \%$ success rate in using a technology termed "cranial dynamics." This technology claims to repair damaged developmental switches in the brain that "connect 
the child's brain/computer and its software" (Byonetics, 2012, para 3). A quick scan of the Internet will return literally hundreds of similar programs and organizations, all claiming to have new, innovative ways to treat a child with autism. The proliferation of all of these independent agencies, programs, and organizations on the local, state, and federal levels surely would tempt one to assume there must be services and supports to fill any gaps in any situation or need. However, for adults with ASDs that does not seem to be the case.

Despite the rise in federal- and state-funded agencies, a gap appears to exist in the provision of services, education, and resources for people with disabilities and their families, especially those with ASDs. Independent nonprofit organizations have attempted to fill this gap. Today hundreds of disability-specific nonprofit organizations exist in the United States and internationally. Autism, although a relative newcomer to the conversation, is represented by its share of organizations dedicated to research, treatment, education, and rights for the autistic community.

An indicator of this growth industry is organizations such as Autism Speaks and Defeat Autism Now. One of Autism Speaks' goals, delineated in their mission statement, is "facilitating global research into the causes, treatments, prevention and an eventual cure for autism" (2011, para 3). The mission statement of Defeat Autism Now (2007) is self-evident. Although their cause appears noble, the message has not been well received by the ASD population. As Grandin said, "If I could snap my fingers and be nonautistic, I would not--because then I wouldn't be me. Autism is part of who I am" (as cited in Sacks, 1995, p. 291). Denying autism is a repudiation of who those with ASDs are as individuals. Sinclair stated in his famous essay "Don't Mourn for Us” (1993), 
Autism is a way of being. It is not possible to separate the person from the autism. Therefore, when parents say, "I wish my child did not have autism," what they are really saying is, "I wish the autistic child I have did not exist, and I had a different [nonautistic] child instead.

Read that again. This is what we hear when you mourn over our existence. This is what we hear when you pray for a cure. This is what we know, when you tell us of your fondest hopes and dreams for us: that your greatest wish is that one day we will cease to be, and strangers you can love will move in behind our faces (as cited in Shore, 2004a, pp. 149).

The implications of this type of deficit thinking is that autism is not a condition to be embraced as part of the person's character, and that somehow those on the spectrum need to be "fixed."

Another issue, for which very sparse literature exists, is the need for an autismrights movement. In 2008, the director of the Child Study Center at New York University (NYU) published controversial advertisements intended to spur parents of those potentially undiagnosed children with autism to seek care for their children at NYU. The director did not anticipate the backlash from the autistic community:

Autism activists spearheaded a huge protest. The chief organizer was 20 -year-old Ari Ne'eman, who has an Asperger's (autism without speech delay) diagnosis. In a memo to his Autistic Self Advocacy Network, he denounced the campaign as relying on "the oldest and most offensive disability stereotypes to frighten parents." While people with diagnoses of autism and Asperger's have difficulty with social interaction, he added, "We are not incapable of it and can succeed and thrive on our own terms when supported, accepted, and included for who we are." Stereotypes of autism were self-fulfilling, he argued. As he told me later, autistic adults were abandoned to "rot in institutions because of the perception that there is no way they can live in the community" (Solomon, 2008, para 2).

Following this protest, NYU withdrew the advertisements. Other autism advocacy groups have also surfaced with the objective of providing for the autistic community in our society, not as an adjunct to it. Their goal is an acceptance of those with ASDs in the larger "neurotypical" society. These organizations, such as Autism Network International, Aspies for Freedom, and AUTCOM are all older and more established than 
the ASAN, but have a similar mission. An internet search today would yield over 100 autism rights links. Though still dwarfed in number by those offering cures or dedicated to eradication of autism, the autism-advocacy trend seems to offer hope for persons with autism, families; and rights of self-determination.

Although many disability communities have a history of extensive activity and expansion of dedicated research, the autism community has rapidly become one of the most active. Part of this activism is because much is still unknown regarding the cause of ASDs. The IACC is an advisory committee established by the federal government in 2006 as a result of the Combating Autism Act. The IACC clearly delineated the lack of research in many areas and allocated government resources to the study of these deficiencies and the expansion of autism services. A reality of the times is that action follows available financing. Additionally, private, independent organizations and services have grown exponentially, as parents try to find methods of early intervention to assist their children. Table 4 lists a sampling of autism organizations, in addition to the ones specifically considered in this study. 
Table 4

Sampling of Autism Research and Service Organizations

Advancing Futures for Adults with Autism

Asperger Syndrome and High Functioning Autism Association

Autism One

Autism Science Foundation

The Bureau of Autism Services

The Dan Marino Foundation

Eden Family Services

Families for Early Autism Treatment

Families of Adults Affected by Asperger Syndrome

Future Horizons

The Global Autism Project

The Global and Regional Aspergers Syndrome Partnership

International Center for Autism Research and Education

National Autism Association

Organization for Autism Research

Talk Autism

Talk About Curing Autism

Unlocking Autism

U.S. Autism and Asperger Association

Following is a brief introduction of six select autism organizations and a description of their founding, guiding principles, mission statements, and goals. The organizations are the ASA, Autism Speaks, the ASAN, the AUTCOM, the Association of Retarded Citizens (Arc), and the Autism Research Institute (ARI).

I chose these particular organizations as a representative sample for several reasons. ASA is the first and oldest organization in the United States to focus on ASDs. Autism Speaks is currently the most well-known and well-funded autism organization in 
the United States. They have used famous spokespersons such as actress McCarthy to assist in their notoriety. The others were selected for their relevance to young adults with ASDs. ASAN and AUTCOM appear to be the most oriented toward self-advocacy and adult-outcome focused of all the various autism organizations. I selected The Arc and ARI due to the size of the population served, high national recognition, and because they provide a representative sample of other similar organizations. Respondents mentioned all of these organizations in the online survey. A few other organizations were added to the study for their specialized offerings, because of the number of times respondents mentioned them in the survey, or due to the uniqueness of their offerings.

\section{Autism Organizations}

\section{The Autism Society of America (ASA)}

The very first autism organization in the United States was founded by Rimland in 1965. Rimland was the parent of a son with autism and eventually banded together with other parents of children with autism to found the National Society of Autistic Children. In 1968, Sullivan was elected the first president of the National Society of Autistic Children, which later became known as the National Society for Children and Adults with Autism and is now known as the ASA. The ASA continues to operate today with a strong national presence, as well as state and local chapters throughout the United States.

The ASA describes itself on its website as follows:

Over the last 40 years, the Society has grown from a handful of parents into the leading source of information, research and reference on autism. The Autism Society is the oldest and largest grassroots organization within the autism community. Today, more than 120,000 members and supporters are connected through a working network of nearly 150 chapters nationwide. The Autism Society membership continues to grow as more and more parents and 
professionals unite to form a collective voice representing the autism community. (2011c, p. or para 1)

The mission statement of the ASA is the following:

The Autism Society is dedicated to increasing public awareness about autism and the day-to-day issues faced by individuals with autism, their families and the professionals with whom they interact. The Autism Society and its chapters share a common mission of providing information and education, supporting research, and advocating for programs and services for the autism community. (2011a, para1)

The ASA certainly is well established and nearly universally recognized in the United States as a leading organization in the autism community.

\section{Association of Retarded Citizens (The Arc)}

Initially founded in 1950 as the National Association of Parents and Friends of Mentally Retarded Children, the name was later changed in 1953 to the National Association for Retarded Children. In 1973, the organization was again renamed the National Association for Retarded Citizens, and again in 1981, The Arc of the United States. Since 1992, it has just been known as The Arc of the United States.

The Arc's mission statement simply states, "The Arc promotes and protects the human rights of people with intellectual and developmental disabilities and actively supports their full inclusion and participation in the community throughout their lifetimes" ( 2014b, para 1).

The Arc lists their core values as People First, Equity, Community, Selfdetermination and Diversity (2014b). The Arc also lists their guiding principles as "Participatory Democracy, Visionary Leadership, Public Interest, Collaboration, Transparency, Integrity and Excellence" (2014a, para 6). The Arc calls itself the "largest national community-based organization advocating for and serving people with 
intellectual and developmental disabilities and their families" (2014d, para 1) They also claim to serve all ages and to embrace multiple disabilities including autism.

The Arc claims to be the "nation's leading advocate for people with intellectual and developmental disabilities" (MetLife, 2014, para 1). The Arc includes the following areas as their principles offerings: "Public Policy, Supports and Services and Education and Activism" (Arc, 2014c, p. 1). Under supports and services ${ }^{4}$ they include education, residential, employment, family, and recreational support and services.

\section{Autism Speaks}

One of the newest and most recognizable autism organizations is Autism Speaks.

Founded in 2005 by the Wrights, the grandparents of a child diagnosed with autism,

Autism Speaks claims to have

grown into the nation's largest autism science and advocacy organization, dedicated to funding research into the causes, prevention, treatments and a cure for autism; increasing awareness of autism spectrum disorders; and advocating for the needs of individuals with autism and their families. (2014, para 1)

The Autism Speaks mission statement is posted on their website as follows:

Our Mission at Autism Speaks, our goal is to change the future for all who struggle with autism spectrum disorders.

We are dedicated to funding global biomedical research into the causes, prevention, treatments, and cure for autism; to raising public awareness about autism and its effects on individuals, families, and society; and to bringing hope to all who deal with the hardships of this disorder. We are committed to raising the funds necessary to support these goals.

Autism Speaks aims to bring the autism community together as one strong voice to urge the government and private sector to listen to our concerns and take action to address this urgent global health crisis. It is our firm belief that, working together, we will find the missing pieces of the puzzle. The organization's tag line is:

\footnotetext{
${ }^{4}$ The Arc is one of two organizations in this study that actually do provide some direct services to clients. The other is some of the local chapters of the ASA.
} 
Autism Speaks. It's time to listen. (Autism Speaks, 2011, paras 1-3)

\section{Autism Research Institute}

ARI was founded in 1967 by Rimland to spread the news of a seemingly effective treatment called applied-behavior analysis or behavior-modification therapy, as well as to research potential biomedical treatments. Today the ARI website lists its mission as the following:

To conduct and foster scientific research designed to improve the methods of diagnosing, treating, and preventing autism. ARI also disseminates research findings to parents and others worldwide seeking help. The ARI data bank, the world's largest, contains over 40,000 detailed case histories of autistic children from over 60 countries. ARI publishes the Autism Research Review International, a quarterly newsletter covering biomedical and educational advances in autism research. (2014, para 1)

\section{Autism National Committee (AUTCOM)}

AUTCOM was founded in 1990. The AUTCOM website claims they are "the only autism advocacy organization dedicated to 'Social Justice for All Citizens with Autism' through a shared vision and a commitment to positive approaches" (2011, para

1). The site also claims that AUTCOM was founded

To protect and advance the human rights and civil rights of all persons with autism, Pervasive Developmental Disorder, and related differences of communication and behavior. In the face of social policies of devaluation, which are expressed in the practices of segregation, medicalization, and aversive conditioning, we assert that all individuals are created equal and endowed with certain inalienable rights, and that among these are life, liberty, and the pursuit of happiness (2011, para 1).

\section{Autism Self-Advocacy Network}

Previously introduced, ASAN was founded in 2006 by Ari Ne'eman. ASAN lists

their mission statement as follows:

The Autistic Self Advocacy Network seeks to advance the principles of the disability rights movement with regard to autism. Drawing on the principles of the cross-disability community, ASAN seeks to organize the community of Autistic 
adults and youth to have our voices heard in the national conversation about us. ASAN believes that the goal of autism advocacy should be a world in which Autistic people enjoy the same access, rights, and opportunities as all other citizens. We hope to empower Autistic people across the world to take control of our own lives and the future of our common community. Nothing About Us, Without Us! (2011, para 1)

The ASAN claims to be founded and operated by people with autism. ASAN's focus is on acceptance, accommodation, and equal rights for individuals with ASDs.

\section{California Regional Centers}

California, in addition to the nonprofit and research organizations mentioned in the previous paragraphs, also has a state-funded and chartered service known as the regional centers. The DDS is a state-funded and legislatively mandated state agency for the administration of services to those with disabilities, including ASDs. The DDS administers and delivers services through 21 regional centers that are publicly funded, independent, not-for-profit organizations. The DDS and their network of regional centers are the final resources studied in this dissertation.

\section{Continuing Need for Autism Services}

Despite the myriad resources, services, and organizations that assist people with autism, there is still significant research and literature reporting the unmet needs for this population of young adults. Whether specific services exist but are inaccessible due to expense or inconvenience, or do not exist at all, the focus of this study was to evaluate how well organizations serve the young-adult population with autism and to identify successes or failures.

\section{Summary}

The review of literature yields some broad categories worthy of further examination. Researchers suggested benefits and a need for additional, tailored supports 
for individuals with ASDs, particularly for young adults who are seeking independence and employment (Cimera \& Cowan, 2009). Researchers (Howlin, 2000 and Eaves \& Ho, 2007) also supported the need for additional research that examines the benefits of training and assistance for developing vocational, assisted living, socialization, and recreational skills (Hanley-Maxwell, 199).

Additional resources and supports, as well as self-advocacy and rights for individuals with autism, are not only desirable for the person with autism, but also in the best interest of the entire population. Turnbull and Turnbull (2002) asserted that

the new paradigm assumption about individuals with disabilities is that he or she is inherently worthy and is entitled to full citizenship in his community. Because he has functional impairments, he needs more support in order to be successful in his key environments, but with that support he can be a productive, contributing, respected member. (2002, p. 93)

When individuals with ASDs become "higher functioning" and productive citizens, leading more fulfilled and happy lives, the cost of health care and welfare will decrease.

However, researchers also suggested significant deficits in available services and supports that impede the ability of young adults to achieve a better quality of life. Some of these deficits that arise from programs, policies, and decisions are made with the best of intentions for those on the autism spectrum; ironically, though, they do not meet the needs of young adults with ASDs. The purpose of these organizations, with knowledge gleaned from their era, while well-meaning, may now actually be a hindrance to the overall quality of life and the positive growth for those on the spectrum. For this reason, the role of nonprofit organizations and their potential to bridge the gap for services and supports is the focus of this study. 
This study analyzed the resources and services offered by these organizations, discerning how well they address the needs and gaps in the adult population with ASDs, and provides suggestions for areas of improvement. 


\section{CHAPTER THREE}

\section{METHODOLOGY}

\section{Introduction}

Chapter 3 describes the methods used to gather and analyze the data for this study. My personal reasons for researching this topic follows a restatement of the research questions. I explain why I selected specific methods to conduct this study and discuss the research survey, the site, sample selection, and interviews. The remainder of the chapter focuses on data-collection and -analysis techniques. Chapter 3 closes with a brief summary of my role as researcher, limitations, and the significance of the study.

Before describing the methodology used, a restatement of the research questions is appropriate to frame the information in this chapter. The four questions that guided this study follow:

Research Question 1: How do organizations designed to support young adults with autism address ASDs and how do they define their role in providing support specifically to this population?

- What are the policies, organizational procedures and practices to address their target population?

- What factors support or challenge their efforts?

Research Question 2: How do young adults with ASDs, who have used one or more of these organization's services, define their needs?

- How do autistic young adults with ASDs evaluate the various organizations in relationship to meeting or not meeting their needs? 
Research Question 3: How do the parents and family members of young adults with ASDs define the needs of their family member with autism?

- How do parents and family members evaluate the services of the organizations studied in meeting their family member's needs?

Research Question 4: What implications can be drawn from these findings that could help to inform policy and practice for organizations that attempt to provide service to young adults with ASDs?

\section{Background}

The impetus for this study was my experience with my now 23-year-old son who has autism. Diagnosed at the age of 3 and a half, he completed rigorous in-home behavior modification and discrete trial therapy for nearly 10 years. My son was "mainstreamed" 5 in general-education classrooms for all of his elementary and secondary education. He graduated in 2009 with a 3.5 grade-point average from Scripps Ranch High School in San Diego.

As I introduced in Chapter 2, Hanley-Maxwell et al. (1995) authored The Second Shock: A Qualitative Study of Parents' Perspectives and Needs during Their Child's Transition from School to Adult Life. They referenced a "second shock" : the reaction that many parents have when confronted years later, when their child is transitioning to adult services. Upon our son's graduation from high school he matriculated to a local community college where my wife and I had our "second shock" experience, confronted with the lack of support for his college-level study.

\footnotetext{
${ }^{5}$ Mainstreaming refers to supports offered to children who qualify for special-education classes but instead attend general-education classes with neurotypical peers. The more commonly used term today is "inclusion."
} 
Our son is the reason I began a doctoral-studies program in 2005. I knew I wanted to conduct a research study related to autism. The combination of our "second shock" community college experience and our experiences with many of the organizations discussed in this study led me to envision the creation of a worthwhile study focusing on adults with ASDs

Several related topics were proposed for this study. However, the advice of my committee and my personal reflection on our family experiences solidified the rationale for this study. To date, a paucity of research focuses on service organizations specializing in ASDs as their services apply to young adults. Additionally, there is a welldocumented gap that exists between what is reported as needed and what services are actually provided for young adults with ASDs (Sullivan, 2007; IACC 2012). As stated in the Interagency Autism Coordinating Committee Strategic Plan Update 2012; "new findings about disparities in service delivery to and outcomes for adults with ASD point to the urgent need for research to understand the reasons for these disparities and to ameliorate them" (IACC, 2012, p. 46).

\section{Site Selection}

A significant factor that entered into the selection of the methodology was the unique situation of adults with autism in California. The provision of the Lanterman Act, which mandates lifelong entitlement for services for adults with developmental disabilities, makes this state a unique case in the United States, in that California is the only state with such a mandate. Although many other states have varying levels of eligibility for services for young adults with ASDs, being eligible is not the same as being 
entitled. An individual can be eligible, but not have services available to them. In entitlement, a person is mandated by law to receive services so they must be available.

The Lanterman Act was introduced in 1969 by Lanterman. The law states, An array of services and supports should be established which is sufficiently complete to meet the needs and choices of each person with developmental disabilities, regardless of age or degree of disability, and at each stage of life, and to support their integration into the mainstream life of the community. (Lanterman Act, Section 4512 part a)

It is this statement that is chiefly responsible for the formation of the California system of regional centers.

Begun in the 1960s, the work of Lovaas at the University of California, Los Angeles is still viewed as a breakthrough and a legitimate component in the therapy and treatment of children with autism (Warren et al, 20011. Lovaas' work, specifically the use of applied-behavior-analytic therapy, was not without controversy. This initial work in the 1960s included use of electric shock and other aversive "procedures," documented in a Life Magazine article titled "Screams, Slaps and Love" (Grant, 1965). These procedures were eventually discontinued and replaced solely with rewards for behaviors that were to be encouraged, whereas behaviors that needed to be extinguished were merely ignored. Lovaas helped make the southern California area a hub of autism research and activity, despite the paucity of further outcomes data. ${ }^{6}$

San Diego was the home of Rimland and the ARI, founded in 1967. Despite Rimland's death in 2006, the ARI continues to operate in San Diego. The city also hosts

\footnotetext{
${ }^{6}$ It should be noted here that Lovaas's methods and claims of success are not without controversy or detractors. The claim that a "sizable minority achieve normal educational and intellectual functioning by seven years of age" (Lovaas Institute, 2012) has long been a source of controversy.
} 
numerous independent autism-support and resource organizations, as well as the Autism Institute at the University of San Diego.

All of the above factors made California, specifically southern California, and San Diego in particular, the ideal setting for this study. The availability of knowledgeable resource experts, many of whom either worked directly with or were influenced by the work of Rimland and Lovaas, as well as a large population of adults with ASDs were also of significant factors that shaped the conduct of this study.

\section{Case Study}

I selected a case-study format, because this problem fits the following descriptions from Stake (2000), Patton (2002) and Yin (2009) of what a case study is and when its use is appropriate. Stake said, "Case study is not a methodological choice but a choice of what is to be studied" (2000, p. 435). Yin defined a case study as "an empirical inquiry that investigates a contemporary phenomenon in depth and within its real life context, especially when the boundaries between the phenomenon and the context are not clearly evident" (2009, p. 18). Additionally, "the case study inquiry ... relies on multiple sources of evidence with data needing to converge in a triangulating fashion" (Yin, 2009, p. 18). Patton expressed that "the case study is a readable, descriptive picture of or story about a person, program, organization, and so forth making accessible to the reader all the information necessary to understand the case in all its uniqueness" (2002, p. 450).

The "case" to be considered is the current status of young adults with ASDs and how their identified needs are either being met or not being met through evaluation of autism resource, research, and service organizations. In this study of organizations that 
serve the needs of people with ASDs, I considered data arising from multiple sources of evidence, from different viewpoints, and from various levels of involvement.

The purpose of this study is to provide a snapshot of the identified needs and available services and supports for young adults with ASDs. I designed the investigation to provide an account of the current status of services and supports available to young adults with autism, to assess how well the organizations providing these services and supports are meeting their needs, and to discern the causes that underlie their actions.

\section{Methods}

As I pondered what methods would best fit my proposed study, the phrase that continued to come to mind was: "If you know one person with autism, you know one person with autism." Although I do not know who first used this phrase, it has been repeated many times by one of my committee members, among many others, and the wisdom in its simplicity steered me toward wanting to do a deep, rich qualitative study on this topic. The case-study format seemed to be the most valuable methodology and one that could possibly add something to the ongoing dialogue on the condition of and services for adults with autism.

What soon became apparent when I was designing the study was the usefulness of quantitative online surveys. Indeed, the quantitative survey was helpful to frame and guide the qualitative segment. The quantitative section adds volume to the initial data as well as confirms the purposively selected organizations. As Patton described,

Researchers are using aspects of both quantitative and qualitative methods in their studies because they need to know and use a variety of methods to be responsive to the nuances of particular empirical questions and the idiosyncrasies of specific stakeholder needs. (2002, p. 585)

This is why I selected a mixed-methods format for this study. 
I selected a mixed-methods case-study methodology for this study, combining an online survey (see Appendix A) with a series of interviews. A mixed-methods study refers to a "class of research where the researcher mixes or combines quantitative and qualitative research techniques, methods, approaches, concepts or language into a single study" (Johnson \& Onwuegbuzie, 2004, p. 17). I conducted 25 separate interviews with a representative sample from several targeted organizations and a random sample of young adults with ASDs and their parents currently being served by each organization. Later in the study, I conducted another 7 separate interviews with a purposively selected group of government officials, lobbyists, advocates, and individuals with first-hand experience of the California State DDS as well as other governmental service and support agencies.

I preselected six organizations for inclusion in the study because it is likely that a family dealing with autism has interacted with at least one of these organizations. When parents receive the initial autism diagnosis or even when they suspect their child may have autism, they will often first turn to the Internet. When typing the search word "autism," the sites for Autism Speaks, ASA, and ARI all appear on the first page of Google results. Therefore it is likely that anyone seeking assistance or support would have started their search with one of these organizations.

Two of these are high-visibility organizations due to their size, national presence, and the amount of information that is readily available about each of them: ASA and Autism Speaks. I also selected The Arc, ' due to its long national presence in the field of mental retardation and for the unique way the organization handles adult autism services.

\footnotetext{
${ }^{7}$ The Arc was originally called the National Association of Parents and Friends of Mentally Retarded Children.
} 
I selected the San Diego Regional Center (SDRC) because it is one of the 21 regional centers established in the State of California as a result of the Lanterman Act specifically to outsource and administer disability services. Anyone seeking services for an adult on the autism spectrum is likely to be familiar with the regional centers. The ARI is also a nationally known organization mainly due to its founder, Rimland, one of the pioneers who also helped found ASA. ${ }^{8}$ I selected AUTCOM and ASAN due to their focus on autism rights and self-advocacy. The emphasis on civil rights and self-advocacy naturally aligns with the current situation of adults with autism.

The results of the online survey confirmed the original hypothesis that all six organizations were worthy of inclusion. I discarded other additional organizations considered for the study when interviews with representatives revealed them to be too small and specialized in comparison to the six purposively selected organizations. The online survey also validated inclusion or exclusion from the study. I eliminated from consideration from this study any organization that was recognized by less than $10 \%$ of survey respondents. None of the original six organizations considered for this study were deleted from the list. Table 5 summarizes the organizations selected for further study.

Each interview was conducted in accordance with a standardized format I designed. Appendices $\mathrm{B}$ and $\mathrm{C}$ show the interview guides used as a framework for the interviews. Appendix B presents the guide used for interviews with representatives of autism research, resource, and service organizations. This interview guide focused on the mission statement of the organization; their guiding principles; organizational structure; and ideologies, language, beliefs, and assumptions. Appendix B also guided the

\footnotetext{
${ }^{8}$ ASA was known as the National Society for Autistic Children until the late 1970s.
} 
interview, appraising how the organization self-evaluated their success and what the organization viewed as the major needs and gaps in service for young adults with ASDs. Additionally, Appendix B helped guide the conversations regarding funding and resources for the organization.

Table 5

Summary of the Mission Focus and Summarized Mission Statements of Selected Organizations

\begin{tabular}{|c|c|c|c|}
\hline Organization & $\begin{array}{c}\text { Year } \\
\text { founded }\end{array}$ & Mission focus & Summarized mission \\
\hline Autism Speaks & 2005 & $\begin{array}{l}\text { Fund research for } \\
\text { causes and treatments }\end{array}$ & $\begin{array}{l}\text { research causes and cures and } \\
\text { raise public awareness }\end{array}$ \\
\hline $\begin{array}{l}\text { Autism Research } \\
\text { Institute }\end{array}$ & 1967 & $\begin{array}{l}\text { Research and } \\
\text { education }\end{array}$ & $\begin{array}{l}\text { research to improve methods } \\
\text { of diagnosing, treating, and } \\
\text { preventing autism }\end{array}$ \\
\hline $\begin{array}{l}\text { Autism Society of } \\
\text { America }\end{array}$ & 1965 & $\begin{array}{l}\text { Grassroots-improve } \\
\text { the lives of all } \\
\text { affected by autism }\end{array}$ & $\begin{array}{l}\text { leading voice and resource for } \\
\text { education, advocacy, research, } \\
\text { and support }\end{array}$ \\
\hline The Arc & 1953 & $\begin{array}{l}\text { Inclusion and } \\
\text { participation }\end{array}$ & $\begin{array}{l}\text { comprehensive provider of } \\
\text { services to children and adults } \\
\text { with developmental } \\
\text { disabilities }\end{array}$ \\
\hline $\begin{array}{l}\text { Autism National } \\
\text { Committee }\end{array}$ & 1990 & Social justice & $\begin{array}{l}\text { social justice for all citizens } \\
\text { with autism }\end{array}$ \\
\hline $\begin{array}{l}\text { Autism Self- } \\
\text { Advocacy Network }\end{array}$ & 2006 & $\begin{array}{l}\text { Public-policy } \\
\text { advocacy }\end{array}$ & $\begin{array}{l}\text { disability rights and self- } \\
\text { advocacy movement }\end{array}$ \\
\hline
\end{tabular}
Note. The Arc $=$ Association of Retarded Citizens.

Appendix $C$ exhibits the guide used for interviews conducted with young adults with ASDs and their parents or family members. This interview guide was slightly different, because it helped frame the interview around the perceived needs of the individual with autism. It also addressed how these needs were or were not being met, what supports exist, the ease of access to those supports, and their opinion of where, or if, 
a gap in services and supports exists. Appendix D displays the sample e-mail request I sent to potential interview candidates.

The online survey provided some basic quantitative data regarding services needed and provided, ease of accessing these services, and overall satisfaction levels with various services. I also used the survey to evaluate if other organizations should be considered for study. Due to the open-ended format of the survey, I eliminated from consideration any organization that was recognized or mentioned by less than $10 \%$ of respondents. The survey requested potential interview candidates to self-identify as being willing to be interviewed and started to suggest some areas of met and unmet needs for young adults with autism. I provide a summary of the survey results in Appendix E.

In the next phase of the study, I used a qualitative approach to determine the current situation of young adults with ASDs. This type of approach allows the researcher to gain a more holistic, deep, and rich understanding of the problem (Feagin, Orum, \& Sjoberg, 1991). Qualitative-research methods appear to be most appropriate for the type of research and questions that needed to be answered in this study. As Patton described, "Qualitative methods facilitate study of issues in depth and detail. Approaching fieldwork without being constrained by predetermined categories of analysis contributes to the depth, openness and detail of qualitative inquiry" (2000, p. 14). The intent of this study was to address the experiences and satisfaction with service providers of young adults with ASDs.

When analyzing the data, I continued to question why this situation exists. The first round of interviews suggested I needed to have more in-depth understanding of the effects of the political and legislative process on young adults with ASDs. This round of 
questioning led to an additional set of interviews conducted in the fall and winter of 2013-2014 with purposively selected representatives of the government and political process. I interviewed state employees and elected officials in the area of developmental disability, lobbyists, advocates, and political figures well versed in the issue of adult developmental-disability services.

\section{Why This Study?}

The opportunity to independently study organizations whose stated mission is to support individuals with ASDs, and then conduct interviews with group representatives to either confirm or challenge their stated goals and performance, resulted in a clearer understanding of the environment and the challenges these organizations face. The ability to couple these findings with the reported experiences of young adults with ASDs and the perspectives of their parents and family members resulted in an opportunity to compare viewpoints. Finally, the inclusion of the governmental and political perspectives allowed for triangulation of the data (Yin, 2003) to achieve a clearer, more holistic picture of the situation that exists for this population today. Additionally, the needs of young adults with ASDs and the increasing number of young adults entering this population every year underscores why this study needed to be done.

\section{Survey}

I first conducted an online survey, sent to 20 autism-specific databases and autism Listservs in Southern California. Examples of the databases considered were the LinkedIn Autism Researchers group and autism online-support groups such as Valerie's List, a popular San Diego-based electronic newsletter. I also sent requests for 
participation to several autism parent-support groups such as the San Diego and Los Angeles chapters of ASA and ARI.

I was a bit surprised by the difficulty in obtaining completed surveys. I incorrectly assumed there would be a multitude of willing participants. Many professionals I interviewed at the various autism-resource organizations described the phenomenon of "survey burn-out" that many parents and family members experience regarding ongoing requests to participate in autism-related surveys. The survey garnered 124 total responses with five being partially completed, another 16 disqualified for not meeting the desired prerequisites. Ultimately 103 completed qualified surveys were returned.

\section{Interview Site and Sample Selection}

I selected purposive samples of a minimum of 12 young adults with autism and/or their parents for interviews. I drew participants from the respondents to the survey who indicated their willingness to be interviewed on this topic. I also purposively selected several other interview candidates due to the uniqueness and depth of their experience with the topic, such as parents who were involved in numerous autism organizations and activities, or who had held significant volunteer roles in these organizations. For each organization considered, the goal was to speak with a minimum at least two individuals who had first-hand experience in the organization. This goal was far exceeded and each organization had a minimum of three interview respondents who had used their services. For four of the organizations, at least six interview respondents had used their services. Several individuals had experience with more than one organization. Although it was generally considered to be possible to identify and segment their experiences with each organization individually, the potential for confusion and "spillover" from one experience 
to another seemed likely. For example, it is entirely possible that a person being interviewed could have some confusion recalling from which specific organization they may have received certain information or services. This will be explained later in the discussion of possible limitations of the study.

The study was based in San Diego due to the convenience of access to the organizations and, as previously mentioned, a large population of adults with ASDs available to me. I formulated a schedule for interviews following University of San Diego Institutional Review Board approval in October 2011. Interviews commenced in November 2011, and were complete at the end of August, 2012. In September 2013, I filed and received approval for a request for an update to the Institutional Review Board to cover additional interviews commencing in October 2013 and concluding in December 2013. These additional interviews allowed for the inclusion of the political and legislative portion of the study.

The following three tables list the organization and position of interview participants. Table 6 lists all the interview respondents from the autism organizations. Table 7 lists all the parents, family members, and individuals with autism who I interviewed. Table 8 lists all the political and legislative representatives interviewed as part of the study. To protect confidentiality, the interview participants listed in Table 6 are identified by their organization. 
Table 6

Interview Participants From Autism Organizations

\begin{tabular}{llc}
\multicolumn{1}{c}{ Organization } & \multicolumn{1}{c}{ Position } & $\begin{array}{c}\text { Years with the } \\
\text { organization }\end{array}$ \\
\hline $\begin{array}{l}\text { San Diego Regional Center } \\
\text { The Arc of San Diego }\end{array}$ & $\begin{array}{l}\text { Manager, Special Projects } \\
\text { Executive Director }\end{array}$ & 8 \\
ASA, San Diego Chapter & President & 17 \\
Autism Research Institute & Director & $4 * *$ \\
Autism Speaks & Dir. Housing/Adult Services & 6 \\
Autism National Committee & President & 1 \\
Autism Self Advocacy Network & Founder/President & $1 * *$ \\
Autism Society of America & President/COO & 6 \\
Consulting Firm & Founder/Owner & $1 * *$ \\
TERI, Inc. & Founder/President & 15 \\
Autistry Studios & Cofounder/ Executive Director & 3 \\
\hline $\begin{array}{l}\text { Note. ASA = Autism Society of America; } \text { The Arc=Association of Retarded Citizens; ** also on parent } \\
\text { list. }\end{array}$ &
\end{tabular}


Table 7

Parent/Autistic Adults Interview Participants

\begin{tabular}{ll}
\hline \multicolumn{1}{c}{ Relationship } & \multicolumn{1}{c}{ Person with autism } \\
\hline Parent/Researcher & 28 -year-old son \\
Parent/Advocate & 21 -year-old son (Asperger's) \\
Parent/Volunteer & 20 -year-old son \\
Parent & 40 -year-old son** \\
Parent & 20 -year-old son** \\
Person with ASD & 40 years old \\
\hline \multicolumn{1}{c}{ Interview participants selected from survey respondents } \\
\hline Parent & 19 -year-old son \\
Parent & 23 -year-old son \\
Parent & 23 -year-old daughter \\
Parent & 23 -year-old son \\
Person with ASD & 24 -year-old male \\
Person with ASD & 23 -year-old male \\
Person with ASD & 25 -year-old female \\
Person with ASD & 27 -year-old male \\
Person with ASD & 29 -year-old male \\
\hline Note ASD = autism spectrum disorder;*also on organization list
\end{tabular}

Note. $\mathrm{ASD}=$ autism spectrum disorder; ${ }^{* *}$ also on organization list

The political and legislative interviews conducted included the following: 
Table 8

Political/Government Interview Participants

\begin{tabular}{lc}
\hline Organization & Years with the organization \\
\hline Area Board XIII, State of California & 7 \\
Governor's Council on Developmental Disabilities, State & 30 \\
of Minnesota ${ }^{* *}$ & \\
Autism Society Los Angeles/Advocate & 20 \\
Council on Developmental Disabilities, State of California & 14 \\
Disability Services Association, State of California & 2 \\
Employment and Community Options & 28 \\
Independent Disability Consulting Practice ** & 20 \\
\hline Note. $* *$ outside California &
\end{tabular}

I conducted most of these interviews in San Diego, California, although I also selected participants from other locations. The availability of interview respondents with expert knowledge from outside the State of California was important, as the data gathered from these interviews provided contrast to the practices and procedures used in California. The interview respondents from outside the State of California also yielded a deeper appreciation for how services are being provided and how adults with ASDs are being accepted and incorporated into the community in other areas of the country.

I conducted these conversations either by telephone or through electronic media. I identified the additional parent-interview participants through their response to the survey indicating their willingness to participate in this study. Some participants required followup interviews, due to issues raised that demanded clarification and additional information.

\footnotetext{
${ }^{9}$ Although I conducted most of these interviews with experts in the State of California, I conducted several other interviews with expert resources from outside the state.
} 
The literature review suggested organizations that should be included in the study, specifically chosen due to their size, national or local notoriety, and the high probability that a family or individual with ASDs would have knowledge of them, and most likely would have had some previous interaction or experience with the organization. These organizations characterize their primary mission to be supporting persons with ASDs. The organizations that were initially considered for study, with a brief description of their mission statement are listed below:

- Autism Speaks focuses on researching causes and cures and to raise public awareness.

- ARI's focus is research to improve methods of diagnosing, treating, and preventing autism.

- ASA claims to be the leading voice and resource for education, advocacy, and research.

- The Arc of San Diego is a comprehensive provider of services to children and adults with developmental disabilities, not specifically those with autism.

- AUTCOM focuses on social justice for all citizens with autism.

- ASAN focuses on disability rights and is a self-advocacy movement for persons with ASDs.

- The SDRC is one of 21 such centers established under the Lanterman act in the State of California for persons with developmental disabilities.

\section{Data-Collection Methods}

The initial data-collection method was through an online survey (see Appendix A). The online provider SurveyGizmo was used to create and deliver the survey. 
SurveyGizmo offers their services free of charge to any user with a valid ".edu" e-mail address. The creation of the survey was relatively simple, and the program provided adequate tools for the specific purpose of the survey. Because the survey was designed to be a precursor to the much deeper qualitative portion of the study, this provider was more than adequate to fulfill my requirements.

The survey consisted of 18 questions. Questions $1-4$ requested basic demographic data for the individual with autism, including geographic location, age, diagnosis, and education-level attained. Questions 5-9 asked for information about the most important needs for the young adult with autism and how well they have been met by service and resource organizations, specifically the six original organizations intended for study. Responders also could write in the names of other organizations in this sequence of questions. Questions 10-13 asked where the young adult with autism lived and what their employment status is, as well as their level of satisfaction with both of these situations. Question 14 was an open-ended question requesting any positive or negative statements about any particular autism service and resource organization. Questions 15-18 asked about the respondent's willingness to be interviewed and if they desired to be sent results of the survey.

Following return and tabulation of the data from the surveys, I established an initial interview list. I considered individuals who represented the organizations to be studied, as well as volunteer respondents, for interviews. I sent formal introductory e-mails to all proposed interview candidates. A sample of one of the e-mails appears in Appendix D. I recorded, transcribed, and coded all interviews and took extensive field 
notes. I used a separate interview format for organizational representatives and for parents, family members, or young adults with ASDs.

The importance of two additional organizations in the lives of young adults with ASDs emerged from the survey and parent interviews. They are TERI Campus of Life, located in Oceanside, California, and a smaller niche organization called Autistry Studios, located in northern California. They were subsequently added to the study and provided an excellent contrast to the larger, more popular organizations. Their services tended to be on a much smaller scale, more highly specialized, and each seemed to enjoy a small yet ardent following. I then conducted personal interviews following two formatted interview frameworks (see Appendices B and C) The format shown in. Appendix B was used for interviews conducted with representatives of the individual organizations. Appendix $\mathrm{C}$ was used for interviews with young adults with ASDs and their parents.

\section{Data-Analysis Methods}

I first analyzed the survey responses quantitatively using basic descriptive statistics. I coded the open-ended questions using line-by-line open-coding methods, and then grouped the coded data into themes using axial coding (Strauss \& Corbin, 1990). I analyzed the data seeking trends and patterns. Due to the low number of responses, I did not need to use a software program for data analysis. I also analyzed survey responses to confirm the decision to include the six initial organizations for inclusion in the study.

This decision was based on all six organizations receiving significant mention and comments form a large number of survey respondents. It was obvious these six organizations were leaders, at least in name recognition, to a majority of survey 
respondents. Respondents mentioned these six organizations so frequently in the survey responses that they obviously warranted inclusion in the study. A minimum of $50 \%$ of participants had to have either knowledge of or direct experience with the organizations for me to confirm their inclusion in the study. The data analysis then focused on the qualitative-analysis portion.

I first analyzed the individual interviews using line by line open coding (Strauss \& Corbin, 1990). After coding each interview in this manner, I conducted a second round of coding and analyzed codes to create themes or categories using a process called axial coding (Strauss \& Corbin, 1990). This process is also called first-cycle and second-cycle coding (Saldana, 2009, p. 45). I coded each interview immediately after conducting it. When all interviews had been coded twice, I performed a third pass through the data to validate the axial codes and to see if any additional trends had surfaced. This additional pass also ensured the uniformity of themes and categories, as well as accounting for any time-lag bias ${ }^{10}$ and a possible lack of standardization due to the length of time between the first interview in November 2011 and the final one in fall 2013.

Another crucial step entailed "themeing." As Saldana argued, "Themeing the data is appropriate for virtually all qualitative studies" $(2009$, p. 140). Ezzy stated that "unlike content analysis which begins with predefined categories, thematic analysis allows categories to emerge from the data" (2002, as cited in Saldana, 2009, p. 83). The third review of the codes revealed several new themes that emerged and brought the data more

\footnotetext{
${ }^{10}$ Time-lag bias refers to the concern that certain conditions or information may have changed in the time elapsed from the date of the first interview being conducted to the last one being conducted. An example would be the publishing of the DSM5 replacing the DSM IV and any potential effect this may have had on the data.
} 
clearly into focus. I then carried these themes forward into the findings discussed in Chapter 4.

Each organization examined in this study contributed in a meaningful way to the understanding of the overall situation that exists for young adults with ASDs and the services and supports this population needs. I analyzed their stated mission, primary functions, operations, populations served, and the results of their efforts both from the organization's perspective as well as from the viewpoint of those they serve. A set of interviews with organizational representatives and adults with ASDs and family members added important perspectives to the overall status of the services and supports offered and what services and supports this population says they need.

I then analyzed the data considering two sets of evaluations. The first set of evaluations was internally based, consisting of what the organizations said about their own performance and their self-evaluation based on interviews with their representatives. I also considered what the organizations claimed and published on their websites. This comparison used what was publicly available, as well as information derived from the interviews with organizational representatives, including their own self-evaluation of the organization's performance.

The second evaluation was externally focused, consisting of the perceptions of the population served by the organizations. The analysis consisted of external interviews and what is published by external sources regarding the performance of the organizations. I then compared the two sets of evaluations, internal and external, for similarities, differences and inconsistencies. The result was a clear picture of what needs are being 
met and not met by the identified organizations. Also, I compared the self-evaluations of the organizations to how their users evaluated their performance.

I included one final set of influences to their provision of services in the analysis of the data: external factors. These included geographic location; interrelationships with federal, state, and local agencies; demographics of the population served; public and community relations; as well as many others, all of which have an effect on an organization's ability to provide services to the adult autistic community. It is not possible to analyze the performance of these organizations without also considering the external factors that affect their ability to operate and their operational environment.

\section{Researcher's Role}

As previously explained, I am the parent of a now 23-year-old son with autism. The desire to study autism is what provided the original impetus to enter the University of San Diego doctoral program when this son was still a 14-year-old high school student. Since graduating from high school, resources available to him have significantly decreased. Adult needs that require the assistance and services of agencies and organizations have also surfaced. It is personally and professionally satisfying to be able to make a contribution to this field of study. Being so closely involved with the issues raised in this dissertation, I was continually aware of the potential for my own personal bias and how it would affect this study. Each person with autism is unique and how autism manifests in their abilities, demeanor, and personality varies considerably. I needed to continually look at each individual with autism as just that: an individual with autism. It was essential that I not compare their condition to how my son's autism is 
manifested or assume that I knew the details of their specific needs, strengths, and challenges.

My intent was to be able to take advantage of an "insider/outsider" perspective based on my experience as the parent of a young adult with ASDs as well as a researcher (Yin, 1994). This unique perspective was particularly helpful in the triangulation of information from a researcher perspective, as well as from the vantage point of someone who has actual experience with many of the organizations and first-hand knowledge of young adults with ASDs and their parents.

It is also significant that I have personally experienced the various stages through which a parent progresses in dealing with a child with autism, starting with the desire to find causes and cures, and over time, to the need for transition services for independent living and adult supports. It was critical to be able to bracket some of my stronger feelings and observe as a neutral and unbiased researcher, while still drawing on the empathy and understanding from a parent's perspective. I relied on the use of a second reader and the advice of committee members to assist in keeping potential bias from being introduced into the study.

\section{Limitations}

This study was limited in several ways. First it only focuses on autism organizations and problems in the United States. It was limited further geographically to California, because it is the only U.S. state with entitlement for adult services. At this point it is again critical to emphasize why this word entitlement is critical and unique to California. Entitlement means that a service is mandated by law. In California, services for adults with developmental disabilities are an entitlement. The term eligibility only 
refers to whether a person is considered to have met the requirements to receive services. Those services may or may not be available, and being eligible does not guarantee that services will be provided. In California the term entitlement means those services are mandated by law and must be provided by the state.

I collected survey responses from outside California; they served as a valuable contrast to the in-state experience. Several interviews also contained the perspectives of those residing outside California. This comparison of the California data set to the data derived from the rest of the country was useful, especially as it pertains to the terms entitlement and eligibility. The study was limited in scope and size by the number of organizations to be studied, as well as the amount of time and number of individual participants who were interviewed from each organization.

As most of the research was conducted in southern California and primarily included interviews with people residing in this region, it may be biased by the existing conditions of this area with respect to employment, independent living, availability of resources, access to individual organizations, and many other factors such as economic conditions. Particularly crucial to this bias is, again, the term entitlement. In California the population to be served is not only eligible to receive these services, but are entitled to receive them under the law.

The conditions that exist in this region are not reflective of policies, procedures, and experiences in other states. Although I conducted some interviews with participants residing outside southern California, the study was essentially influenced more heavily by existing California policies, and more specifically southern California policy, procedures, and practices. 
The review of the literature helped mitigate some of this particular limitation. To alleviate this limitation, the study would have had to include interviews conducted in many more states, and a full analysis of each state and regional policy, as well as data. Instead I decided to narrow the focus of the study to a manageable sample and focus solely on California and a more potentially data-rich site, given the concentration of young adults with ASDs and the unique provisions of the Lanterman Act. The policies that apply to California agencies were sufficiently stringent without having to consider multiple states' individual procedures, which would have greatly expanded the study while possibly limiting its effectiveness. To meet all of those conditions would have gone beyond the limits of what was practical in this study. As previously discussed, researcher bias is also a limitation I considered. All these limitations were evaluated when formulating the recommendations for potential further study discussed in Chapter 5 .

Due to the sampling criteria and the above-stated limitations, the results of this study have "limited generalizability" to the adult population with ASDs (Patton, 1980). The hope, however, is that this research is helpful in providing some analytical insights that can motivate additional investigations into organizations that promise to provide support for young adults with ASDs in other states.

Patton (2002) described this same concept, which he called "extrapolation":

Extrapolations are modest speculations on the likely applicability of findings to other situations under similar, but not identical, conditions. Extrapolations are logical, thoughtful, case derived, and problem oriented rather than statistical and probabilistic. Extrapolations can be particularly useful when based on information-rich samples and designs, that is, studies that produce relevant information carefully targeted to specific concerns about both the present and the future. $(2002$, p. 584)

My expectation is that the insights present in this study will lead to future advancement in the field of autism and autism research. 


\section{Significance of the Study}

First published in January 2011 and updated in December 2012, the IACC Strategic Plan points out specific gaps in knowledge with respect to adult services, supports, and community inclusion. It stated, "the needs of adults with ASD continue to be understudied. Over the last two years, relatively few peer-reviewed published studies have examined the needs of adults with ASD or service interventions to improve their functioning and quality of life" (IACC, 2012, p. 45). This study attempted to address a portion of that knowledge gap by looking at organizations that provide services to this underserved population of young adults with autism. Although many organizations claim to assist the autistic population, how well do they actually achieve their goal in the views of those they serve? What are the actual experiences of the autistic community in accessing and using these services and supports? This study helped identify what needs, defined by the autistic community, are currently not being met by any of the existing organizations in the study, and why they are not being addressed. 


\section{CHAPTER FOUR \\ FINDINGS}

\section{Overview}

The purpose of this study was to investigate the current situation of young adults with ASDs. I wanted to find out how major autism service and resource organizations defined and fulfilled their roles, how the young-adult population defined their needs, and how these organizations had either met or not met expectations. This chapter will report the findings from the online survey and then follow with an examination of the interviews conducted with over two dozen participants. Three distinct groups were interviewed as part of my research; they were young adults with ASDs and their parents, senior representatives and leaders of autism service and resource organizations, and a panel of subject-matter experts and professionals in the field of developmental disabilities.

I begin by addressing the role of service organizations and the perspectives of those who rely on them. Then, I report the findings to Research Questions 2 and 3 by providing feedback from young adults with ASDs and their families regarding their interactions with these organizations. Finally, I address Research Question 4, which asks what implications can be drawn that will inform these organizations with respect to their policies and procedures.

\section{Major Organizations that Address ASDs}

I designed the first research question and subquestions to help in understanding the major organizations that conduct research and provide services and support to persons with ASDs, particularly in relationship to young adults. Research Question 1 asked, How 
do organizational models designed to support young adults with autism understand ASDs and how do they define their specific role in providing support to this population?

To address these issues, I studied seven organizations, using a mixed-methods model. I primarily relied on sources of data that included organizational publications, news items, professional journals and their respective websites, and the survey results of adults with ASDs and their family members who have used these organizations for support. I supplemented them with other sources, such as interviews with young adults with ASDs, interviews with representatives from all seven organizations, as well as interviews with selected experts in the field.

I begin with a brief description of each organization, their abbreviated mission statements, and how they see their roles in supporting the adult population with ASDs. Next, I describe how they attempt to carry out their mission, including policies, procedures, and actions. Finally, I describe the factors that support or challenge their efforts.

\section{Descriptions of Organizations}

The organizations included were ASA, Autism Speaks, AUTCOM, ASAN, ARI, The Arc of San Diego, and SDRC. These organizations define their roles in their mission statements. These organizations can be grouped into three major categories. The first category is related to national-level awareness, research, and dissemination of information. Three of these organizations-ASA, Autism Speaks and ARI-are devoted to research, dissemination of information, raising public awareness, and furthering the rights and benefits of those with ASDs. Two of them-ASA and Autism Speaks-are large national organizations that enjoy name recognition and significant resources, 
funding and donations. ARI, despite having a similar mission, does so on a much smaller and localized scale.

The next major category includes the two organizations that focus specifically on issues of civil rights and self- advocacy. ASAN and AUTCOM focus very specifically on the rights of persons with ASDs and have a politically focused agenda. ASAN focuses more on the self-advocacy theme as highlighted in their motto: "Nothing about us, without us." AUTCOM, despite also championing self-advocacy, has a politically based mindset and focuses on issues of defending and raising awareness of the civil rights of persons with ASDs.

The last two fall into the category of providing or enabling direct resources and services. The Arc is a provider of services and resources to persons with developmental disabilities, of which autism is becoming a larger focus. The SDRC, although not a provider of direct services, sources and funds direct services for their clients. Neither of these organizations are solely focused on serving the needs of the autism community, but rather all persons with developmental disabilities. Senior representatives of both organizations stated that autism has become a major area of focus, and in the case of the SDRC, persons with ASDs represent the majority of their new constituents. Table 9 summarizes these organizations' purposes, taken verbatim from their published mission statements. 
Table 9

Organization Mission Statements

\begin{tabular}{|c|c|}
\hline Organization & Mission statement \\
\hline ASA & Improving the lives of all affected by autism. \\
\hline Autism Speaks & $\begin{array}{l}\text { Dedicated to funding research into the causes, prevention, treatments, } \\
\text { and a cure for autism; increasing awareness of autism spectrum } \\
\text { disorders; and advocating for the needs of individuals with autism and } \\
\text { their families. }\end{array}$ \\
\hline AUTCOM & Dedicated to social justice for all citizens with autism. \\
\hline ASAN & $\begin{array}{l}\text { Advance the principles of the disability rights movement with regard } \\
\text { to autism. }\end{array}$ \\
\hline ARI & $\begin{array}{l}\text { Along with their research and funding of research studies, ARI began } \\
\text { an initiative in } 2002 \text { to focus on issues related to adults on the autism } \\
\text { spectrum and their families. }\end{array}$ \\
\hline The Arc & $\begin{array}{l}\text { Supports and empowers persons with disabilities to achieve their life } \\
\text { goals. The Arc is a service provider, not specific to autism. They serve } \\
\text { those with a wide variety of developmental disabilities. }\end{array}$ \\
\hline SDRC & $\begin{array}{l}\text { To serve and empower persons with developmental disabilities and } \\
\text { their families to achieve their goals with community partners. SDRC is } \\
\text { one of } 21 \text { regional centers for persons with developmental disabilities } \\
\text { in the State of California. They provide case management, help find } \\
\text { resources and service providers, and ultimately provide funding for } \\
\text { contracted services. }\end{array}$ \\
\hline
\end{tabular}

Note. ASA = Autism Society of America; AUTCOM = Autism National Committee; ASAN = Autism SelfAdvocacy Network; ARI = ; The Arc = Association of Retarded Citizens; $S D R C=$ San Diego Regional Center.

\section{Organizational Mission Statements and Perception of Roles}

I now examine these organizations and how they self-define their mission, as well as how they perceive their roles. Specifically, I offer evidence as to how and why the needs of young adults with ASDs are not being addressed. I also explore the fact that one organization (The Arc) focuses on the people with disabilities community in general, and not specifically young adults with ASDs and that the two organizations with a single 
political focus (ASAN and AUTCOM) seem to demonstrate a greater clarity in their approach.

Needs of adults not addressed. Perhaps the most striking finding was that the needs of adults with ASDs are not explicitly addressed by the organizations studied. As can be seen from the excerpted mission statements, they do not mention services specifically for adults with ASDs. In many cases where adults are mentioned, it appears to have been an afterthought and certainly not the primary focus population for the organizations. Several statements indicated that their services are for all ages, most notably ASA, which states that their services are for "all affected by autism" (2011, para 1) and AUTCOM, which states that their services are for "all citizens with autism" (2011, para 1).

Clearly, the needs of adults with ASDs have not been a priority for many of these organizations. This can be seen in the comparative amount of resources dedicated to adult issues in these organizations. Autism Speaks (2011) proclaimed it is the leading autism research and service organization in the world, yet only hired their first dedicated employee to handle adult issues a few years ago. This employee told me, "I've been around a long time but Autism Speaks has never had a specific position on adult services until July of this year". Autism Speaks still only has two full-time employees devoted to adult issues. To put this in perspective, their 2012 financial report lists over $\$ 18$ million paid in salaries for the year.

In the Autism Speaks (2012) Annual Report, the president's letter states, "There is still a misconception that autism affects only children. In fact, over 500,000 young adults with autism will age out of school-based services over the next decade and there is no 
national strategy to address their needs." Despite this calling out of the issue, there is only one paragraph that addresses adult issues in the rest of the 29 page report.

The fact that these organizations did not address, or at least did not initially include adults as part of their focus was surprising. A number of possible explanations exist, all of which are critical in understanding the issues that adults with ASDs face.

Possible explanations. One possible explanation is that these organizations were founded by parents of children with autism who were on the leading edge of trying to get help for their own children, and thus set the trajectory for the organizations. Another reason may be related to funding. A senior representative of the SDRC elaborated on this concept:

For instance, there is money for early childhood autism services. Plenty. I'm not sure what kind of return we always get on the investment. But there is an amazing amount of money in that ... from eighteen months of age to six years old, we pour ninety eight percent of our resources into that. Now, you know, who could argue with prevention and trying to get [these children] on track? You can't argue with that. But on the other hand, if that leaves nothing to (my 23-year-old son with ASD) and all of his cohorts, all of the twenty year olds, well that might be misguided. So there has to be some re-figuring out of our policies. ... but there is a limited amount of money and the state is only, every single six months now, is chopping off a little more.

Perhaps the most obvious reason for the lack of focus on adults by these organizations is the seemingly sudden expansion of the population of adults with ASDs.

The senior official with The Arc of San Diego commented on this relatively new phenomenon:

So, we've recognized that autism is a condition that is (moving to) the forefront because of the diagnosis capability. And that it may have been ongoing at a hectic level for the last twenty years, but we are just now seeing those individuals that have had that diagnosis come into where they would be within our possible sight for services. I don't know of a community organization that is focused on adults. I 
don't know of any one organization that says, "We are specialists in this field for adults."11

The first dedicated adult-services employee at Autism Speaks lamented the lack of training for workers, as well as the lack of adult programs noting, "That piece, that most of the service system was built for people with intellectual disabilities or physical disabilities. They just haven't caught up to the needs of people with autism." The employee went on to stress that it was difficult to even know where to send families: "If there's not a place for me to direct a family to in a local community that's very challenging and difficult because you know that family is going to be sort of left with minimal direction."

Certainly the initial focus on children's issues and services left the adult community behind in addressing their particular ongoing needs. Despite the lack of a long and loud outcry to date to illuminate this growing problem, this may be changing. The San Diego ASA representative offered this comment:

There are lots of agencies now, lots of information about early intervention out there, so people don't feel quite as lost. They are lost when their kids are getting to be this age. So, I certainly see us moving in a direction of trying to grow some way of supporting adults.

Focus on developmental disabilities. The data also revealed that although all of the organizations have a focus on autism, two of them-The Arc and SDRC - are also concerned with other developmental disabilities. Although these two state that their focus is on all developmental disabilities, autism has increasingly become one of their most important, if not their most important focus, and certainly represents the majority of their

\footnotetext{
${ }^{11}$ This is not exactly true, as it should be noted that there are several national and community organizations that specialize in adults with ASD issues such as the National Association of Residential Providers for Adults with Autism, among others.
} 
new customers. A significant issue is in how they choose to address this growing trend and area of need through their organizations, while keeping to the principles in their mission statements. Because their initial focus was on all other developmental disabilities, the tools and resources for autism have been relatively late in developing. Evidence of this finding can be found in their respective mission statements. For example The Arc states they are a provider of services to persons with disabilities. They do not mention autism specifically; rather, they cast a wide net over those to whom they provide support and how they provide those services. The senior Arc representative I interviewed stated,

Our strategic plan says to learn more about autism, and different ways that we can do that. So, we've recognized that autism is a condition that is becoming in the forefront because of the diagnosis capability. And at this point we don't know enough about what service, and there isn't money-you know we just don't have money floating around to do it-so it would have to be something where we could establish that it is worth the resource development, no one else is doing it, and it is out there. Our position also in this strategic plan is, not to create a program that duplicates somebody else's process.

The SDRC online information and mission statement indicate the SDRC is one of 21 regional centers for persons with developmental disabilities in the State of California. They provide case management, help to find resources and service providers, and ultimately provide funding for the services. Their specific mission indicates that they seek to assist those with developmental disabilities to "lead productive and satisfying lives." A senior representative at the SDRC explained how this issue of providing for adults is a challenge to his organization: "We have nothing specifically related to autism. Just like there is nothing specifically related to the other qualifying conditions."

For both these organizations, autism appears to be a relatively new focus, specifically as it applies to adults. The Arc has never had a channel for addressing adults 
with ASDs, whereas the SDRC has had children with autism as clients for over 40 years, but is only now starting to feel the impact of these children maturing into adults with continued challenges and needs.

Single-focused organizations more effective. The next critical finding is that the two organizations that have a single focus appear to more effectively channel their efforts, resulting in the ability to successfully fulfill their mission. AUTCOM and ASAN are solely focused on civil rights issues, and specifically on representing the civil rights of young adults with ASDs. Whereas other organizations are spread thin in trying to address multiple goals and often for multiple constituencies, AUTCOM and ASAN seem to have greater clarity in their mission and objectives, and as a result, are more effective in accomplishing them.

AUTCOM self-identifies as the only autism-advocacy organization dedicated to "'Social Justice for All Citizens with Autism' through a shared vision and a commitment to positive approaches." They approach autism not as an illness or condition that a person "has," but as a series of variables manifested in a myriad of ways. Thus, they seek to provide options that allow persons with ASDs to lead inclusive lives while being respected and not judged for their disability. They believe

it is important to view the behavior of people with autism/PDD as meaningful adaptations and to take a positive, respectful approach to them, forgoing the common tendency to judge their competence and capacity on the basis of their sensorimotor challenges. (Autcom.org, 2011, para 7)

ASAN takes a very political approach in pursuing its mission of "seeking to advance the principles of the disability rights movement with regard to autism" (ASAN, 2012, para 1). According to their website, they employ a wide variety of activities that

\footnotetext{
${ }^{12}$ AUTCOM has adults with ASDs that serve on their Board of Directors.
} 
"include public policy advocacy, the development of Autistic cultural activities and leadership trainings for Autistic self-advocates" (2012, para 3) This is also the only organization that was founded by, led by, and staffed by persons with ASDs. They, along with AUTCOM, share a singleness of purpose in focusing on the rights of persons with ASDs and their ability to be empowered to control more of their own destiny and have a larger voice in their rights as citizens.

One of the questions in the online survey asked participants for their overall satisfaction with all the organizations they had ever used. Two organizations, ASAN and AUTCOM, were rated higher than larger multipurpose organizations. Respondents submitted no negative comments on the survey about either ASAN or AUTCOM. I believe this may be because these two organizations are solely focused on issues of civil rights. They mainly accomplish their mission by promoting awareness through education programs, e-mail campaigns, and publications, and by organizing campaigns to spur political action. These can be achieved by encouraging letter writing to elected officials and organizing rallies, conferences, and meetings designed to raise awareness and spur political action.

\section{Organizational Policies, Procedures, and Actions}

Beyond all the organizations' perceptions of their roles, I wanted to understand what policies, procedures, and actions these organizations use to carry out their mission statements. The data suggested two things. First, these organizations use a variety of ways to address their target audience. They all have a strong web presence through their online websites and they use events and publications to gain awareness and notoriety. Most have active e-mail campaigns or at least a recurring e-mail list to keep their 
organization's actions in the public eye and to keep their customers aware of their actions. The organizations ASAN and AUTCOM, although having a smaller presence, nonetheless play an important role. They are self-advocates who have a decidedly politically focused agenda, trying to play an accountability role for government agencies and larger national organizations. All the other organizations also include lobbying and a political agenda in their list of actions and events.

Generally, communication and publicity efforts are proportional to the size and national presence, popularity, or notoriety of the organizations. For example, an organization such as Autism Speaks spent over \$2.2 million in advertising in 2012 and over $\$ 600,000$ on other marketing efforts. By contrast, the entire budget for the ASA in 2011 was $\$ 3.4$ million, which included all their programs, administration, and fundraising efforts (2011a).

\section{Influence of the Regional Center}

Beyond the ways these organizations make their presence known, the data also showed that the SDRC is the state-appointed authority to administer case management and the budgeting and payment authority for funding of services. The SDRC is identified early in the school system (for children over the age of 3 ) and has a steady flow of consumer cases to manage. They are a particularly powerful entity because of their charter from the state and their ability to commit funds to pay for services. The SDRC website clarifies their position and charter from the State of California on their website:

The San Diego Regional Center is one of 21 Regional Centers for persons with developmental disabilities in the State of California. These centers were originally established to assist persons with intellectual disabilities and their families in locating and developing services and programs within their communities. These original centers were established in 1965 under legislation sponsored by Assemblyman Frank Lanterman. (2011, para. 1) 
As discussed previously, The Lanterman Act is unique to California. It became effective in 1969 and its provisions mandate lifelong entitlement to services for those with developmental disabilities. Their charter soon expanded to serving many types of developmental disabilities including intellectual disabilities and, ultimately, autism and ASDs.

A senior representative of the SDRC outlined the legitimacy of the SDRC and their source of authority, as well as their procedures regarding funding of services, noting that "In California, once someone becomes eligible, they are eligible for life." The representative elaborated that this is one of the values of the regional center; that its mission focuses on the specific needs that arise during each chapter of a person's life. These needs include transition periods, and they continue for senior citizens all the way through issues of death and mortality. This participant described the regional center as the "funder of last resort" in that the regional centers try to exhaust all other avenues for funding before relying on services funded through the regional center. Other sources include funding from insurance and Medi-Cal to other organizations, nonprofit organizations, and various private and public funding sources, all of which are explored before the regional center purchases and provides the service. The regional center clearly plays a critical role in meeting the needs of adults with ASDs.

\section{Organizational Supports and Challenges}

The final area of concern I explored regarding organizations that support adults with ASDs addressed the supports and challenges they experience in attempting to carry out their missions. Three specific findings related to the question of support and one 
important finding and two contributing conditions regarding the challenges to their work, which I articulate below.

Support-Value of the Lanterman Act. The first finding that supports organizations' work is that the Lanterman Act is critical. The Lanterman Act, which is the most significant legislation with regard to adults with ASDs in California, mandates lifelong entitlement. Entitlement is far different from eligibility. It has a huge effect on conditions and expectations for this population. One may be eligible to receive services, but if they are not available or offered then eligibility does very little. Entitlement denotes the responsibility of the state to provide the needed services. This act simply puts the burden on the state to provide the needed services and supports for adults.

The implications of the entitlement issue are that the autism service and resource organizations are a necessary part of the state's ability to fulfill its responsibilities with respect to the entitlement to services for adults with ASDs. Without these organizations, particularly the regional-center system, it is doubtful the state could even attempt to meet its obligation to adults with ASDs.

Donor support. The second factor that supports these organizations' efforts can be answered simply and with one word: donors. These organizations enjoy exceptional support from donations and fundraising efforts. Autism Speaks, in particular, relies heavily on the generosity of donors. According to their latest annual report (2012) they raised $\$ 58.8$ million in that year. By contrast, ASA lists total income and contributions for 2012 as just under $\$ 3$ million (2013, p. 2). The largest organization clearly enjoys considerable support from donors and other contributors, however each organization, 
with the exception of the state-funded regional centers, relies on outside support, specifically donations, to accomplish their missions.

Support-Growing population of adults with ASDs. A third support is the growing population of adults with ASDs. The CDC (2012) indicated that approximately one in 88 American children are on the autism spectrum. Currently, they estimate that one in 54 boys and one in 252 girls are diagnosed with autism in the United States. This represents a tenfold increase in autism diagnoses over the past 40 years. The Autism Society estimates that this is a 10-17\% annual growth rate of diagnoses (ASA, 2011b).

This increase in the number of identified persons with ASDs is due to many factors including better diagnostic criteria, lessening of the stigma associated with a diagnosis of autism, and necessity for a clinical diagnosis to access funding for services. The adult population with autism is growing exponentially. As this population becomes larger and more pronounced, and as their needs are chronicled and publicized, the social pressure to support these organizations becomes more pronounced. It is clear that the government healthcare system is not going to be able to address this problem by itself; therefore, a continuing and ever-increasing need exists for these organizations to fill the gaps in services the government cannot provide.

Accompanying this growing population of young adults is the significance of parental influence. Parents become more desperate for services as their children approach adulthood and are still dependent on them, producing a feeling that any services are better than being "shut out." This growing population and the fears of their primary caregivers, (usually their parents) creates a vast need for these organizations to survive, expand, and thrive. 
Several areas were identified as challenging the work of these organizations. These include the growing adult population diagnosed with ASDs, the lack of focus on adult issues by many of these organizations, financial stresses, competition with the other organizations for donations and funding, and the lack of a mandate to actually do the work or provide services.

Challenge-Growing size of adult population. Although the growing size of the adult population provides support for the organizations, it is also a significant challenge. The same numbers that create the need and support for these organizations also challenge them in the enormity of the problem they are facing. This is becoming increasingly alarming to service providers. As a senior official with The Arc told me:

I think the Regional Center is afraid, they are scared to death of autism because it is growing, the diagnosis is growing, and as a result, it could put such a financial burden on the system that there will be a negative impact. So the state has to be prepared to bring in more resources.

Challenge-Interagency relationships. Another challenge is that the organizations that state their mission as aiding those with autism and their families also have challenges in interacting with each other. A senior state government official described this phenomenon: "Infighting between organizations is hurting them. They can't agree and it is a much more complicated disability. Expectations in the autism community are much higher and the systems are not in place to support this."

Challenge - No direct assistance. One final challenge to these organizations is their mission statements, bylaws, and charters. Although they all profess to be interested in helping those affected by autism, the majority of these organizations actually do not 
render direct assistance, except in some limited, specific circumstances. ${ }^{13}$ The verbiage in these documents is very general regarding the purpose of the organizations. The ASA, for example, lists actions such as "promote and advocate for the general welfare," "promote family and community support," and "further advancement in study, research, education and training" (2011d, para 1). Nowhere in the document does it state as a mission to offer or provide direct support. Nearly every organization uses similar wording to describe their mission or purpose. Even the regional centers, funded by the state, do not actually directly provide services or support to persons with ASDs. They are a funding source and recommend vendors who they, in turn, pay to provide the direct services.

The above discussion focused on the organizations and the organizational perspective of their mission, supports, and challenges. The next two research questions sought to understand these organizations from their clients' perspectives.

\section{Definition of Needs and Evaluation of Organizations that Address Autism Spectrum}

\section{Disorders}

A critical part of this study was to try and understand what adults with ASDs and their family members define as their needs in supports and services, as well as how they evaluate the performance of organizations that are attempting to meet those needs. Research Questions 2 and 3 follow:

2. How do young adults with ASDs who have used one or more of these organization's services define their needs?

\footnotetext{
${ }^{13}$ The Arc does offer some direct service programs for adults, mostly in the form of workshops at their sites. Additionally, the local chapters of the ASA offer some direct services mostly in the form of resource fairs, monthly community support meetings, and family programs such as the San Diego ASA's Family "Swim Nights" and "Movie Nights."
} 
3. How do the parents and family members of young adults with ASDs define the needs of their family member with autism?

Sources of data for these questions were the online survey, which was supplemented by interviews with young adults with ASDs, as well as their family members. Because the online survey did not specifically identify whether the participant was a young adult with ASD or a family member, I have combined Research Questions 2 and 3, which considers both perspectives (The survey questions were worded "How do you or your family member with ASDs ..."). From analysis of the open-ended comments and e-mail addresses provided by participants, the majority of surveys were completed by parents or family members. To assess any possible differences between the two viewpoints, I conducted in-depth interviews with six young adults with ASDs and nine parents and family members. When citing these, I will differentiate between the two groups, although the differences between the two are negligible. Additionally when quoting from the interviews, I will specify whether it is from young adults with ASDs or parents.

To set the context, I will begin with a brief description of the three main areas of need that emerged for the adult population with ASDs. Next I will describe the level of satisfaction with service providers and resource organizations, reported by young adults with ASDs and by their parents or family members. I will then describe the three areas of need in greater detail, including data from the interviews. Finally, I will describe some other challenges that emerged as significant for young adults with ASDs.

Overview of areas of need. The results of the online survey identified three main areas of need that emerged as being highly important and are perceived to be 
inadequately addressed by organizations. These three areas were identified by young adults, as well as by their parents and family members. These three areas of need are employment or daytime activity, living arrangements including assisted or supported living, and social and recreational opportunities.

The survey question asked participants to select from a list and identify the services they thought were most needed for young adults with autism. Multiple responses were allowed and the 103 participants provided 440 total responses, identifying areas of need. In order of most common, responses were the following: vocational skills development training (84\%), living skills assistance/training (81\%), job placement assistance (80\%), and assisted/supported living placement (77\%).

In addition to those who identified living skills as an area of need, under the "other" category, 24 participants mentioned socialization skills and social training as most needed services for the adult with ASDs population. The combination of these two responses was the justification for including social and recreational activities as one of the three main areas of need. The interviews with both groups confirmed this category for inclusion as well.

The most significant finding from this question was that vocational skills/job placement and living skills/supported living assistance were all in the range of 75 to $88 \%$, far eclipsing college assistance or any other identified need. These data suggest that two of the areas identified in the literature review as lacking in research-adult outcomes in employment and semi-independent or independent living arrangements-are also identified as the two most needed services. Appendix E lists the complete response data for these survey questions. 
Dissatisfaction with available services and supports. A majority of the participants are unhappy with the employment situation, postsecondary education experience, and vocational-training services. A large percentage of the sample population is unemployed or receives no employment assistance. In the overall survey results, none of the 103 participants stated they were "very satisfied" and only $14 \%$ said they were "satisfied"; $32 \%$ responded "neutral" and 54\% were either "dissatisfied" or "very dissatisfied."

The survey included a question that asked what (if any) needs for the young adult with ASD have not been met or offered by any source/organization they contacted. This was an open-ended question with a place for write-in comments. All 103 participants answered this question listing 224 individual areas of need that had not been met or offered. This equated to an average of 2.2 unmet needs per participant. Of the 224 total responses, the following were the most often mentioned as not being met or available: job and employment assistance, social-skills training, assistance with health issues, and assistance with living arrangements or supported living.

A common frustration expressed in survey responses and confirmed in all interviews centered on the regional center and was described by a parent: "Regional Center is great, but they are stretched too thin. There is a very confusing maze of services available."

In response to the open-ended question, which asked what supports have not been met or offered, the following is a sampling of the responses. All of these comments were specifically traced to parents or family members: 
- San Diego Regional seems to not to want to be bothered to give support or tell what supports will help or even supports available to help a person.

- Our county offices of Mental Health/Mental Retardation Case Management are so overloaded that getting help with finding out what services/supports are available are hard to obtain.

- Our Regional Centers are overwhelmed by autism and are trying to put together "cookie cutter." If there's one thing any parent with a child with autism can agree upon is that they are all different.

- Autism Speaks does just that--they speak and little else.

The interviews conducted with parents and with young adults with ASDs confirmed the survey results. I conducted interviews in an open-ended manner with no intention of asking "leading questions" or suggesting any preconceived notions of whether any organizations were or were not meeting expectations. Most interviews started with a simple question asking if they had used any organization's services and, if yes, to tell me about their experience. These conversations uniformly started with a quick reflection of gratitude that any assistance was available, but all quickly turned to unsolicited complaints, frustration, and anecdotal information of the inability of any organization to meet the needs of young adult with ASDs.

Expanding on areas of need. In response to the open-ended question, What are the most pressing need(s) right now for young adults?, the parent of an adult son with Asperger's Syndrome commented,

For our son there are two primary needs - first, a living environment away from home where he can develop in his relationship and life skills. The second is to have a job where the employer will understand our son's Asperger's condition and work to support him as he develops his work skills. 
Another parent exclaimed; "Everything! Day programs, living situations, behavioral support, jobs!, community activities. There is very little for the very involved adults with autism." Other responses included providing viable day programs, help with planning for the future, and legal advice or estate planning. As one parent put it, "So much to do, so little time and unsure of what will best meet his needs." A final comment from the parent of a 25-year-old son was, "the needs range from acceptance in the real world to day to day survival." As noted previously, these needs can be consolidated into three categories, described in greater detail below.

Transition to adulthood. The survey uncovered and the interviews confirmed a perceived need for a better transition/preparation process from the school system to adulthood. As stated above, over half of the participants rated their overall experience with services and supports as either dissatisfied or very dissatisfied. Additionally, $77 \%$ of participants responded that their family member with ASDs still resided at home, 53\% were unemployed, and 56\% reported an unsatisfactory posthigh school educational or vocational experience. (See Appendix E for detailed employment and living-situation statistics.) While not specifically addressing transition services, it could reasonably be inferred from the data that transition services, if available, were either not being used or were not effective, resulting in a less-than-satisfactory postsecondary education experience. A parent offered this observation:

Transition services in high school for individuals with ASD are a name with no substance. Once graduated or aged out of high school the only living skills/job prep skills program, either I or our case worker know of, are directed toward individuals with ID and not appropriate for high functioning autism or Aspergers.

In response to the open-ended question querying What are the most pressing need(s) right now for young adults?, several participants directly mentioned transition 
services including the following comments: "Transition services into postsecondary education and appropriate testing accommodations categories by testing agencies":

Real effective transition services including: One-Social skills for both personal and work relationships, Two-Identification of areas of strength, ThreeAssociation of areas of strength with real world jobs, Four-Earlier identification of possible tracks for achievement of jobs within areas of strength and interest.

One parent stated that the schools needed

Individualized transition services-not the lacking ${ }^{14}$ (existing) transition services that the school districts offer that cater to many different individuals with many other disorders. Autism needs individualized resources and programs.

Follow-up interviews specifically addressing the area of transition services provided in the high schools yielded uniformly negative responses. All six of the young adults and nine parents interviewed described their transition experience as less than satisfactory. Several parents pointed out that the transition services were in name only and lacked any effective substance. They perceived that their respective school systems seemed focused on just getting these students out of their system and to be relieved of having to continue to attempt to provide meaningful transition assistance to them.

The young adults with ASDs who were interviewed, although echoing these sentiments, also generally felt that transition services were in name only. Their consensus was that school administrators or counselors were "putting a check in a box" to say that transition assistance and counseling had taken place. The process was tedious and administrative, and not geared to any tangible transition, leading to a needed service or skill.

\footnotetext{
${ }^{14}$ The word "lacking" here referred to this parents' characterization of transition services as lacking in substance, and specifically not tailored to the needs of young adults with ASDs.
} 
Employment. A majority of the survey participants were dissatisfied with their employment situation, postsecondary education experience, and vocational-training services. A large percentage of the sample population is unemployed or has no employment assistance. The survey confirmed this as a specific area of need and concern: $53 \%$ reported being unemployed, whereas the national average for this age group is $29 \%$ (Pew Research, 2014); 17\% reported having part-time employment with supports, whereas $12 \%$ reported part-time employment without supports. Only $2 \%$ reported having full-time employment and $21 \%$ reported not needing employment at this time. (The majority of respondents who indicated they did not need employment at this time were confirmed to be still be involved in full-time education.) A table showing these results is provided in Appendix E.

When asked about the satisfaction and appropriateness of their or their family member's employment situation, only $17 \%$ stated it was appropriate and satisfactory. Over half labeled it as unsatisfactory. In the open-ended section for this question, participants commented, for example, "Finding and retaining gainful employment. He's fully capable and willing to work, but his poor social skills and past employer's unwillingness to mentor him along have resulted in multiple firings which have resulted in greater decrease in his self-confidence," or "My son has a college degree-BS in Environmental Science earned in four years with no special help and with honors. No one will help him find a job. He can't even get a job cleaning toilets." These statements are representative of dozens of similar comments provided regarding the employment situation of young adults with ASDs. Interviews with parents and young adults underscored similar concerns. 
For postsecondary education or vocational training, $56 \%$ of participants deemed it unsatisfactory. Only $9 \%$ deemed it both appropriate and satisfactory. One participant wrote, "Job training or placement is not available from the government. They only pretend to offer it." Fourteen participants specifically mentioned job training or vocational-skills training as either an unmet need or something not offered by any source they had contacted. Over half the participants said a job was the most pressing need for young adults with ASDs right now. This was by far the most popular response by nearly double the amount of the next highest (socialization mentioned by 28 participants).

Living situation. The survey and interviews revealed that three quarters of the sample population is living at home with their parents. Only $7 \%$ responded they reside independently. None of the participants reported they or their family resided in a state or private institution. By comparison, the national average for the age demographic 18-31 still living at home with parents is 36\% (Pew Research, 2014), which represents the highest total in over 4 decades.

A case worker involved in attempting to access an appropriate living situation for young adults with ASDs commented, "The struggle he and his family is having is he wants to move out and he understands he needs assisted living, but finding a vacant spot that will accept him seems impossible." Another regional-center case worker listed the following as specific areas of need for young adults desirous of independent living: "Appropriate high quality residential options with well-trained support staff, secondary educational opportunities, social recreational activities and classes, such as drama, dance and art and vocational opportunities." 
Social/recreational. The final area of need can be categorized as social and recreational. Young adults with ASDs routinely suffer from feelings of isolation and not fitting in with their peers. Much of this is a byproduct of years of one-on-one therapy and "tailored" specialized services. In many schools the additional resources provided to children with ASDs include "pull out" time for speech and behavioral and occupational therapy. Despite providing necessary services, these pull-out sessions serve to further isolate the young student with ASDs from their peers. Additionally the behavioral challenges and often honest and blunt statements made by children with ASDs do not assist them in forming friendships or alliances with their peers.

The early roots of isolation are exacerbated in transition to adulthood, when the person with ASDs starts to desire relationships, friendship, and interactions they observe being enjoyed by their neurotypical peers. Although harder to quantify than employment, education, and living arrangements, the social and recreational deficits cannot be ignored as they are mentioned by a large majority of survey participants as well as in interviews with parents and young adults with ASDs.

These young people are also at an age where interest in a relationship with a significant other is increasing, although most do not have the social skills required to begin to form the basis of a friendship. Most young adults interviewed on this topic expressed their frustration with their inability to meet a suitable significant other with whom to share their experiences and interests. Parents also struggled with seeing their young adult child with ASDs frustrated in their desire to have an age-appropriate relationship with a significant other. 


\section{Summary of Research Questions 2 and 3 Findings}

Nearly every aspect of normal adult life is a challenge for the majority of young adults with ASDs. Arguably the three most important factors that define adult satisfaction are employment and therefore financial status, housing or living arrangements, and social interaction and relationships. All three of these areas are a significant area of need for young adults with ASDs. It is hard to imagine a young adult having a feeling of security or sense of self-worth when all three of these areas manifest with significant deficiencies.

There is a perception that young adults with ASDs are being underserved by the organizations that purport to support their needs. Their survey and interview responses indicated dissatisfaction with the opportunities available to them and the organizations that espouse being their advocates and supporters. If these organizations exist to support people with ASDs, why is their approval rating so low among the adult population with ASDs? The survey results and individual interviews would seem to suggest a mismatch between what the organizations perceive to be their success and approval rate and how they are viewed by their customers and constituents.

\section{Implications to Inform Policy and Practice}

I wanted to learn was how the data from the survey and interviews with young adults with ASDs, their parents and family members, and senior-leadership representatives of the seven organizations fit together. Were there any common themes? As a culmination of this study, what lessons could be learned and what implications could be extracted that could prove helpful for young adults with ASDs in the future? Specifically, the final research question was, What implications can be drawn from these 
findings that could help inform policy and practice for organizations that attempt to provide service to young adults with ASDs?

The most glaring implication from the first three questions was an apparent disconnection between what the organizations say they offer and what the participants felt they received. In seeking to put this into context, I realized there was something missing. If the focus was going to be on policy and practice, I needed input and observations from experts in the field. As a result I added a series of interviews with a panel of experts to round out the data. These were a distinguished group of professionals with governmental agency, political, advocacy, lobbyist, and disability-rights experience. Their roles and experience varied from serving in governmental positions such as the California State Council on Disabilities to political lobbyists who have represented young adults with ASDs issues. A full list of their experience and qualifications is included in Chapter 3 on Table 6.

Those interviews helped frame the rest of the data and provided three additional implications regarding policy and practice. In this section I will explore these four. I will first expand on the apparent discrepancy between participants and service providers, as seen from the perspectives of the leaders in key organizations. Then I will conclude with the three implications culled from the data the experts provided related to financial, systemic, and political issues, and how these three aspects affect the policies and practices of the organizations.

\section{Apparent Mismatch}

As I have demonstrated from the responses to the survey made by young adults with ASDs and their parents or family members, there is not a high regard for the service 
and support they are receiving from the primary service and support organizations. More than half of them described their overall experience with all services as dissatisfied or very dissatisfied, over half felt their employment situation was unsatisfactory, and over half perceived their educational or vocational training experience to be unsatisfactory. Nearly $77 \%$ reported they were still living at home with their parents while the national reported average in this same age group is only $36 \%$. This seems to indicate a critical gap in services to help these young people transition to adulthood successfully. Clearly there is dissatisfaction with the services and supports provided, manifesting in young adults with ASDs being dissatisfied with their status and situation in society.

In interviews with senior-leadership representatives of these organizations, although they displayed frustration at the scope of the problem, there also appears to be a critical difference in how they view their own performance, compared to the views of those who receive their services. For example, a regional-center representative estimated that if polled, adults with ASDs would offer between 60 and $75 \%$ positive ratings in regard to timeliness of services. This interviewee's assessment was that any negative feedback was related to the mismatch between parent expectations and desired outcomes. This person's opinion was that the expectations of parents are much higher than they were 30 to 40 years ago when parents' main worry was just for their child with disabilities to be safe. This representative did not know how the regional center's satisfaction ratings could stay the same when the expectations of their customers are rising, and while the center's funding situation will not be able to sustain the same level of service programs. These answers demonstrated a certain level of resignation to the fact that regional centers struggle just to provide a minimal level of service and that, as the 
expectations of parents continues to rise, this will certainly lead to decreased levels of satisfaction by regional-center clients.

Self-evaluations from the other organizations considered in this study were not as rigorous as that of the regional centers. Self-evaluation is a difficult undertaking under normal circumstances, and may be particularly difficult when trying to evaluate autismsupport services. Based on data analysis I conducted on organizational annual reports, as well as interviews with their leaders, it appears these organizations tend to rate themselves on the amount of activities performed and not necessarily on numerical or quantifiable outcomes. They evaluate and quantify the amount of activity they perform, but do not seem to measure the value provided or outcomes of those interventions, as reported by their customers.

There is no doubt that much activity goes on in these organizations; however, it does not appear to be focused or coordinated. The organizations tend to have broad and loosely defined goals with few specific and numbers-based metrics to assess the impact they are having on their customers. For example under the heading "services" on the ASA's mission statement, they list; "Building capacity within local communities for service delivery to individuals and their families" (201 le, para 1). Similarly, Autism Speaks lists a goal of striving "to raise public awareness about autism and its effects on individuals, families and society" (2011, para 2). What they call their metrics or scorecard is quite loose and not a rigid standard of performance. They also appear to evaluate little based on direct feedback from their customers, even in a qualitative format. When I asked these organizations' senior leaders whether they conducted surveys or requested customer feedback, they tended to deflect or not answer directly. 
The disconnection between what these leaders feel they are providing and what the recipients feel they are receiving may be related to this failure to adequately assess the organization's programs. These leaders may have been aware of the problems they faced. Although some organizational representatives were quite upbeat and optimistic about the level, depth, and quality of services being provided, others reflected a sense of frustration, helplessness, and inadequacy over what they could do in the face of huge unmet needs. Other interviews reflected the systemic problems as a source of frustration and a roadblock in their efforts to provide the best possible care and service to the youngadult population with ASDs that need them. Still others reverted to resignation that this was the current environment and voiced their resolve to provide the best possible service within the constraints of the system in which they must operate.

Two of the larger organizations included in the study were the ASA and Autism Speaks. Interviews with representatives of these two organizations conveyed a sense of frustration at their attempt to try to "do it all." As the largest two organizations (in membership and donations), the representatives conveyed a sense of needing to provide something for everyone on the autism spectrum and at all ages and stages. They expressed that this desire occasionally results in spreading their resources too thin. Many also stated that the demands resulted in their inability to impact areas that are not the main focus or strength of their organizations.

Even given these frustrations, most organizational leaders saw their services in a far more positive light than did their clients. This outcome prompted my final set of interviews with established experts in the field of disability services. If well-meaning and dedicated people are missing the mark with their intended customers, perhaps a broader 
perspective is needed to establish causation. Not only did the data from the expert interviews yield excellent insights regarding this disconnection, but also provided a useful framework to consider how these implications can help inform policy and practice. Specifically, their responses demonstrated three categories of difficulties that contribute to the significant unmet needs of adults with ASDs and their family members.

The first of these difficulties was related to specific financial issues. The next was termed systemic or the actual system in which these organizations have to operate. Finally they addressed political and legislative difficulties. These three issues had also been addressed by the organization leaders I interviewed earlier, as they spoke of impediments to their success. It was important therefore, to expose the problems and roadblocks to providing needed supports.

\section{Financial Implications}

The experts seemed to agree on three reasons for financial problems: state budget cuts have significantly impacted services funded by the regional centers, services for adults with ASDs are variable and expensive, and no adequate financial support is dedicated specifically to services and supports for adults with ASDs in autism service and resource organizations. These financial frustrations were reflected in that the parent and family interviews revealed a seemingly random and often-confusing process of what services get funded and what total dollar amount is allocated to their young adult with ASD. Many who responded to the survey or were interviewed stated their concern at the amount of effort and stamina required to see the process through to completion and actually receive the desired (or any) services. 
A review of the budget cuts in California for the previous 5 years shows a disturbing trend of continued reductions affecting the DDS. In fiscal year 2012-2013 the cuts amounted to $\$ 200$ million from the DDS budget. Included in this $\$ 200$ million was an anticipated $\$ 70$ million in funding savings due to implementation of State Bill 946 , which mandated insurance for individuals with autism. The assumption was the insurance companies would be bearing this portion of the burden and the $\$ 70$ million was removed from the funding allocation. These cuts also included a $1.25 \%$ reduction in funding for the regional centers, which was reduced from an initially proposed $4.25 \%$ reduction. In 2011 the DDS was tasked with identifying \$174 million in savings and reductions. Similar cuts were experienced in every year since 2007 (California Department of Developmental Services, 2014).

One interview participant who had more than 30 of state-government experience in California stated,

We have had five straight years of cuts in the Department of Developmental Services. There have been over one billion dollars in cuts to the Regional Centers. ... We are falling off a cliff in the state budgets. The cause and effect was so clear. The cumulative cut was forty billion dollars. You can come up with reasonable solutions in the range of five to ten percent cuts, but after that you are cutting into the bone.

Adding to the dilemma was the perception that budget reductions were applied unequally: "All the cuts were absorbed in the community and not in the state institutions." As has been shown repeatedly, the state-funded and -run institutions are the system's choice of last resort for a young adult with ASDs. The conditions are poor, the buildings themselves are old and in disrepair, they are more expensive to staff and maintain. The services provided and method of delivering them seems to be more 
appropriate for a prison than a rehabilitation or vocational and educational service provider.

Another of the expert panel offered, "As they get older the services get more expensive. Budgets have not increased and the providers are unable to give salary increases." Even when well-intentioned, the result of efforts on behalf of young adults with ASDs often has an opposite effect to what is intended. For example, in efforts to raise the minimum wage for workers with disabilities in California, "They fought for a raise in minimum wage (for persons with disabilities who are employed) but there was no increase in the budget. You can't pass this law and not increase the budget." So although those working saw an increase in their wages, the failure to pass a corresponding increase in the budget ultimately resulted in fewer young adults having funded work programs. This expert summed up the state-budget issue, specifically as it related to the regional centers and young adults with ASDs as "The Regional Centers have to balance their budgets and the autism influx is killing them."

The second part of the financial problem was the perception that services and supports for adults with ASDs are variable and expensive, compared to other developmental-disability conditions. A poignant example of this was the story of a 22year-old young man who had aged out of the school system, but had yet to find an appropriate day program tailored to his specific needs. In this case, his parents were both highly aware and had intimate knowledge of the applicable laws and what services could be available, and were particularly relentless in advocating for their son. They also had the resources and time to devote to rigorously pursuing services for his needs. The outcome was that SDRC placed him in a tailored live-in program in the county and 
funded the entire program at a cost of roughly $\$ 12,000$ per month. Although this program was appropriate and tailored to this young man's situation, it is not hard to realize that regional centers cannot afford to pay for this type program on a broad scale.

The final facet of the financial problem the experts identified was inadequate financial support dedicated specifically to services and supports for adults with ASDs at autism service and resource organizations. An example can be seen in looking at the organization Autism Speaks. The Autism Speaks annual financial report lists over $\$ 9.2$ million in salaries for program-services employees, yet they admit to having only two full-time staff devoted to adult services. Based on existing executive-compensation data, the salaries for these two positions would most likely amount to a combined $\$ 300,000$, which is a generous estimate, given the organization's nonprofit status. On this basis, the adult-services employees represent approximately $3 \%$ of the total employee budget; thus, one might conclude that Autism Speaks does not place a high priority on their adult community services.

Where, then, does Autism Speaks, and perhaps others, invest money? An expert advocate and disability-rights activist explained, "ASA and Autism Speaks were organizations started by well-meaning people of 'means' and celebrities. Their focus became fundraising and the attention of the community." Specifically with regard to Autism Speaks, "They are spending hundreds of thousands of dollars in publicity-the money raised never reaches anybody (with autism)," and concluded:

Autism Speaks has a mixed reputation. They raise more money than all the others combined. Only four cents of every dollar raised goes to community 
organizations. ${ }^{15}$ The rest goes to overhead, research, and public relations. Over eight million dollars was raised in Los Angeles and the community got zero dollars in grants in 2013.

Taken together these three elements of the financial problem paint a grim picture of the future for young adults with ASDs. An experienced former state government representative predicted,

The bubble is coming. People are living longer and there is a growing senior population. They are refinancing it on the backs of the Federal Government. It is a four billion dollar price tag in California with over 270,000 people. Eventually the Feds will push it back to the states. There is infighting on costs of services and great disparities on costs.

As the population of young adults with ASDs increases, the situation appears to be getting worse, with less and less being available for them. The implication for policies and procedures for the organizations is going to require addressing this fiscal reality. Further recommendations will be offered in Chapter 5.

\section{Systemic Implications}

The next aspect of the problem on which all the experts agreed was the system itself. Specifically, they referred to the following four systemic issues:

1. There is no clear cut path for parents, family members, or young adults with ASDs to follow that directs them to needed services and supports.

2. Governmental bureaucracy may be getting in the way of those attempting to provide services.

3. The existing system of state-run institutions is outdated and expensive.

\footnotetext{
${ }^{15}$ These figures appear to be fairly accurate. From the Autism Speaks 2012 annual-report financial statements, the amount listed for family-service grants and awards is a little over $\$ 2$ million of the total $\$ 64$ million in total operating expenses. By contrast, fundraising expenses totaled over $\$ 16$ million.
} 
4. The current organizations in place were not set up for today's expectations or definition of success for young adults with ASDs.

For the issue of clients not having a clear-cut path, the illustration given above of the $\$ 12,000$ a month outcome demonstrates the scope of the problem. One expert on disability services stated, "There are ten percent of the families that know how to fight within the system and the other ninety percent do not." No system seems to be in place that families can follow to access services or even to find out what is available and to what they are entitled. Parents interviewed repeatedly conveyed their sense of frustration, anger, and despair in attempting to access services for their young adult.

The governmental bureaucracy may be impeding those organizations attempting to provide services. One expert commented,

There is widespread corruption. You see providers becoming Regional Center executives and Regional Center executives becoming providers. The Regional Centers have turned into a patronizing bureaucracy with no room for creativity or innovation. They don't want to lose power-they are the least innovative in the country.

With respect to the service level offered to clients, another offered, "The regional centers shifted gears. They used to be case managers trying to get you what you needed. Now they are masters of illegal, behind the scenes committees providing reasons why you're NOT getting what you need." A final observation was, "The San Diego Regional Center is very protective of its position. It is not focused on their clients' desires or best interests and has become a self-serving network between the providers and their own organization."

The experts interviewed were nearly unanimous in their disapproval of the bureaucracy created to administer disability services in the State of California. One of them explained how this came about: 
Parents created the Lanterman Act and the Regional Centers. They did not want their kids in institutions but they didn't know what to do. They wanted them living in the community and they saw that the institutions were horrible. They never envisioned the bureaucracy that would be created; they just wanted a resource to find services. There was no building that existed-it was just a funding path with social workers. Now it is a four billion dollar DDS annual budget. There are careerists at the regional centers that think they know better than the parents. They are very patronizing to the parents and they decide what they will fund.

An experienced advocate and lobbyist averred, "Everything we are able to do is in spite of the Department of Rehabilitation. They are only pleasing each other. They are not about the consumers. They only care about how their newsletter looks." Finally, a career disabilities-services employee offered, "At the start it was a fluid exciting time. Parents actually could help their children. Then it turned into a horrible system with bureaucrats in control."

One of the worst examples of this bureaucratic crisis was the creation of statefunded and -administered institutions for those with developmental disabilities. While they are slowly being closed, five still exist in California. It is not easy to do away with these. One expert offered an opinion on the dilemma of trying to abolish the institutional systems:

It's all a function of money. What could be done for 16 thousand dollars per person per year in the community model costs 200 thousand per person in the institutional system and they are using less than ten percent of the space available. They should all be closed down, but the unions fight it and the two thirds of the legislature who are Democrats support the unions.

It is encouraging that the population in these institutions is down from 5,700 in 1994 to 1,325 in 2014 , a 20 -year decline. Two of the five remaining institutions, have a population of less than 100 patients. The implication for the service and resource organizations is that soon there will be no institutional system on which to fall back and all services and supports will be pushed down to the local level. The caution here is that 
the money previously spent on adults with ASDs at these institutions may not follow them to the local level, thereby creating a further deficit in available funds for their services and supports.

The next aspect of the systemic problem identified by the experts was that the current organizations were not set up for today's expectations or definition of success for young adults with ASDs. At the time they were established, they provided what was deemed adequate and appropriate for those with developmental disabilities. Today's definition of success for young adults with ASDs includes education, employment, and living in the community in an independent or semi-independent lifestyle. The definition of success the system was built to support was more basic, and included health, safety, and welfare issues. As one interview participant said,

The system of services in the nation and particularly in California was never designed for this (ASD) population. It was built for the Mentally Retarded and Down Syndrome kids where there were no expectations of attending college. I think you have identified the real problem - the system is not designed for this population to succeed in a real sense.

Another interview participant offered an explanation as to why this systemic issue exists: "Infighting between organizations is hurting them. They can't agree and it is a much more complicated disability. Expectations in the autism community are much higher and the systems are not in place to support this." Clearly these organizations need to establish policies that will allow them to collaborate and operate in harmony rather than each fighting for their individual survival. One example of this competition and infighting is the well-documented comments made by ASAN President and founder Ne'eman regarding a 2009 Autism Speaks video entitled "I Am Autism" (Wallis, 2009). Perhaps the IACC could assist in fostering this cooperation by linking funding for the organizations to those that demonstrate they cooperate with their peer organizations. I 
will discuss this topic of cooperation between organizations further in Chapter 5 under recommendations.

A participant with significant government experience summarized the entirety of the issue as follows;

The problem is the size and scope of the problem. It is a pebble in the pond. The issues in California are as big as any national government. They are constantly playing catch up. It's not that they don't care, but the programs were designed 40 years ago and their systems are not efficient. Nothing is easy to fix in the state of California. The issues are so big, so diverse and so complex.

\section{Political and Legislative Implications}

The final facets of the problem, with significant implications for informing policy and procedures, were political and legislative. Interview participants all clearly placed a significant portion of the responsibility for the current situation on political motivations. In sum, they believed the government, starting at the federal level, does not know how to address this problem and has sought solutions that do not address the real issues. One example of this was the forming of the IACC.

The IACC was formed in 2006 by the federal government to focus solely on issues regarding autism. Although appearing to be well intentioned, the existence of the IACC has had the detrimental outcome of aiding the bypassing of entities that should be held accountable for assisting with the problem. Several interview participants referred to the formation of this committee as a way in which federal-government agencies would not have to individually address the problems of adults with ASDs. Instead of individual agencies needing to address these issues, they are able to deflect the problems to the IACC. As one interview participant stated,

I think the Inter-Agency Advisory Council is a wonderful idea, but I don't like how it's set up. I think if you are going to have a federal agency deal with autism and get everyone together you have to get the Justice Department there, the 
Department of Labor, etc. You know it is an incestuous - that is a bad word-it is coordinating within the agencies dealing specifically with autism. But we have to get Department of Labor at that table too. And it's heavily research oriented and research is great and $I$ benefit from research, my son benefits from research but somewhere we've got to get some service now [too].

One government policy expert equated the government endorsement of the IACC to be synonymous with the government saying: "So autism (advocates and representatives), go coordinate with the inter-agency committee." While this expert had no ill feelings about the IACC itself, the problem was with the government's actions. This interviewee interpreted government support of the IACC as a way to ease the responsibility on other government agencies, such as Department of Labor and Department of Housing and Urban Development, who have the charter and bear the responsibility to be part of the conversation and solution to the problem. The IACC needed to be an adjunct to and work with the other governmental organizations, not a replacement for them, or as a means by which specific agencies avoid their responsibilities:

What scares me is that what happens in government a lot is that we allow government to define who the players are. It's addressing the needs for my kid and I think the Department of Labor needs to be accountable to someone. Why is there such a high unemployment rate among adults with autism? Housing has to be accountable. The Justice Department should be seeking resources when schools continually discriminate against students who are autistic or with disabilities and we don't see that being part of those discussions so that's what my feeling are about the inter-agencies.

Thus, whereas the creation of the IACC could be seen as a positive step in recognizing the scope of the problem of autism, it appears to have created more problems than it solved. 
I was completing the data analysis for this project when a critical legislative issue arose in the form of a bill. California Senate Bill 468 (SB 468), known as the selfdetermination bill, was introduced in February, 2013. The bill indicated the following:

Requires the State Department of Development Services to implement a statewide self-determination program, which would give program participants an individual budget to be used for the purchase of services and supports to implement the individual program plan. ${ }^{16}$ It also requires each [regional] center to be responsible for implementing the program as a term of its contract and to establish a local voluntary advisory committee to provide oversight. (Orange County, 2014, para 1)

The timing of the vote on California State Bill 468 (signed by Governor Brown on October 9,2013 ) was very fortunate, as it provided a microcosm of the political issues at stake and how the bill was or was not supported by factions in the autism community. Although young adults with ASDs, their parents, advocates, and many others largely united in support for the bill, not surprisingly, the regional centers came out as harsh critics, citing the increased administrative workload it would cause and questioning the competence of families to decide for themselves what is best for their family member with ASDs. They also contended that the bill would increase administrative costs by putting the financial decision making in the hands of families who are ill prepared to make these decisions.

A lobbyists and advocate I interviewed disagreed with the regional centers' stance, stating,

On self-determination: "If you (parents and adults with ASDs) control the money they are not going to screw it up because there is just not enough money to go around. There is a natural tension between provider and family.... The Selfdetermination Bill is a game changer in California. California is the first state that

\footnotetext{
${ }^{16}$ Although the Individual Program Plan was agreed upon by the regional center and their client, the responsibility for deciding how the dollars would be spent in support of that plan and which particular service provider would be used would now be up to the client to decide.
} 
has a law that empowers the family to control the money. It's going to take a while but it will be a game changer.

This comment referenced that the regional centers' power and influence would be greatly diminished when the financial-decision-making responsibility was transferred out of their control to that of the family.

An expert observer from another state wondered, "The Harvey and Connie Lapin sponsored Bill (SB 468-Self-Determination)_-Why was it threatening to the Regional Centers? It was a win-win-win but the Regional Centers went ballistic." Although this should have been welcomed by the regional centers, they instead interpreted passing control of the funding to the families as a threat. This opinion further supported the assertion that control of the money seemed to be more important to the regional centers than the satisfaction of and support provided to the families.

Certainly the implications of this bill will not be felt for many years, but many interview participants suggested that the political fight around this concept will also continue for many years. Although it may be the law, it was also designed to be phased in on a slow timetable. It will be interesting to observe the level of cooperation offered by the regional centers as they are tasked with implementing this bill..

\section{Summary of Research Question 4 Findings}

In summary, the findings for the fourth research question were critical to the purpose of my research. They uncovered the disconnection between the organizations and their clients and pointed to the reasons some needs of adults with ASDs remain unmet. In fairness to the organizations, some additional context is provided here. Most of these experts focused on the macro issues at the state and local levels, and certainly there are 
enormous issues to be dealt with on that scale. However, detailing information at the local level provided some encouragement.

My interviews with senior organizational representatives at the local level revealed dedicated, passionate, and committed individuals who, I sensed, deeply want to help young adults with ASDs. I could sense their frustrations with the financial, systemic, and political landscape that seems to present roadblocks to their work. Although on a national or state level the problems seem insurmountable, many positive actions are taken at the local and community levels to help young adults. The senior leader of the San Diego chapter of ASA related, with a great deal of pride, the local programs and initiatives they have sponsored that, despite not costing much money, seem to have an impact on a small segment of the community. These smaller and community-based programs will be described further in the recommendations listed in the following chapter.

The findings outlined in this chapter are an aggregate of the entire data set. Each individual organization has strengths and weaknesses and each seeks to fulfill their mission statements. The findings sum the broad range of data collected. Taken individually, each organization would disagree slightly from the findings above. Some would be viewed more favorably in one particular area, whereas others would fall below the average expectations. Parents and young adults however, face the reality of addressing the aggregate results, and the experiences they related to me about all the organizations in this study result from the lack of one clear path of where to go for the best possible assistance and support for their individual situation. 
Although the findings from Question 4 helped inform some of the implications for organizations with respect to their policies and procedures, it also raised additional questions: Is this a civil rights issue, or an issue of even deeper national health policy? How does the United States fare in comparison to other countries with different healthcare systems in supporting young adults with ASDs? Could this be a possible reason why studies conducted on adult outcomes for persons with ASDs have been centered in Australia, the United Kingdom, and Canada? These additional questions will be explored in the following chapter when I discuss my recommendations for potential future research.

This chapter attempted to capture all the significant findings from the online survey and interviews. In the next chapter I summarize the findings, identify significant themes, introduce my conclusions, and propose some recommendations for future study. 


\section{CHAPTER FIVE}

\section{CONCLUSIONS, IMPLICATIONS, AND RECOMMENDATIONS FOR FURTHER STUDY}

The purpose of this study was to investigate the current situation of young adults (defined as 18-29 years old) with ASDs. I wanted to find out how the major autism service and resource organizations defined and fulfilled their roles, how the young adult population defined their needs, and how these organizations had either met or not met their expectations. Prior to beginning data collection, I researched the available literature including searching for any previous studies that may have been conducted. I also thoroughly reviewed the organizations' published documents as well as their online websites and professional journal articles, and drew upon the substantial amount of reading I have done on this subject since my son was first diagnosed with ASD over 20 years ago. I used a mixed-methods research format that included an online survey as well as interviews with more than two dozen selected participants.

The four research questions that guided the study were:

Research Question 1: How do organizational models designed to support young adults with autism understand ASDs and how do they define their specific role in providing support to this population?

Research Question 2: How do young adults with ASDs who have used one or more of these organization's services define their needs?

Research Question 3: How do the parents and family members of young adults with ASDs define the needs of their autistic family member? 
Research Question 4: What implications can be drawn from these findings that could help to inform policy and practice for organizations who attempt to provide service to young adults with ASDs?

The impetus for this study was my 23-year-old son who has autism. We have personally experienced the drop off in services and supports since his graduation from high school in 2009. Knowing how committed and attuned we are to ensuring the right conditions for his success, I began to wonder if this was a common thread for other young adults with ASDs. Speaking with our local ASD community confirmed almost unanimous very similar circumstances for other young adults with ASDs. The literature review revealed very little has been written about adult outcomes in the autism community. As the population of young adults with ASDs inevitably continues to expand, their need for services and supports will continue to grow as well. This study was my modest attempt to try to highlight the needs of this community and the important issues that young adults with ASDs face. The major findings were detailed in Chapter 4 . In this chapter I summarize the major findings, present my perceptions of common themes and their implications, and offer recommendations for future areas of investigation.

\section{Summary of Major Findings}

Five major findings emerged from analysis of the data:

- Young adults with ASDs report having significant unmet needs specifically in the areas of employment, continuing education, living situation, and socialization and recreational activity. 
- The young adults with ASDs and their family members perceive a mismatch between what is needed and what is provided by service and resource organizations.

- A mismatch exists between how organizations perceive their performance and what their users report on their experience. Organizations rate their performance much higher than the satisfaction ratings provided by their users.

- Adult issues appear to not be an area of emphasis for autism service and resource organizations.

- Interviews with a variety of experts identified three major causes of the current situation regarding young adults with ASDs: financial, systemic, and political.

These findings were discussed in depth in the previous chapter. Again, these findings represent an aggregate of the data. Certainly each organization has strengths and weaknesses; the overall findings above are a compilation of an analysis of all the data collected. I will now explore the themes that accompanied them.

\section{Major Themes}

Due to the enormous volume of data, there were a variety of conclusions that could be drawn. From these, I selected four compelling themes. I selected these because I believe that they are ones on which individuals on all sides of the issue would agree, whether they be young adults with ASDs, their family members, organizational leaders, or subject-matter experts in the field.

- Nearly every aspect of normal adult life is a challenge to the majority of young adults with ASDs. 
- The population of adults with ASDs is rapidly expanding, as are the problems associated with this segment of young adults.

- The existence of so many segmented entities and organizations concerned with young adults with ASDs have resulted in confusion, lack of information, lack of awareness and research, and lack of coordination between all concerned stakeholders.

- Adults with ASDs appear to be an afterthought in the larger conversation of the myriad issues impacting the ASD community.

\section{Theme 1: Nearly Every Aspect of a Normal Adult Life is a Challenge}

Although challenges certainly exist throughout the full lifespan for persons with ASDs, those encountered as an infant and throughout childhood have some preexisting accommodations and prepared supports readily available. These supports are offered in early intervention strategies at children's hospitals and independent agencies, as well as in the regional centers. Additional supports are available once the child enters the school system and these supports, guaranteed by IDEA, continue through completion of secondary education or upon reaching age 23 .

Once the young adult either ages out of the school system or completes secondary education, the majority of these supports are no longer available. The young adult with ASDs and their family then enter a confusing world, often not knowing where to turn for continued support. Unlike in school, where at least 5 to 7 hours per day are professionally supervised and in the company of age-appropriate peers, young adults are now left largely to fend for their own daily routine and frequently are isolated, interacting almost exclusively with immediate family members. 
A small minority of these young adults, who are most fortunate, have some form of employment or daily-activities program that keeps them engaged, stimulated, and developing. A larger percentage of these young adults have a patchwork of some type of activity, therapy, or training that keeps them at least minimally engaged. Regrettably, the overwhelming majority do not have a job, program, or other structured daily activities. Most of these young adults live at home with their parents or immediate family and spend countless hours on their computers, in front of a television, or engaging in unproductive repetitive activities. They live a very isolated and lonely existence that further exacerbates their autistic behaviors. Many interview participants reported a decrease in social activity and a regression in their family member with ASD's progress and development, once they entered this stage.

This situation is a huge challenge as well as an opportunity for service and resource organizations. They have the opportunity to make a tremendous impact on the lives of so many young adults and to foster a new era of opportunity, challenge, and growth for many thousands of young adults with ASDs. The policies and procedures put in place now to deal with this ever-expanding population will have effects for decades to come. As health care becomes increasingly expensive and complicated and insurance lobbyists seek to protect insurance providers from being severely impacted by the costs of lifetime autism services, service and resource organizations bear a tremendous responsibility for designing strategies that will serve the needs of their constituents. Perhaps other countries offer best practices to address issues of young adults with ASDs in their societies. 
A society has the responsibility to care for those whose conditions are physically and mentally debilitating, even as they reach adulthood, and we therefore should not ignore the developing situation of young adults with ASDs once they have aged out of the school system.

\section{Theme 2: The Problem is Rapidly Expanding}

As documented throughout this paper and in numerous professional studies, the scope of the problem is rapidly expanding. With the incidence of autism diagnoses now as high as one in 68 births, and the increasing number of teenagers and young adults being diagnosed with an ASD at an older age, the term epidemic, which I recognize generates a certain amount of sensationalism, may not be out of line. The Autism Society reports a tenfold increase in autism diagnoses over the past 40 years, equating to a 10 to $17 \%$ annual growth rate.

Services, supports, and organizations that support persons with ASDs are in a growth industry. The need for these organizations to not only continue to do what they are doing, but also to expand their offerings is immense. Healthcare reform and expense has been a headline news topic for most of the tenure of President Obama. With healthcare costs continuing to increase, the landscape for the population of young adults with ASDs worsened. The growing numbers of adults with ASDs have caused concerns for insurance providers, leading to reluctance to provide coverage for autism treatments and prescriptions. Also healthcare providers experience some fear and anxiety as they may not have had to deal with so many or such varied cases of adults with ASDs in the past. The result is a growing population of users with special needs and decreasing federal, state, and local budgets to fund these needs. The gap must be made up 
somewhere and it is precisely these service and resource organizations that will ultimately be called upon to help bridge that gap. How they respond may be the most significant development in whether, ultimately, the situation for young adults with ASDs improves or further declines.

This situation is also a tremendous opportunity for these organizations to be relevant and guarantee their survival and expansion by being able to fill this gap in required services that the federal, state, and local governmental agencies cannot provide. As the formation of the IACC underscores, the federal government should be eager to partner with organizations that can help alleviate some of the strain that will be placed on the federal healthcare system related to autism. Much of this partnering will be directly related to how much leverage can be brought from all the organizations, most specifically ASAN and AUTCOM, as that is their primary area of focus, in keeping issues of autism services and rights central in the mind of Congress.

\section{Theme 3: Confusion and Lack of Information, Research and Coordination}

As confirmed by interviews with providers and users of services, the process to decipher what is available, what is appropriate, and how to actually access and enter the system is reported as a "confusing maze." The volume of comments reporting anger, frustration, and even despair from parents and family members of young adults with ASDs in their attempts to source services and supports was discouraging.

When asked to rate their satisfaction level in accessing services, young adults and their families termed their experience as either dissatisfied or extremely dissatisfied in over half of their survey responses. In the dozens of interviews conducted and over 100 surveys completed, not a single incidence emerged of someone relating how easy, 
straightforward, or streamlined their process was to access services. Every participant, even those in the same geographic area, seemed to relate a different path and told stories of even being given conflicting guidance from the same source on where and how to access services and support.

Compounding and contributing to this confusion is that there appears to be very little interaction between organizations that are essentially in the same space regarding service provision. Organizational representatives confidentially shared that previous attempts at sharing information, unifying efforts, dividing responsibilities, and cooperating on similar efforts were supported in theory only and were never followed through to completion. The apparent competition between organizations for clients is a detriment to progress. Several organizations appear to duplicate the same effort and this also leads to confusion among constituents, as each offers different opinions and advice. Any proposed collaboration rarely happens, and as the experts I interviewed shared almost universally, each organization seems intent on protecting their own "rice bowls." With so many young adults in need of support, it would seem there is no lack of opportunities for all these major organizations to survive, remain financially solvent, be relevant, and make an impact. Although competition may be healthy for some business ventures, in this circumstance it appears to be misguided and unnecessary. The needs are so great, and the enormity of the problem so large and diverse, that cooperation between organizations would seem to ensure opportunity for all. This would also perhaps allow each organization to select an area or two of specialization, which would further foster cooperation, as they could refer clients to the correct organization for that particular need. The examples of ASAN and AUTCOM as single-purpose organizations seems to offer an 
example of this prospect, and in fact they were the only two organizations to have no negative comments directed at their offerings in this study. ${ }^{17}$

Organizations will have to improve their levels of collaboration and perhaps cooperate on areas of specialization. The government may need to help encourage cooperation between the organizations by offering grants, tax incentives, and direct aid to organizations that act in concert with others. Continuing in the current mode of operation will foster increased levels of competition and continuing decline in service to, and satisfaction for their clients.

\section{Theme 4: Adult Issues in ASDs Appear to be an Afterthought}

As originally suspected, confirmed in the literature review, and reinforced in the study, adult issues appear to be an afterthought in the field of ASDs. For example, an indepth look at the literature on ASD uncovered sparse writings or studies on the topic of adults with this condition, or studies done on adult outcomes for children with ASDs. This outcome may be an obvious result of many of the organizations' initial purposes, which were stated to be to fund research for prevention and finding a cure for autism. No emphasis and certainly no funding is available except for those efforts in support of prevention and search for a cure.

In researching the individual organizations through their publications, websites, annual reports, and journal articles, I found that the emphasis in nearly every case was on children with ASDs. In my initial efforts, I was hard pressed to even find a picture of an adult on the Autism Speaks website or in their reports. This situation has improved

\footnotetext{
${ }^{17}$ ASAN and AUTCOM are primarily advocacy organizations and do not directly or indirectly provide any services, perhaps partially explaining why they received no negative comments.
} 
slightly in the past 3 years, although the focus of Autism Speaks, ASA, and the ARI still appears decidedly biased toward children.

There are very few employees at these organizations whose roles are dedicated specifically to adult issues. For this study I interviewed the very first dedicated adultservices employee at Autism Speaks, who had been in the role less than 8 months when the interview took place the first time, in February 2012. During the course of my research over the past 3 years, I noted what seems to be a positive gradual increase in the number of individuals who are conversant in adult issues at each of these organizations and an overall increase in level of awareness that ASDs expand far beyond being a "children's issue."

In addition to the lack of dedicated employees, organizations offer a relatively fewer services for adults, in comparison to those offered for children. This seems to be particularly egregious given that children are also a focus of the school systems and have a great many of their services mandated by the IDEA. This is also to be expected, as parents seek early intervention supports for their children diagnosed with being on the autism spectrum at the earliest possible age. There is sound research and multiple testimonies that early intervention strategies are a critical component to progress for children diagnosed with ASDs. However, by the time their child has aged out of schoolsponsored supports, many parents reported just being "tired" and worn out by years of actively having to fight for support for their children.

An additional element to this implication is that the early emphasis on the search for a cure for autism may have inappropriately and inadvertently kept parents and family members from doing long-term planning for their family member with ASDs. Although 
they may have harbored strong hopes that a cure would be found, the reality of not planning for adulthood may have strongly contributed to the current situation of adults with ASDs.

These organizations have a huge opportunity to extend their influence and make a lasting contribution to the plight of adults with ASDs, the larger autism community, and society in general. They are positioned to be relevant and make a major contribution to a problem that may soon become one of the nation's largest healthcare concerns.

It is probably easier for organizations to maintain their status quo and certainly they all have a core customer base, which they know is not only being continually replenished but also is expanding exponentially. Also, no immediate financial gain or other enticement to expand their offerings to adults exists, other than the intrinsic value to be derived, and their in-depth knowledge of the issues makes them ideally suited to expand their roles in this area. I believe, however, they are critical players in the future of all adults with ASDs. They are currently attempting to bridge some significant gaps in needed services and supports and there is no doubt they are important, relevant, and providing much-needed expertise to the larger autism community. They can, however, do so much more and have an even greater impact and legacy on the future of this community.

\section{Personal Reflections}

I first entered the University of San Diego doctoral program in 2005 solely with the intent to conduct my dissertation work in the field of autism in hopes of garnering information that would one day help my son. I have certainly accomplished that, but have also garnered so many more experiences and knowledge. Along the way, I realized what 
a privilege it was to be able to be immersed, albeit part-time, in the academic environment. I also recognized the rigor and amount of effort required to do serious academic research.

I have learned much about autism and my son's future challenges from so many other facets and sources that I potentially would not have uncovered. I was also encouraged to look at multiple viewpoints and stakeholders, and this has enriched my appreciation of the myriad of factors involved in important social issues such as this one. During the course of my research, my committee members encouraged me to look at my topic as part of a larger pattern in history of not only disability rights, but perhaps even civil rights.

Is this a civil rights issue or an issue regarding our overall healthcare system? As my research progressed, one of my committee members encouraged me to look at other disability communities and their stories, as a comparison group. This challenge to my critical thinking led me to consider a historical perspective of other disability-rights movements, but also to look at some other basic civil rights struggles in the United States. This investigation helped form a question that can be stated, Is this issue of adults with ASDs a disability-rights issue or a greater issue of civil rights?

In the course of interviewing one of the professional experts with significant government, political, and advocacy experience, the expert exclaimed: "There is a level of discrimination. The colleges are not ready for these kids with ASDs and society is not ready. They do not do well with mental health issues." This was a reminder of the question: Is this a disability or ASD rights or a civil rights issue for these young adults? If it is a civil rights issue, what can be learned from other civil rights movements that can be 
adapted and help accelerate to quicker solutions? I have come to the personal conclusion that the overarching issue may be more about their civil rights than simply ASD or disability rights, for reasons I will now explain.

When one closely considers the issues in the civil rights movement of the late 1950s and 1960s, compared to the accessibility-rights issues of people with disabilities in the 1970s, it seems apparent that what is taking place now with the young adult population with ASDs is really a civil rights issue. In other words they are seeking the same rights as the African American and disabled communities before them, which include the right to work, the right to continued education, appropriate living conditions, and the right to self-determination. Many, starting with Grandin, one of the earliest and most famous successful individuals with ASDs, have proven they can thrive, but the question remains: Why are there so many barriers and roadblocks?

Ne'eman is the President and cofounder of ASAN. He founded the organization in 2006 with Robertson as a support and service organization for autistic persons while also serving to educate the public and advocate for public policy for those with autism. The organization existed for its first 5 years solely as an all-volunteer organization. It was not until January 2011 that its application for nonprofit 501(c) (3) status was approved and they then began to hire their first paid staff members.

ASAN has kept their mission very focused on civil rights issues that affect persons with autism. The initial success of the organization is largely attributed by Ne'eman to a singular purpose: to strive for autistic persons to be equally included in society, including in such areas as education, housing, and healthcare, as well as a myriad of services and supports. The general framework of their model is a community-based 
one in which individuals with ASDs are fully included in their communities and in the decisions and policies that are made that affect their lives.

Although a relatively small sample size, the survey responses bore a higher approval rating for ASAN and other smaller organizations. No negative comments emerged about either ASAN or AUTCOM. I believe this is mainly due to the realization that these two organizations are focused on a much narrower and also a basic and undeniable part of the problem, essentially the question of civil rights.

An interview participant who is close to the political issues through work as an advocate and lobbyist stated of ASAN, "Ari Ne'eman is leading the protest and it helps that he is not a complete zealot. He can appreciate the concerns of parents. All the organizations need to be a little more flexible like this." The zealot comment struck a chord with me. My study of the civil rights movement of the early 1960s revealed that there were so many leaders who chose violent means or used inflammatory language to try to "shock" the country, and their efforts, while certainly drawing attention to the issues, arguably were limited in their success because they alienated the majority of people. It was not until King took up the mantle as lead spokesperson that the movement gained a respected leader who was listened to, precisely because he was not perceived as a radical, zealot, or revolutionary.

Of course, it is impossible to consider the civil rights ramifications of this issue without considering the legislative aspects. The senior adult-services person at Autism Speaks affirmed that one of the major issues facing adults involves legislation; "We (autistic adult community) are still facing discrimination on many levels and we need to figure out what policies will support adults going forward whether it is in support of anti- 
discrimination, employment, insurance for adults, housing policy and funding." The interviewee believed all of these issues had significant legislative ramifications for adults with ASDs.

Significant evidence accrued that many other preceding disability-rights issues were also civil rights issues. The Americans with Disabilities Act of 2000 addresses many other disability issues in light of civil rights implications, such as employment of the handicapped, building and work-place accessibility, public transportation and air carrier access and accommodations, among many others. The common theme through many of these civil/disability-rights issues is the underlying question of our national medical and healthcare system. Without a true healthcare "safety net" in the United States, it is predictable that these issues of civil or disability rights will continue to be debated. The problem, indeed, is a much larger one and beyond the scope of this study, but a valid concern and important topic nonetheless.

Obviously, this topic is broad and deserves a much more comprehensive treatment than I can offer here, but it was important for me to raise the concept, in that it absorbed much of my thinking during the final stages of this study, particularly as I considered the political and legislative aspects of the ASD issue. I will include this in my recommendation for future needed research. First, I will articulate those issues that incurred limitations on the research I have done.

\section{Limitations}

As previously disclosed, my status as a parent of a young adult with ASD is a source of potential bias to this study. Although my life experience with this child certainly helped frame the issues and served as an excellent foundation for some specific 
questions, I need to recognize the probability that my opinions influenced how I interpreted the data. Whereas my personal status most likely introduced some level of bias, I did use second readers and individuals outside of the autism community to offer critiques; however, any assumption that I completely removed my own feelings and opinions would be unrealistic.

The small scope of survey and interview participants is also a limitation and means that these findings have limited generalizability to a larger population. I believe the findings and themes are still valid, but again need to be investigated and researched on a much larger and deeper scale.

The geographic limitation of this study being centered mainly in southern California and specifically in San Diego is another limitation. San Diego, and California in general, appears to be at the leading edge of much of the autism awareness and research, so findings of inadequacy here can only suggest that the situation may be much more dire in less autism centric areas of the country.

Another bias I have to recognize is that I have had personal experiences with most of the organizations studied. Although our experiences have, for the most part, been both positive and negative, it would be normal for these to potentially cloud opinions. Again the use of second readers and the critique of my committee members helped alleviate some of that bias.

I also recognize that the data was based solely on those participants I was able to reach through the survey and those who are intimately familiar with the issues involved. I sense a much larger majority is uninformed and unaware of the enormity of the issue, and 
struggles on a daily basis to get a minimal level of assistance for their family member with ASDs.

Finally, I also recognize that, due to my family situation, I am immersed in the topic of adults with ASDs on a close, daily, and personal basis. This also is a limitation of the study. Still, in spite of these limitations, I believe I was able to offer a critical perspective and draw logical conclusions from the data as it was presented. I can only hope these findings provide a snapshot or at least one aspect of the problem.

\section{Recommendations for Future Research}

It is my hope that this study will make some contribution to the current small body of literature that exists, documenting outcomes for young adults with ASDs. My research produces several recommendations for future study:

- Research adult outcomes including employment, continuing education, and independent or semi-independent living situations, particularly in the United States.

- Investigate processes or strategies that can facilitate the coordination of issues between organizations, local, state, and federal governments, and the consumers of these services.

- Discern whether the needs of young adults with ASDs are civil rights-related issues, and if so, what processes and policies from previous civil rights movements can inform the way ahead for young adults with ASDs. Additionally, this issue should also be considered in the larger context of the U.S. national healthcare system. 
- Investigate the accountability of the organizations regarding how money, accumulated from donations, grants, and federal funds, is spent. Although organizations exist that monitor the overhead and administrative costs of nonprofit organizations, a need exists for a system of accountability including how money is distributed at the local and national levels.

- Research the usefulness and success of community-based local programs that are conducted on a personal basis and investigate opportunities to scale this model.

\section{Research on Adult Outcomes}

There is certainly a well-documented need for more dedicated research on the adult outcomes of children with ASDs, particularly in the United States. One of the disappointing discoveries during the literature review was the paucity of research that had been done on adults with ASDs and adult outcomes for those with ASDs. Further disturbing was the fact that the majority of studies had been performed outside the United States. With this large number of service and resource organizations, including some that even have the term "research" in their names, it would appear imperative to have some local research on the status of adults and adult outcomes here in the United States.

\section{Coordination Between Organizations, Governments, and Consumers}

Interviewees made many references to the relationships between the organizations considered in this study. Some comments from organizational representatives were harsh and directed pointedly at their associate organizations. Similarly, many comments by organizational leaders displayed an overall lack of cohesion and cooperation between autism service and resource organizations. So much need for research, support, funding, 
and publicity, presents an excellent opportunity to research the history of cooperation between like-minded nonprofit organizations, and to investigate the best practices to foster cooperation and collaboration and to share information between autism service and resource organizations, for the benefit of all.

\section{Civil Rights/Disability Rights and National Health Care}

As discussed briefly above, the concept of looking at the situation of adults with ASDs as a larger civil rights issue, rather than as a disability-rights or even service and support issue, I believe, bears investigation. Multiple facets of this question should be examined including public policy and laws, the success or failures of previous disabilityrights movements and communities, and the role of lobbyists and advocacy groups in fostering change in public policy.

If this is considered a civil rights issue, are there existing policies and laws that appropriately could be applied to help the situation of young adults with ASDs? What can be learned from previous civil rights movements as well as previous disability-rights movements? Certainly this question regarding civil rights is an important one.

Researchers should investigate the existing disability rights laws and their current level of enforcement, compare policies and laws between states, and compare how persons with ASDs are treated relative to other disability communities. These topics tie with my recommendation for more studies on adult outcomes for persons with ASDs, as those outcomes in employment, housing, and education all may be significantly influenced by the application of basic civil rights and inclusion policies. I include this recommendation because in much of my research, the influence of law and public policy 
had a large influence and was prominently mentioned in many of the interviews I conducted.

Finally, if taken together as both a civil and disability-rights issue, a larger issue of national healthcare bears investigation. Should not the healthcare system of the country be in compliance with deeper values such as basic civil rights of all citizens, even those with disabilities? Perhaps one reason for my finding that a lack of studies address adult outcomes in the United States, rather than outcomes in countries like the United Kingdom, is the problem of the healthcare system. Countries that have a true national healthcare system also have the data to support these studies. Although the United States has healthcare agencies, very little coordination and interaction occurs between individual clients and the corporations that provide service in healthcare support. Again, this is a deeper issue and requires much dedicated research to adequately address, beyond the scope of this study.

\section{Financial Accountability of Organizations}

Another recommendation is a study of the accountability of all the service, resource, and research organizations as to how the funds they receive, whether through grants, federal funding, or donations, are actually spent. Although most have publicly published financial statements and year-end reports available to be reviewed, the exact distribution of funds and what expenditures fall under broad categories such as "family services and grants" bears examination. When persons are asked, upon checking out at their local grocery store, if they would like to donate to one of the autism organizations, where exactly does that money go? The assumption could be that it goes to assist local children or adults with autism, whereas the reality is that it is probably routed to the 
national headquarters for use at a national level. I am not suggesting that this is an inappropriate or even a deceptive practice; merely that a clearer and more transparent understanding of how the donations are processed and distributed would be advisable.

This issue of accountability was also raised at a December 2011 conference at Harvard Law School (Autistic Self-Advocacy Network, 2012, para 8) addressing Ethical, Legal and Social Implications of Autism Research. The project was funded by a grant to ASAN. One aspect discussed was exactly the topic of inclusion of self-advocates on institutional review boards. Clearly, at this conference, self-advocates opined there needs to be more accountability as well as representation in private granting agencies regarding funding and how those funds are spent.

\section{Local Community Involvement at a Personal Level}

One final recommendation, although a little beyond the scope of this study, is the formation of local community programs. During the past year and a half, as I was completing this study, my wife and I had begun a home-based program for our son. Inspired by Turnbull's (2012) keynote address at the ASA National Conference and exposition on July 26, 2012, we started a program in our home based around the idea of a monthly meeting and Turnbull's observation that: "Your friends want to help you but they don't know how, and you don't want to ask them for their help." We hold a monthly meeting/social event at our home on the first Friday of the month and all our friends in our son's support structure sign up on his master calendar to do outings and events with him. The intent is to strengthen his socialization and improve his peer-interaction skills through these events with nonfamily members, rather than with paid therapists or autism professionals. 
The results have been excellent with our son not only having experiences he may not have had, but also in his willingness to try new things with a variety of people. He has done everything from physical work outs, baking and cooking, and dog walking, to attending arts and entertainment events. Based on the "it takes a village" theme, he has made excellent progress in his social skills and has shown improved flexibility in his ritualized behaviors.

The challenge and final recommendation is to investigate if this person-centered program is a scalable model that can be replicated on a recurring person-by-person basis, and be scaled to include multiple individuals at a time in the same program. This appears to be a logical and empowering potential solution, or at least part of a solution that could help ease the enormity of the outstanding still-unmet needs of young adults with ASDs.

\section{Conclusion}

The topic of adults with ASDs, their future, opportunities, growth, and progress as a community is a topic which will always be a priority for me and many other families who live with a family member with ASDs. I recognized that I and my family are fortunate to be able to provide for our son and also to be able to research opportunities that will help in his continued quest for independence, meaningful and relevant work, and ultimately, his personal relationships and happiness. Many families are not as fortunate in having the time, financial resources, or opportunities to be able to do the same for their loved ones.

It is my hope that this topic continues to gain attention and focus and that others take up the cause of researching the possibilities and tapping into the talents and intelligence that this population of young adults with ASDs have to offer. We have seen 
amazing abilities in our son in the areas of art, music, and empathy for others, and it would be a shame to see the potential contributions and talents of so many others with ASDs go unused, undiscovered, and undersupported. 


\section{REFERENCES}

American Psychiatric Association. (1994). Diagnostic and statistical manual of mental disorders (4th ed.) Washington, DC: American Psychiatric.

American Psychiatric Association. (2013). Diagnostic and statistical manual of mental disorders (5th ed.) Arlington, VA: American Psychiatric.

Americans with Disabilities Act, 42 U.S.C. 12101 et seq. (1990).

Arc. (2014a). Fusion. Retrieved June 5, 2011, from

http://www.thearc.org/page.aspx?pid=3352

Arc. (2014b). Mission and values. Retrieved June 5, 2011, from

http://www.thearc.org/who-we-are/mission-and-values?

Arc. (2014c). Trust for life. Retrieved June 5, 2011, from

http://www.thearcoftexas.org/trust/index.php\#home

Arc. (2014c). Who we are. Retrieved June 5, 2011, from http://www.thearc.org/who-weare/

Asperger, H. (1944). Die "Autistischen Psychopathen" in Kindesalter. Archiv fur Psychiatrie und Nervenkrankheiten, 117, 76-136.

Asperger Foundation International, 2005.

Autism National Committee. (2011). About AUTCOM. Retrieved June 5, 2011, from http://www.autcom.org/about.html

Autism National Committee. (2011). Welcome. Retrieved June 5, 2011, from http://www.autcom.org/about.html

Autism Research Institute. (2011). The Autism Research Institute and Defeat Autism Now. Who we are and what we do. Retrieved June 5, 2011, from http://www .autism.com/about_ari_faq

Autism Research Institute. (2014). ARI initiatives. Retrieved June 5, 2011, from http://www.autism.com/initiatives

Autistic Self-Advocacy Network. (2011). About the Autistic Self-advocacy Network. Retrieved June 6, 2011, from http://www.autisticadvocacy.org/about-asan

Autistic Self-Advocacy Network. (2011). Fact Sheet: Café Press and Autism Speaks. Retrieved June 6, 2011, Retrieved from http://autisticadvocacy.org/2011/04/factsheet-cafe-press-and-autism-speaks/ 
Autistic Self-Advocacy Network. (2012). Ethical, legal and social implications of autism research. Retrieved August 19, 2014, from http://autisticadvocacy.org/projects /completed-projects

Autism Society of America. (2011a). About the Autism Society. Retrieved June 6, 2011 , from http://www.autism-society.org/about-the-autism-society/guiding.principles

Autism Society of America. (2011b). Facts and statistics. Retrieved June 6, 2011 , from http://www.autism-society.org/about-autism/facts-and-statistics/

Autism Society of America. (2011c). History. Retrieved June 6, 2011, from http://www.autism-society.org/about-the-autism-society/history/

Autism Society of America. (2011d). Guiding Principles. Retrieved June 6, 2011, from http://www.autism-society.org/about-the-autism-society/guiding-principles/

Autism Society of America. (2011e). Autism Society Mission Areas: Services. Retrieved June 6, 2011, from http://www.autism-society.org/about-the-autismsociety/guiding-principles/mission-and-vision/

Autism Society of America. (2012). Annual Report 2012. Retrieved December 12, 2013, from http://www.autism-society.org/files/2014/03/2012-Annual-Report.pdf

Autism Speaks. (2011). Mission. Retrieved June 5, 2011, from http://www.autismspeaks .org/about-us/mission

Autism Speaks. (2012). Annual report. Retrieved June 5, 2011, from http://www.autismspeaks.org/about-us/annual-reports

Autism Speaks. (2014). About us. Retrieved June 5, 2011, from http://www.autismspeaks.org/about-us

Bettleheim, B. (1967). The empty fortress: Infantile autism and the birth of the self. New York, NY: The Free Press.

Braddock, D. (1999). Aging and developmental disabilities: Demographic and policy issues affecting American families. Mental Retardation, 37, 155-161. doi:10 .1352/0047-6765(1999)037\%3C0155:AADDDA\%3E2.0.CO;2

Braddock, D. \& Parish, S. (2001). An institutional history of disability. In G. L. Albrecht, K. D. Seelman, M. Bury (Eds.). The Disability Studies Reader.

Byonetics. (2012). I Grew Up autistic and Conquered It. Your Child Can Too. Retrieved on October 12, 2013 from http://www.2-b-well.org/byonetics-autism.html

California Department of Developmental Services. (2010a). Information about regional centers. Retrieved June 5, 2011, from http://www.dds.ca.gov/RC/Home.cfm 
California Department of Developmental Services. (2010b). Living arrangements for persons with developmental disabilities. Retrieved December 10, 2010, from http://www.dds.ca.gov/LivingArrang/Home.cfm

California Department of Developmental Services. (2014). Budget information. Retrieved December 10, 2010, from http://www.dds.ca.gov/Budget/Home.cfm

Cameto, R., Marder, C., Wagner, M., \& Cardoso, D. (2003). Youth employment (NLTS2 Databrief). Retrieved from http://www.ncset.org/publications/nlts2 /NCSETNLTS2Brief_2.2.pdf

Cavagnaro, A. T. (2007). Autism spectrum disorders. Changes in California caseload. An update: June 1987-June 2007. Retrieved November 20, 2010, from http://www.dds.ca.gov/Autism/docs/AutismReport_2007.pdf

Centers for Disease Control and Prevention. (2009). Youth employment. Retrieved October 5, 2010, from http://www.cdc.gov/ncbddd/autism/data.html

Centers for Disease Control and Prevention, National Center on Birth Defects and Developmental Disabilities. (2010).

Centers for Disease Control and Prevent. (2010). Prevalence of autism spectrum disorders-Autism and developmental disabilities monitoring network, United States, 2006. Retrieved February 12, 2011, from http://www.cdc.gov/ncbddd/autism/freematerials.html

Centers for Disease Control and Prevent. (2012). Prevalence of autism spectrum disorders-Autism and developmental disabilities monitoring network, United States, 2008. Retrieved August 12, 2012 from http://www.cdc.gov/mmwr/preview/mmwrhtml/ss6103a1.htm

Centers for Disease Control and Prevent. (2014). CDC estimates 1 in 68 children has been identified with autism spectrum disorder. Retrieved May14, 2014, from http://www.cdc.gov/media/releases/2014/p0327-autism-spectrum-disorder.html

Chappela, S., \& Somers, B. (2010). Employing persons with autism spectrum disorders: A collaborative effort. Journal of Vocational Rehabilitation, 32, 117-124. doi:10 .3233/JVR-2010-0501

Cimera, R., \& Cowan, R, (2009). The costs of services and employment outcomes achieved by adults with autism in the U.S. Autism, 13, 285-302. doi:10.1177 $/ 1362361309103791$

Combating Autism Act, 42 U.S.C. 201 (2006).

Corsello, C. (2005). Early intervention in autism. Infants \& Young Children, 18, 74-85. doi: $10.1097 / 00001163-200504000-00002$ 
Cortiella, C. (2010). IDEA 2004 Close up. Transition planning: The individuals with disabilities education act strengthens transition planning services for high school students with IEPs. Great Schools. Retrieved on February 12, 2012 from http://www.greatschools.org/special-education/health/933-idea-2004-close-uptransition-planning.gs

Developmental Disabilities Assistance and Bill of Rights Act, 42 U.S.C. $\$ 15001$ et seq. (2000).

Disability Rights California. (2011). Rights under the Lanterman act. Retrieved August 10, 2011, from http://www.disabilityrightsca.org/pubs/506301Ch01.pdf

Eaves, L., \& Ho, H. (2007). Young adult outcome of autism spectrum disorders. Journal of Autism and Developmental Disorders, 38, 739-747. doi:10.1007/s10803-007 $-0441-\mathrm{x}$

Education for All Handicapped Children Act, 20 U.S.C. $\S \$ 1400-61$ (1975).

Eisenberg, L. \& Kanner, L. (1956). Notes on the follow-up studies. in Kanner, L., Childhood Psychosis: Initial Studies and New Insights. Washington D.C.: Winston, 77-90.

Feagin, J., Orum, A. \& Sjoberg, G. (1991). A Case for the Case Study. Chapel Hill: University of North Carolina Press.

Fombonne, E (2001). Is there an epidemic of autism? Pediatrics, 107 (2), 411-412.

Gallagher, H. (1989). By trust betrayed. Patients, physicians and the license to kill in the Third Reich. St. Petersburg, Florida: Vandamere Press.

Gallaudet University (2012). Celebrating 150 Years of Visionary Leadership. Retrieved on January 13, 2014 from http://www.gallaudet.edu/Documents/Academic/FY2013-Annual\%20Report.pdf

Gerhardt, P. \& Lanier, B, (2009). Addressing the needs of adolescents and adults with autism: A crisis on the horizon. Journal of Contemporary Psychotherapy, 41, 3745. doi: $10.1007 / \mathrm{s} 10879-010-9160-2$

Gerhardt, P. \& Holmes, D. (1997). Employment Options and Issues for Adolescents and Adults with Autism Spectrum Disorders. in Handbook of autism and pervasive developmental disabilities $\left(2,3^{\text {rd }}\right.$ Ed.) Hoboken, NJ: John Wiley and sons doi: 10.1002/9780470939352.ch 17

Gernsbacher, M., Dawson, M. \& Goldsmith, H.(2005). Three reasons not to believe in an autism epidemic. Current Directions in Psychological Science, 14, 55-58. doi:10 $.1111 / \mathrm{j} .0963-7214.2005 .00334 . \mathrm{x}$ 
Giddan. J.\& Obee, V. (1996). Adults with autism: habitation challenges and practices. Journal of Rehabilitation, 62, 70-76.

Goin, R. \& Myers, B. (2004). Characteristics of infantile autism: Moving toward earlier detection. Focus on Autism and Other developmental Disabilities, 19, 5-12.

Grandin, T. (2008). The way I see it. A personal look at autism and Asperger's. Arlington, TX: Future Horizons.

Granpeesheeh, D. (2010). Applied behavior analytic interventions for children with autism: A description and review of treatment research. Annals of Clinical Psychiatry, 21 (3), 162-173.

Grant, A. (1965). Screams, slaps, and love. Life, 87-97.

Grinker, R. (2007). Unstrange minds: Remapping the world of autism. Philadelphia, PA: Basic Books.

Hanley-Maxwell, C., Whitney-Thomas, J., \& Pogoloff, S. M. (1995). The second shock: A qualitative study of parent's perspectives and needs during their child's transition for school to adult life. Journal of the Association for Persons with Severe Handicaps, 20, 3-15. doi:10.1177/154079699502000102

Hendricks, D, \& Wehman, P. (2009). Transition from school to adulthood for youth with autism spectrum disorders; Review and recommendation. Focus: Autism and other Developmental Disabilities, 24(2), 77-88. doi: 10.1177/1088357608329827

Howlin, P. (1997). Autism and Asperger Syndrome: Preparing for Adulthood. London: Routledge.

Howlin, P. (2000). Outcome in adult life for more able individuals with autism or Asperger syndrome. Autism, 4, 63-83. doi:10.1177/1362361300004001005

Howlin, P., Alcock, J., \& Burkin, C. (2005). An 8 year follow-up of a specialist supported employment service for high-ability adults with autism or Asperger syndrome. Autism, 9, 533-549. doi:10.1177/1362361305057871

Howlin, P., Goode, S., Hutton, J., \& Rutter, M. (2004). Adult outcome for children with autism. Journal of Child Psychology and Psychiatry, 45, 212-229. doi:10.1111/j $.1469-7610.2004 .00215 . \mathrm{x}$

Individuals with Disabilities Education Act (IDEA) of 1975, 20 U.S.C. 1400 et seq. (1975).

Individuals with Disabilities Education Act (IDEA) of 1997, 20 U.S.C. 1400 et seq. (1997). 
Individuals with Disabilities Education Act (IDEA) of 2004, 20 U.S.C. 1400 et seq. (2004).

Interagency Autism Coordinating Committee. (2010). IACC strategic plan for autism spectrum disorder research budget. 2010 Jan. Retrieved April 29, 2011, from http://iacc.hhs.gov/strategic-plan/2010/index.shtml

Interagency Autism Coordinating Committee. (2012). Interagency Autism Coordinating Committee strategic plan for autism spectrum disorder research 2011 Jan. Retrieved March 20, 201 1, from http://iacc.hhs.gov/strategic-plan/2011/index .shtml

Itard, J.(1802). The Wild Boy of Aveyron. New York: Appleton-Century-Crofts. ISBN 0139594949 Itard, 1802.

Johnson, R. B., \& Onwuegbuzie, A. J. (2004). Mixed methods research: A research paradigm whose time has come. Educational Researcher, 33(7), 14-26. doi:10 $.3102 / 0013189 \times 033007014$

Kanner, L. (1949). Problems of nosology and psychodynamics in early childhood autism. American Journal of Orthopsychiatry, 19, 416-426. doi:10.1111/j.1939-0025 $.1949 . t b 05441 . x$

Kanner, L. (1973). Autistic disturbances of affective contact, nervous child. In L. Kanner (Ed.), Childhood psychosis: Initial studies and new insights, 2, 217-250. Washington, DC: V. H. Winston. (Original work published 1943)

Kozma, A., Mansell, M., Beadle-Brown, J., \& Emerson, E. (2009). Outcomes in different residential settings for people with intellectual disability: A systematic review. American Journal on Intellectual and Developmental Disabilities, 114, 193-222. doi: $10.1352 / 1944-7558-114.3 .193$

Lane, H. (1984). When the mind hears: A history of the deaf. New York, NY: Random House.

Lanterman Mental Retardation Services Act, 1594 Cal. Stat. § 14 (1969).

Library of Congress, 1975.

Lovaas Institute. (2012). About Dr. Lovaas. Retrieved March 5, 2014, from http://www.lovaas.com/lovaasnote.php

McConkey, R. (2007). Variations in the social inclusion of people with intellectual disabilities in supported living schemes and residential settings. Journal of Intellectual Disability Research, 51, 207-217. doi:10.1111/j.1365-2788.2006 $.00858 . x$ 
MetLife. (2014). Timeline photos. Retrieved from https://www.facebook.com/metlife/photos/a.180916418595517.40358.164505093 $\underline{569983 / 681871548499999 / ? \text { type }=1 \text { \&relevant } \text { count }=1}$

Minnesota Governor's Council on Developmental Disabilities, (2011). Important disability legislation and legal rulings and year of enactment. Retrieved September 21, 2013, from http://www.mnddc.org/

Morgan, H. (1996). Adults with Autism: A Guide to Theory and Practice. Boston: Cambridge University Press.

Muller, E., Schuler, A. \& Yates, G. (2008). Social challenges and supports from the perspective of individuals with Asperger syndrome and other autism spectrum disabilities. Autism, 12 (2), 173-190.

National Center on Secondary Education and Transition. (2002). IDEA 1997 Transition Issues. Retrieved August 1, 2014, from http://www.ncset.org/publications/viewdesc. asp?id=423

National Organization on Disability. (2000). Employment rates of people with disabilities. Excerpted from the N.O.D./Harris 2000 survey of Americans with disabilities. Washington, DC: Louis Harris and Associates.

No Child Left Behind Act, 20 U.S.C. $\$ \$ 6301$ et seq (2001).

Orange County. (2014). Mental Behavioral Health: SB 468. Retrieved August 1, 2014, from http://orange.networkofcare.org/mh/legislate/state-billdetail.aspx ?bill $=$ SB $\% 20468 \&$ sessionid $=2013000$

Patton, M. (2002). Qualitative evaluation methods. Beverly Hills, CA: Sage.

Perry, N. (2009). Adults on the autism spectrum leave the nest. Achieving supported independence. London, England: Jessica Kingsley.

Pew Research. (2014). Social \& demographic trends. Retrieved March 3, 2014, from http://www .pewsocialtrends.org

Pinel, P. (1794). Memoir on madness. American Journal of Psychiatry, 149(6), 725-732.

Pinel, P. (1798). Nosographie Philosophic ou le method de l'analyse appliquee a la medecine. Paris: Mardan.

Piven, J. \& Palmer, P. (1997). Cognitive deficits in parents from multiple-incidence autism families. Journal of Child Psychology and Psychiatry, 38, 1011-1021. 
Piven, J., Palmer, P., Jacobi, D., Childress, D. \& Arndt, S. (1997). Broader autism spectrum phenotype: Evidence from a family history study of multiple-incidence autism families. American Journal of Psychology, 154, 185-190.

Public Law 109-416-Dec. 19, 2006120 STAT. 2821. The Combating Autism Act.

Rimland, B. (1964). Infantile Autism. East Norwalk, CT: Appleton-Century-Crofts.

Rimland, B. (1974). Infantile autism: Status of research. The Canadian Psychiatric Association Journal, 19 (2), 130-133.

Robertson, S. (2010). Neurodiversity, quality of life, and autistic adults: Shifting research and professional focuses onto real-life challenges. Journal of Learning Disabilities, 26, 545-555.

Rush, B. (1835). Medical Inquiries and Observations Upon the Diseases of the Mind. Philadelphia: Grigg and Elliott.

Rutter M. (1966) 'Behavioural and Cognitive Characteristics', in Wing J. K., (ed.) Early Childhood Autism: Clinical, Educational and Social Aspects. London: Pergamon Press

Sacks, 0.(1995). An anthropologist on Mars. New York, NY: Random House.

Salahi, L., \& Chitale, R. (2008). 10 Myths about autism. Experts examine misconceptions about autism. ABC News Medical unit. Retrieved November 10, 2010, from http://abcnews.go.corn/health/oIdand $\bullet$ IuNews/story? id=6089162\&page=I

Saldana, J. (2009). The coding manual for qualitative researchers. London: Sage.

San Diego Regional Center (2011). About Us. Retrieved June 5, 2011, from http://sdrc.org/

Schopler, E., Short, A., \& Mesibov, G. (1989). Relation of behavioral treatment to "normal functioning": Comment on Lovaas. Journal of Consulting and Clinical Psychology, 57, 162-164. doi:10.1037/0022-006X.57.1.162

Schreibman, L. (2000). Intensive behavioral/psychoeducational treatments for autism: Research needs and future directions. Journal of Autism and Developmental Disorders, 30, 373-378. doi:10.1023/A:1005535120023

Scotch, R. (2001). American disability policy in the twentieth century. In P. K. Longmore \& L. Umansky (Eds.), The new disability history: American perspective (pp. 375392). New York: New York University.

SEDL. (2014). Project need. Retrieved from http://autism.sedl.org/index.php/projectneed 
Shattuck, P. (2006). The contribution of diagnostic substitution to the growing administrative prevalence of autism in U.S. special education. Pediatrics, 117 (4), 1028-1037. doi: 10.1542/peds.2005-1516)

Shore, S. (Ed.). (2004a). Ask and tell: Self-advocacy and disclosure for people on the autism spectrum. Shawnee Mission, KS: Autism Asperger.

Smith-Sears Veterans Rehabilitation Act, 40 Stat. $§ 617$ (1918).

Social Security Act, 42 U.S.C. $\$ 701$ et seq. (1935).

Solomon, A. (2008). The autism rights movement. A new wave of activists wants to celebrate atypical brain function as a positive identity, not a disability. Opponents call them dangerously deluded. New York Magazine. May 25, 2008.

Stake, R. (2000).Qualitative Research: Studying How Things Work. New York: Guilford Press.

Stancliffe, R., \& Keane, S. (2000). Outcomes and costs of community living: A matched comparison of group homes and semi-independent living. Journal of Intellectual \& Developmental Disability, 25, 281-305. doi:10.1080/13668250020019584

Stetler, C. (2013, January 29). Rutgers sensory motor integration lab pioneering new method of detecting autism. Rutgers Today. Retrieved August 6, 2014, from http://news.rutgers.edu/issue.2012-09-28.0951227338/article.2012-1020.4901130451\#.U-Zxi-NdWSo

Strauss, A. \& Corbin, J. (1990). Basics of Qualitative Research: Grounded Theory procedures and Techniques. Newbury Park, CA: Sage.

Sullivan, R. C. (2007). The national crisis in adult services for individuals with autism. A call to action (Autism Society of America position paper). Retrieved June 17, 2012, from http://www.autism-society.org/files/2014/04/Adult_Services _vMay2007.pdf

Temple University. (2011). Disability History Timeline. Retrieved June 5, 2011, from https://listserv.temple.edu/cgi-bin/wa?A2=ind $1110 \& \mathrm{~L}=\mathrm{k} 12 \mathrm{admin} \& \mathrm{P}=188963$

Torres, E., Brincker, R., Isenhower, P., Yanovich, P., Stigler, K., Nurnberger, J., ... Jose, J. (2013). Autism: the micro-movement perspective. Frontiers in Integrative Neuroscience, 7(32). doi: 10.3389/fnint.2013.00032

Turnbull, A. (2012, July). Two roads diverged: Living life inclusively for individuals with classic autism. Paper presented to the national conference and exposition of the Autism Society of America. Retrieved August 15, 2014, from http://www .beachcenter.org/resource_library/beach_resource_detail_page.aspx? Type=presen tation\&intResourceID=2694 
Turnbull, A., \& Turnbull, H. (2002). From the old to the new paradigm of disability and families: Research to enhance family quality of life outcomes. In J. Paul, C. D. Lavely, \& Cranston, A.-Gingras (Eds.), Professional issues in special education: Intellectual, ethical, and professional challenges to the profession (pp. 83-117). Westport, CT: Greenwood.

Turner, J. \& Turner, R. 2004. Physical disability, unemployment and mental health. Journal of Rehabilitation Psychology, 49 (3), 241-249.

University of New South Wales, Social Policy Research Centre, Disability Studies and Research Institute. (2008). Effectiveness of supported living in relation to shared accommodation. Sydney, Australia: Parker, S. \& Fisher, K.

U.S. Bureau of Labor Statistics, (2010). Persons with a disability: Labor force characteristics. Retrieved on August 12, 2012 fromhttp://www.bls.gov/news.release/disabl.nro.htm

U.S. Commission on Civil Rights, (2000). Civil Rights 101. Retrieved on September 5, 2012 from http://www.civilrights.org/resources/civilrights 101/chronology.html

U.S. Department of Education, Office of Special Education and Rehabilitative Services. (2007). History: Twenty-five years of progress in educating children with disabilities through IDEA. Retrieved November 22, 2010 from http://www2.ed.gov/policy/speced/leg/idea/history.html

U.S. Department of Health and Human Services, Health Resources and Services Administration, Maternal and Child Health Bureau. (2007). The National Survey of Children's Health 2007. Rockville, MD: Author.

U.S. Department of Justice, Civil Rights Division. (1973). 77-52 Memorandum Opinion for the General Counsel of the department of Health Education and Welfare, Rehabilitation Act of 1973-Nondiscrimination Provision. Retrieved on September 5, 2013 from http://www.justice.gov/sites/default/files/olc/opinions/1977/09/31/op-olc-v001p0210.pdf

U.S. Department of Labor. (1973). Section 504, Rehabilitation Act of 1973. Retrieved August 5, 2012 from http://www.dol.gov/oasam/regs/statutes/sec504.htm

Van Reusen, A., Bos, C., Schumaker, J., \& Deshler, D. (1994). The self-advocacy strategy for education and transition planning. Lawrence, KS: Edge Enterprises.

Vocational Rehabilitation Act, 29 U.S.C. § 701 (1973).

Wallis, C. (2007, January 12). Is the autism epidemic a myth? Time. Retrieved November 15, 2010, from http://www.time.com/time/magazine/article/0,917I, 1576829,00 .html 
Wallis, C. (2009). "I am autism": An advocacy video sparks protest. Retrieved June 5, 2011 , from http://content.time.com/time/health/article/0,8599,1935959,00.html

Ward, M. (1999). Self-determination for people with developmental disabilities and autism. Two self-advocates perspectives. Focus on Autism and Other Developmental Disabilities, 14, 133-139. doi:10.1177/108835769901400302

Warren, Z., McPheeters, M., Sathe, N., Foss-Feig, J., Glasser, A. \& VeenstraVanderWeele. (2011). A Systematic review of early intensive intervention for autism spectrum disorders. Pediatrics, 127 (5), 1303-1311.

Wehman, P. (2006). Transition from school to adulthood for youth with autism spectrum disorders: Review and recommendations. Focus on Autism and Other Developmental Disabilities, 24 (2), 77-88. doi: 10.1177/1088357608329827

Wehmeyer, M., \& Bolding, N. (2001). Enhanced self-determination of adults with intellectual disability as an outcome of moving to community-based work or living environments. Journal of Intellectual Disability Research, 45, 371-383. doi:10.1046/j.1365-2788.2001.00342.x

Welch, P. (Ed.). (1995). Strategies for teaching universal design. Boston, MA: Adaptive Environments Center and MIG Communications.

Wing, L. (1969). The handicaps of autistic children. Journal of Child Psychology, 10 (1), $1-40$.

Wing, L. (2009). Asperger's syndrome: A clinical account. Psychological Medicine, 11, 115-129. doi:10.1017/S0033291700053332 (Original work published 1981)

Wolfensberger, W. (1969). The origin and nature of our institutional models. Washington, DC: President's Committee on Mental Retardation.

Yin, R. (2003). Applications of Case Study Research. Thousand Oaks, CA: Sage.

Yeargin-Allsop, M. Rice, C., Karapurkar, T., Doernberg, N., Boyle, C. \& Murphy, C. (2003). Prevalence of autism in a U.S. metropolitan area. Journal of American Medical Association, 289 (1), 49-55.

Young, L. (2006). Community and cluster centre residential services for adults with intellectual disability: Long term results from an Australian matched sample. Journal of Intellectual Disability Research, 50, 419-431. doi:10.1111/j.1365 $-2788.2006 .00788 . x$ 


\section{APPENDICES}




\section{APPENDIX A}

Online Survey via Survey Gizmo 
My name is Peter Sciabarra. I am a doctoral student at the University of San Diego, School of Leadership and Education Sciences. I am currently conducting research in support of my dissertation involving a comparative evaluation of autism support and resource organizations and how they serve the needs of young adults on the autism spectrum. I am also the parent of a twenty-year-old young adult with autism.

My research is being guided by my Dissertation Committee Co-Chair; Dr. Anne Donnellan, Ph.D. Dr. Donnellan is the founder and director of the Autism Institute at the University of San Diego. You have been identified as someone who may be interested in completing this survey and potentially as a follow-up interview candidate.

Your participation will be purely voluntary and anonymous. Your identification will not be disclosed unless you provide specific written authorization to me stipulating that I may identify you by name for involvement in this study. Additionally, you will not be contacted unless you specifically indicate your desire to be interviewed as part of my research. Please note that despite the "essay boxes" appearing small they can expand to accommodate a much larger volume, so feel free to write as much or as little as you desire in the essay fields - all input is valuable.

I believe this research is important to assist in adding to the body of knowledge concerning supports for young adults with autism. We know of no other survey of this type that aims to assist in identifying needed supports for this growing community of young adults (age 18-29) with autism. Please note the survey is designed to be taken either by a young adult with autism (I) or the parent of a young adult with autism (described here as "My family member with ASD").

I thank you in advance for your consideration of my request. I may be reached at the following:

Peter J. Sciabarra

858.353.4381 (Cell)

858.509.5833 (W)

psciabarra-10@sandiego.edu

University of San Diego IRB approval number: 2011-10-021 
1. I / My family member with an Autism Spectrum Disorder (ASD) is a California

$$
\begin{aligned}
& \text { resident } \\
& \text { C Yes } \\
& \text { C No }
\end{aligned}
$$

hidden=false\&rec

2. I / My family member with ASD has been diagnosed with

C Aspergers Syndrome

C Autism

C Autism Spectrum Disorder (ASD)

C PDD-NOS

C None of the above

C Other Autism-related Developmental Disability Please enter an 'other' value for this selection. $*$ This question is required.

3. I / My family member with ASD is (age)

C 18-21 years old

D 22-28 years old

C 29 or older

C Under 18

4. I/ My family member with ASD has or will receive a

$\ulcorner$ High School Diploma

$\Gamma$ Certificate of Attendance 
5. The most pressing need right now for young adults with autism is:

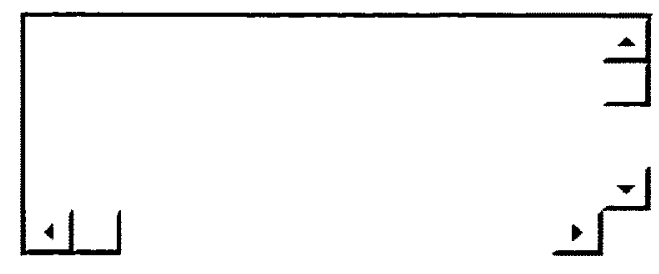

6. I am now using or have in the past used any of the below services (Check all that apply) *This question is required.

$\ulcorner$ California Department of Developmental Services (DDS)

$\Gamma$ Regional Center(s)

$\Gamma$ Autism Society of America

$\Gamma$ Autism Speaks

$\ulcorner$ ACT for Autism

$\ulcorner$ Autism Self-advocacy Network

$\Gamma$ Autism Research Institute

$\ulcorner$ Autism National Committee

$\Gamma$ California Department of Vocational Rehabilitation

$\Gamma$ Autism Now / ARC (Association for Retarded Citizens)

$\ulcorner$ Defeat Autism Now (DAN)

$\Gamma$ Cure Autism Now (CAN)

$\ulcorner$ Other(s) Please specify by name Please enter an 'other' value for this selection.

* This question is required. 
9. What (if any) needs for the individual with ASD have not been met or offered by any source that you contacted?

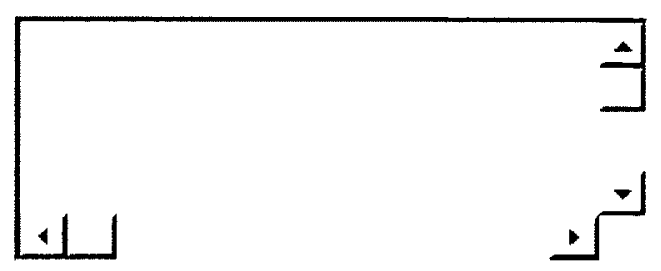

10. I/ My family member with ASD currently lives: *This question is required.

$\Gamma$ At home with parents / family

$\Gamma \quad$ In an assisted/supported living situation

$\Gamma$ Independently with some support $\Gamma$ Independently

$\Gamma \quad$ Is in a group home setting

$\Gamma$ State or Private Institution

\section{$\Gamma$ Other}


11. I/ My family member with ASD is: *This question is required.

$$
\ulcorner\text { Unemployed }
$$

$\ulcorner$ Has part-time employment with supports

$\Gamma$ Has part-time employment without supports

$$
\Gamma \text { Has full-time employment }
$$

$\ulcorner$ Does not need employment at this time

hidden $=$ false $\&$ rec

12. This employment situation is: *This question is required.

$\Gamma$ Appropriate and satisfactory

$\Gamma$ Satisfactory but not age / skill appropriate

$$
\begin{gathered}
\Gamma \text { Acceptable } \\
\Gamma \text { Unsatisfactory } \\
{ }_{\text {hidden=false\&rec }}
\end{gathered}
$$

13. I / My family member with ASD's post-high school education and/or vocational training is: *This question is required.

$$
\Gamma \text { Appropriate and satisfactory }
$$

$\Gamma$ Satisfactory but not age / skill appropriate

$$
\ulcorner\text { Acceptable }
$$


14. Do you have anything you wish to add regarding specific needs or a particular organization - either positive or negative?

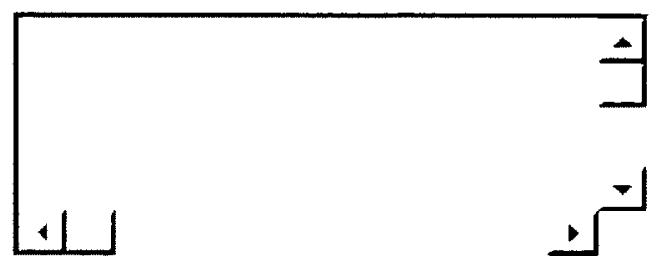

15. Please indicate if you would be willing to do a personal interview to share your experiences regarding any/all of the above. Interviews may be conducted in person, online or via telephone. All personal and identifying information will be kept strictly confidential

\section{a Yes \\ E No}

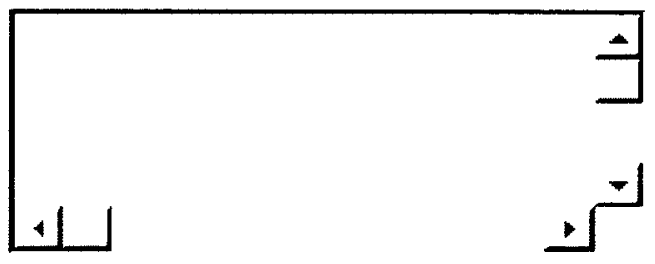

17. Please indicate if you desire to receive the tabulated results to this survey
$\boldsymbol{C}_{\text {Yes }}$
$C_{\text {No }}$ 
18. If yes to the question above please provide your email address

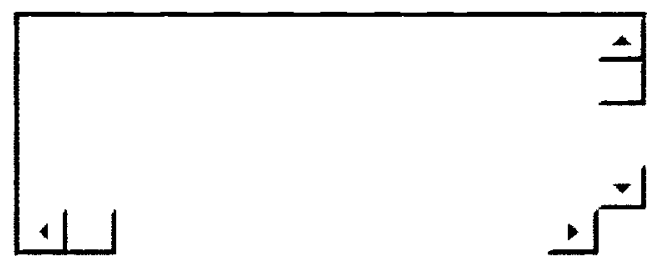




\section{APPENDIX B}

Research Interview Format for Individuals Representing Autism Support and Resource Organizations 


\section{Mission Statements}

- I have read the mission statement(s),guiding principles, and strategic vision:

- How do you define what the organization does?

- How do you define the mission as it specifically relates to young adults?

- How does any of this change with respect to adults

\section{Organizing Principles}

- How are you organized? What are your operational and administrative structures?

- What are your operational practices relating to autism services and supports for adults?

Ideologies, language, beliefs, assumptions?

- What is the organizations underlying beliefs regarding adults with autism?

- Would you say you are more focused on cures and causes or services and supports?

- Do you view your organization as education and research-focused or focused on providing services, assistance and resources?

The needs of young adults with autism

- What do you view as the primary needs of young adults with autism?

- How does your organization attempt to address these needs?

- What is your sense of outcomes achieved in relation to achieving your mission and addressing these needs? How do you measure your success?

- What do you think the organization has achieved? 
- What gaps do you see that exist in needs for young adults with autism - i.e. what are you asked to provide that they can't seem to locate anywhere else?

Resources / Funding

- What percentage of resources / funding is devoted to adults with autism?

- What and who supports and challenges their work?

\section{Additional}

- Anything I haven't asked that I should be thinking about?

- Who else should I speak with? Recommendations for my study? 


\section{APPENDIX C}

Research Interview Format for Young Autistic Adults/Parents 
Demographic Information

- How do they define their needs - academically, employment, living arrangements?

- What supports exist for these needs?

- Are these supports appropriate and/or successful?

- Ease of accessing support?

- Options available or is there just one path/program?

Open ended questions:

- What is the one most important thing you need from your autism organization of choice?

- What service or support that is not currently available to you, would you like to see offered? (this could be not available at their particular organization or not available at any organization)

- What is missing from your or the larger support system? 


\section{APPENDIX D}

Sample Email Request to Interview Candidates 
Dear Mr. /Ms. Xxxxx - I am a doctoral student at the University of San Diego and Dr. Anne Donnellan is my committee chair. She passed me your contact information and said you might be willing to talk to me about disability policy. I am doing my research on young adults with autism and how their needs are being met (or not) through the various autism research and support organizations, as well as through the federal and/or state sponsored programs available to them. Disability policy is not my area of expertise or a major focus of my study, but I am finding it certainly has a major effect on the issues I am exploring.

I was wondering if I could schedule some time to speak with you on this issue and just get a feel for how large the gaps are in what I don't know and where I need to look to ensure I am doing justice to this facet of my topic.

Thank you so much for your consideration of my request - I can send you my abstract as well as my IRB approval if you desire.

Thanks again and I will look forward to hearing from you.

Regards, Pete Sciabarra 
APPENDIX E

Data Tables 
Table E1

Summary of Needs

\begin{tabular}{lcccccc}
\hline & \multicolumn{2}{c}{ Overall } & \multicolumn{2}{c}{ CA } & \multicolumn{2}{c}{ Non-CA } \\
\multicolumn{1}{c}{ Need } & Number & Percent & Number & Percent & Number & Percent \\
\hline $\begin{array}{l}\text { Vocational skills } \\
\text { development/training }\end{array}$ & 86 & 83.5 & 36 & 85.7 & 50 & 81.9 \\
Job placement assistance & 82 & 79.6 & 36 & 85.7 & 46 & 75.4 \\
$\begin{array}{l}\text { College assistance } \\
\text { including tutoring }\end{array}$ & 58 & 56.3 & 25 & 59.5 & 33 & 54.0 \\
$\begin{array}{l}\text { Living skills } \\
\text { assistance/training }\end{array}$ & 83 & 80.6 & 37 & 88.1 & 46 & 5.4 \\
$\begin{array}{l}\text { Assisted/supported living } \\
\text { placement }\end{array}$ & 79 & 76.7 & 33 & 78.6 & 46 & 75.4 \\
Other & 52 & 50.5 & 20 & 47.6 & 32 & 52.5 \\
Total responses & 440 & & 187 & & 253 & \\
\hline
\end{tabular}

Table E2

Summarized Survey Responses

\begin{tabular}{lccc}
\hline \multicolumn{1}{c}{ Category } & All & CA & Non-CA \\
\hline $\begin{array}{l}\text { Overall experience with services } \\
\text { (Dissatisfied or Very Dissatisfied) }\end{array}$ & 52.5 & 45.2 & 57.4 \\
Percent living at home with parents & 76.7 & 72.1 & 76.2 \\
Percent Unemployed & 53.4 & 51.2 & 51.6 \\
Unsatisfactory employment situation & 52.4 & 45.2 & 57.4 \\
$\begin{array}{l}\text { Unsatisfactory Post-HS educational or } \\
\text { vocational training }\end{array}$ & 56.3 & 59.5 & 53.2 \\
\hline
\end{tabular}


Table E3

Employment Data (Listed by Raw Number and Percent of Total)

\begin{tabular}{lcrrrrr}
\hline & \multicolumn{2}{c}{ Overall } & \multicolumn{2}{c}{ CA } & \multicolumn{2}{c}{ Non-CA } \\
\multicolumn{1}{c}{ Employment status } & Number & Percent & Number & Percent & Number & Percent \\
\hline Unemployed & 55 & 53.4 & 22 & 51.2 & 33 & 51.6 \\
Part time with supports & 17 & 16.6 & 6 & 14.0 & 11 & 17.2 \\
$\begin{array}{l}\text { Part time without } \\
\text { supports }\end{array}$ & 12 & 11.7 & 7 & 16.3 & 5 & 7.8 \\
Full time employment & 2 & 1.9 & 0 & 0.0 & 2 & 3.1 \\
Not needed at this time & 21 & 20.4 & 8 & 18.6 & 13 & 20.3 \\
\hline
\end{tabular}

Table E4

Description of Employment Situation

\begin{tabular}{lcccccc}
\hline & \multicolumn{2}{c}{ Overall } & \multicolumn{2}{c}{ CA } & \multicolumn{2}{c}{ Non-CA } \\
\multicolumn{1}{c}{ Employment situation } & Number & Percent & Number & Percent & Number & Percent \\
\hline $\begin{array}{l}\text { Appropriate and } \\
\text { satisfactory }\end{array}$ & 17 & 16.5 & 7 & 16.7 & 10 & 16.4 \\
$\begin{array}{l}\text { Satisfactory but not } \\
\text { age/skill appropriate }\end{array}$ & 11 & 10.7 & 6 & 14.3 & 5 & 8.2 \\
$\begin{array}{l}\text { Acceptable } \\
\text { Unsatisfactory }\end{array}$ & 21 & 20.4 & 10 & 23.8 & 11 & 18.0 \\
\hline
\end{tabular}


Table E5

Postsecondary Education and/or Vocational Training Satisfaction (Listed by Raw. Number and Percent of Total)

\begin{tabular}{lcccccc}
\hline \multicolumn{1}{c}{\begin{tabular}{c} 
Education/vocational \\
\multicolumn{1}{c}{ status }
\end{tabular}} & \multicolumn{2}{c}{ Overall } & \multicolumn{2}{c}{ CA } & \multicolumn{2}{c}{ Non-CA } \\
\hline $\begin{array}{l}\text { Appropriate and } \\
\text { satisfactory }\end{array}$ & 9 & 8.7 & 3 & 7.1 & 6 & 9.7 \\
$\begin{array}{l}\text { Satisfactory but not } \\
\text { age/skill appropriate }\end{array}$ & 6. & 5.8 & 1 & 2.4 & 5 & 8.1 \\
$\begin{array}{l}\text { Acceptable } \\
\text { Unsatisfactory }\end{array}$ & 31 & 30.1 & 13 & 31.0 & 18 & 29.0 \\
\hline
\end{tabular}

Table E6

Independent Living Situation

\begin{tabular}{cccc}
\hline Category & All & CA & Non-CA \\
\hline Percent living at home with parents & 76.7 & 72.1 & 76.2 \\
\hline
\end{tabular}




\section{Appendix F}

Results of San Diego Regional Center Client Poll 2012 
Table F1

Summary of San Diego Regional Center Client Poll 2012 by Percentage

\begin{tabular}{lccc}
\hline & $\begin{array}{c}\text { Extremely } \\
\text { satisfied }\end{array}$ & Satisfied & Total \\
\hline SDRC staff treats me with courtesy and respect & 71 & 25 & 96 \\
SDRC staff responds in a timely manner & 59 & 32 & 91 \\
$\begin{array}{l}\text { Provides information regarding community } \\
\text { services/supports 54 }\end{array}$ & 34 & 88 & \\
$\begin{array}{l}\text { Provides information regarding SDRC funded } \\
\text { services and supports }\end{array}$ & 52 & 35 & 87 \\
$\begin{array}{l}\text { IEP/IFSP includes items that are important to } \\
\text { me }\end{array}$ & 59 & 33 & 92 \\
Overall, I am satisfied with SDRC & 59 & 32 & 91 \\
\hline
\end{tabular}

Note. SDRC = San Diego Regional Center; IEP = individualized education program; IFSP = Individual Family Service Plan. 